\title{
الأثر المحاسبي لخصائص تكنولوجيا سلاسل الثقة Blockchain علي كفاءة سلاسل التوريد (دراسة ميدانية)
}

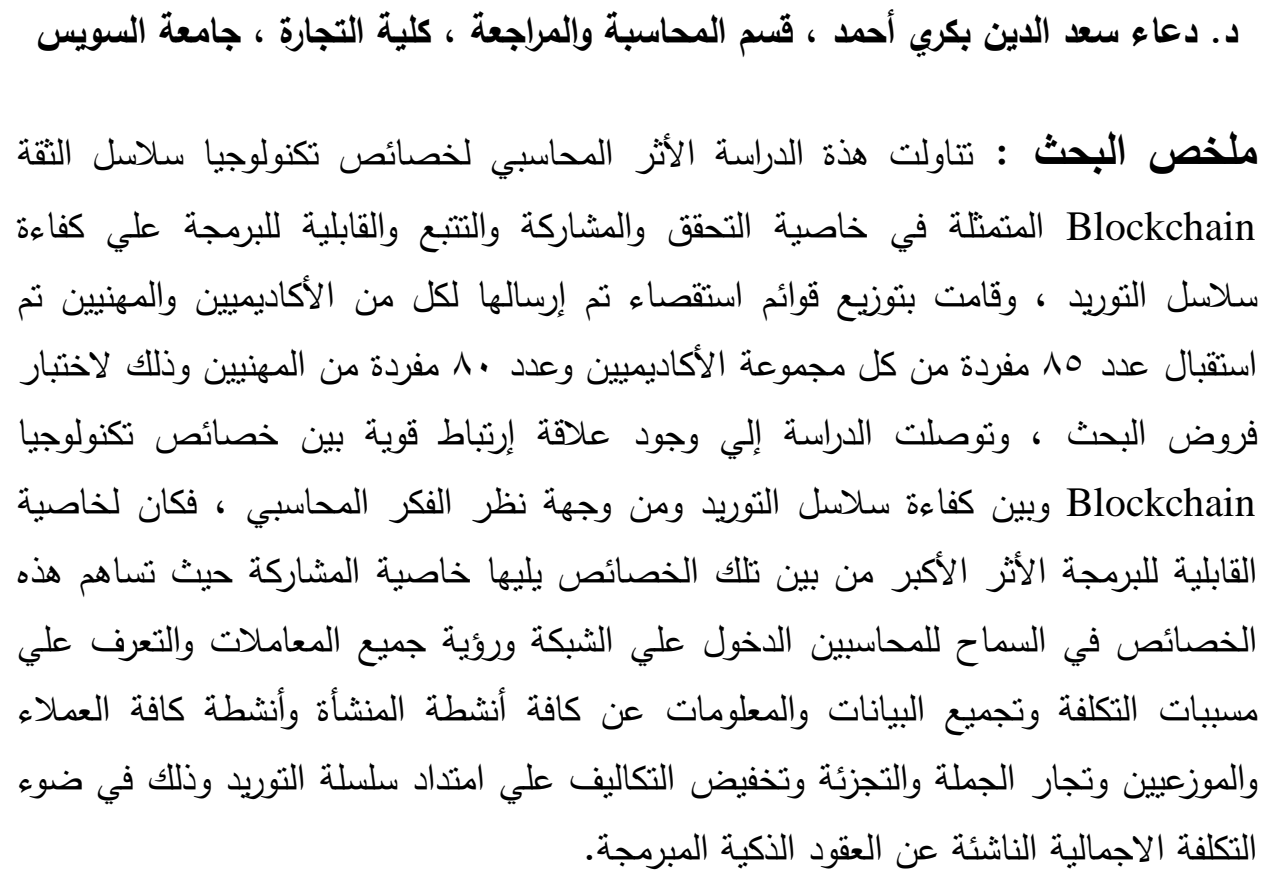

The study examined the accounting impact of the blockchain technology characteristics of verification, participation, traceability and programmability on the efficiency of supply chains, an experimental based questionnaire was sent to both academic and professionals (85 academic, 80 professionals responded) to answer study questions and test its hypotheses, The study found that there is a strong correlation between the characteristics of Blockchain technology and the efficiency of supply chains and from the point of view of accounting thought, so the feature of programmability had the greatest impact among those characteristics, followed by the participation feature, as these characteristics contribute to allowing accountants to enter the network and see all transactions and identify the causes Cost and collecting data and information on all facility activities and activities of all customers, distributors, wholesalers and retailers, and reducing costs along the supply chain in light of the total cost arising from the programmed smart contracts. 


\section{الأثر المحاسبي لخصائص تكنولوجيا سلاسل الثقة Blockchain علي كفاءة سلاسل التوريد (دراسة ميدانية)}

د. د. دعاء سعد الدين بكري أحمد"

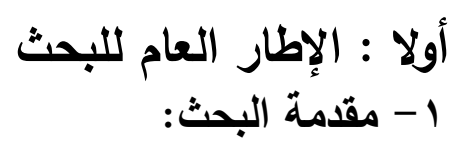

تكنولوجيا سلاسل الثقة Blockchain قد تكون طفرة جديدة لأستخدام الإنترنت وستغير

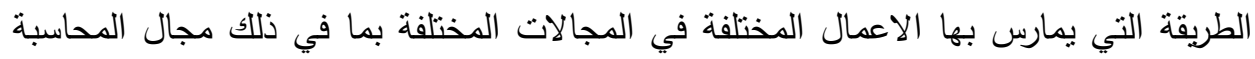

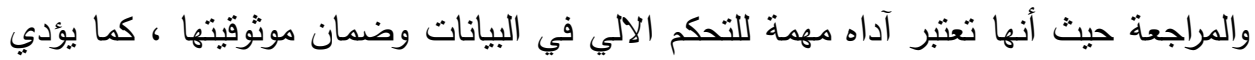
استخدامها الى انخفاض التكاليف على الددى الطويل و تجنب الاخطاء البشرية والتحكم في Enrique \& التلاعب والاحتيال عن طريق التحكم الفوري في المعلومات وتعزيز سلامتها .(Michaela,2019,P.726

ولقد توجهت أكبر مكاتب المحاسبة والمراجعة في العالم(Big Four) نحو استخدام تكنولوجيا سلاسل الثقة Blockchain كأكبردليل علي تتامي استخدام تلاك التكنولوجيا في المجال

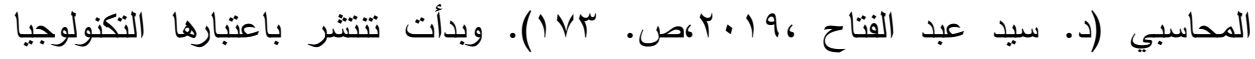
الاساسية للعملة الرقمية المشفرة وذلك لاتمام جميع عمليات الثراء والمبيعات وعمليات التبادل

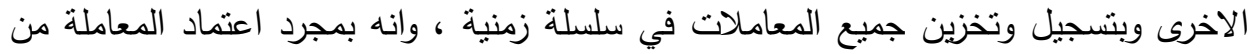
قبل الاعضاء في الثبكة لا يمكن الغاؤها او تعديلها (Alex Hughes. Et al, 2019,p.4)

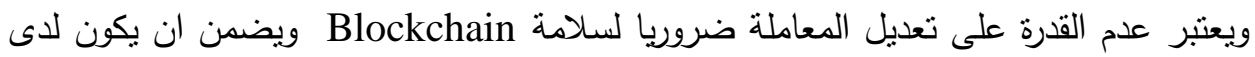
جميع الاطراف سجلات دقيقة ومتمانظة ونظرا لان Blockchain هي نظام موزع فالتغييرات في Blockchain

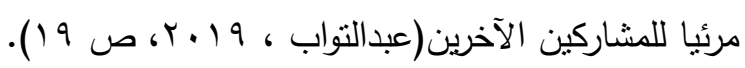
ولما تتميز به تكنولوجيا سلاسل الثنة (Blockchain) من بنية تحتية وانثائية لقد تعددت تطبيقاتها (Qiang Zhang,et al 2020,p.582) واستخداماتها ودمجها في شتى المجالات المحاسبية ، ويعتبر مجال سلاسل التوريد أحد مجالات استخدام تكنولوجيا سلاسل النقة ، حيث يقدم فوائد كبيرة لكافة الاطراف الشاركة في معاملات سلسلة التوريد (SCF) كالاسراع في * مدرس ، قسم المحاسبة والمر اجعة ، كلية التجارة ، جامعة السويس 
العمليات ومشاركة البيانات بأكثركفاءة ودقة وامان ، وتسريع التدفقات النقدية وتخفيض التكاليف الاجمالية وتقليل التعقيد(Hofmann,et al,2018,p.67)، وتوفيرمعلومات تقصيلية ودقيقة وعلي ودماني درجة كبيرة من الثقة وتحقيق قيمة مضافة للمنتجات مما قد ينعكس علي زيادة كفاءة سلاسل

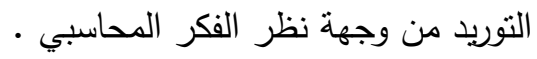

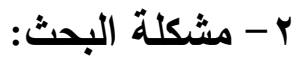

اتجهت الثركات حديثا الي تبادل العديد من المفاهيم والممارسات التي تمكنها من مواجهة المنافسه المتزايده خلا العقدين الاخيرين ، ومن اهم هذه الممارسات والمفاهيم مفهوم سلسلة التوريد ، حيث تعرف سلسلة التوريد بانها تكامل بين تدفقات المنتجات والمعلومات والأموال خلال مجموعة من الاطراف التي تاخذ شكل علاقات بين الموردين والمشترين وصولا الى لي المستهلك النهائي. وفي ظل التكنولوجيات التقليدية يصعب تتبع سلاسل التوريد للوقوف علي ابي عيوب قد تحدث في عملية الانتاج وتحديد نقاط الضعف الموجودة والتعامل لتحديد الموردين المخطئيين باستخدام معلومات التتبع ، كما يصعب جعلها أكثر شفافية وأكثز أمناً نظرا لخطر الاحتيال(Fabian,etal,2018,p.2067)، بالاضافة لوجود العديد من المشكلات التي تواجه سلسلة التوريد والتي من شأنها تؤدي إلي زيادة تكاليفها وتتمثل أهم هذه المشكلات في ، مشكلة

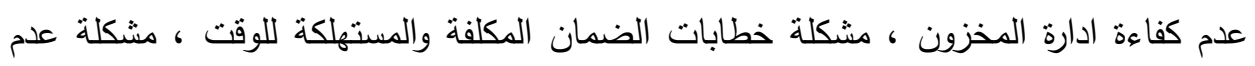

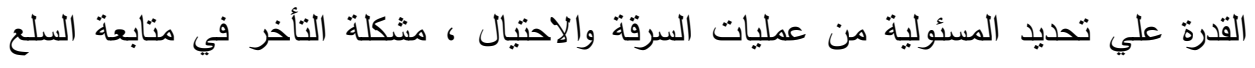
المعيبة ، مشكلة الاعتماد علي سماسرة الجمارك لتجنب الغرامات مشكلة عدم كفاءة توجيه وشحن المنتجات بما يؤثرعلي تكاليف الثحن (Kottler,2018,p.2). وأن زيادة كفاءة سلسلة التوريد تتطلب نوافر مجموعة من المحددات ومنها الثفافية والثقة المتبادلة والمبنية علي استقرار العلاقة بين أطراف السلسلة والذى يحفز علي مشاركة

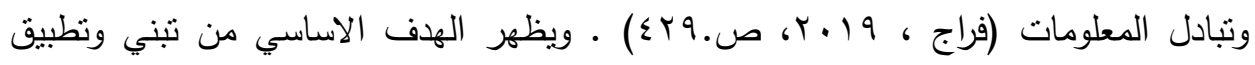

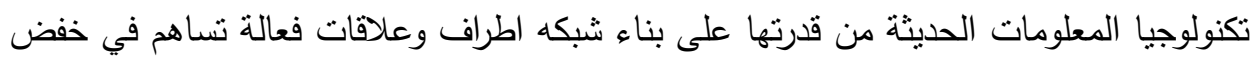

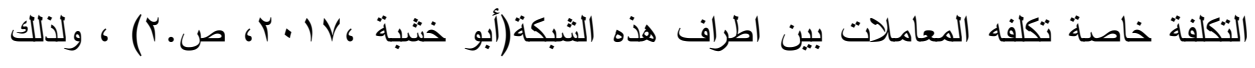
تلعب تكنولوجيا سلاسل الثقة Blockchain كأحد التكنولوجيات الحديثة دور اساسي في احداث التكامل بين العمليات اللوجستية التي تحدث بين اطراف سلسلة التوريد حيث أن الاستخدام 
المنوافق لها يؤدي الى زيادة التعاون والتتسيق بين أطراف سلسلة التوريد ، وهي تكنولوجيا ناشئة تتميز بمجموعة من الخصائص التي قد تجطها قادرة على معالجة المشكلات الحالية وجعل عمليات سلاسل التريد أكثر فعالية وشفافية وأكثر أمناً .

وتخفض تطبيقات تكنولوجيا سلاسل الثقة Blockchain هيكل تكاليف الثركة من خلال خفض تكاليف المعاملات متل تكاليف التفاوض وتكاليف البحث والتخلص من تكاليف الوسطاء

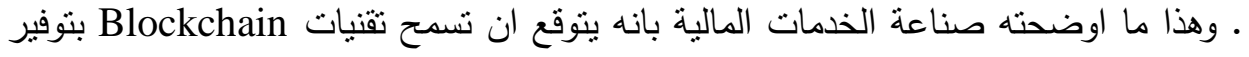

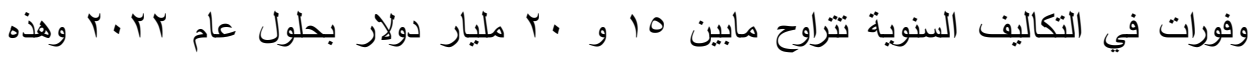
الوفورات ناتجة عن انخفاض في تكاليف البنية التحتية لنكنولوجيا المعلومات والغاء العمليات اليدوية التي لا تضيف قيمة كبيرة للشركة(Morkunas,et al, 2019,p.6) وبمراجعة الادبيات المتاحة في هذا الصدد تبين انه قد تم دراسة مميزات تكنولوجيا سلاسل الثقة Blockchain داخل سلسلة التوريد وناثيرها عليها في كل مراحلها سواء من حيث الثيث Sundtoft \& ) بناء العلاقات داخل سلسلة التوريد او احداث التكامل بينها Freiblmaier,2018،Kinra,2019 ، Fabian,et al,2018) ، كما تبين ان غالبيه الأدبيات

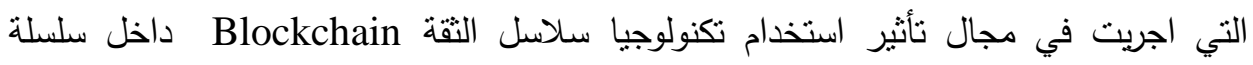
التوريد قد تم اجراؤها في الدول الدنقدمة وفي المقابل يوجد قصور في الدراسات التي قدمت في

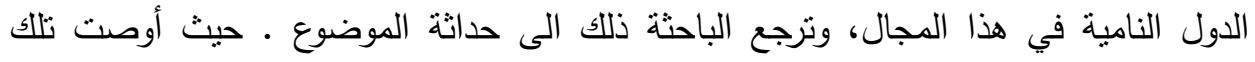
الأدبيات بان هناك حاجة الي المزيد من الأبحاث المستقبلية في مجال استخدام تكنولوجيا سلاسل الثقة Blockchain في زيادة كفاءة سلسلة التوريد. وتحاول الباحثة من خلال هذا البحث الوصول الى نأكيد معقول لإمكانية الإستفادة من تكنولوجيا سلاسل النقة Blockchain من خلال خصائصد المتمتلة فى التحقق ، المشاركة ، التتبع ، والقابلية للبرمجة ، والتعرف على الأثر المحاسبي لتالك الخصائص علي زيادة كفاءة سلاسل التوريد ـ وتتمثل مشكلة البحث في سؤال رئيس على النحو النالي: لإنيا:

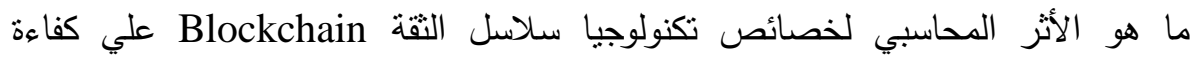
سلاسل النوريد؟ وينبثق من هذا السؤال الرئيس الاسئلة الفرعية النالية :

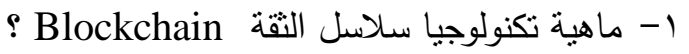


r- هل يحسن استخدام تكنولوجيا سلاسل النقه Blockchain في عمليه تبادل ومشاركة

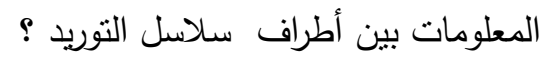

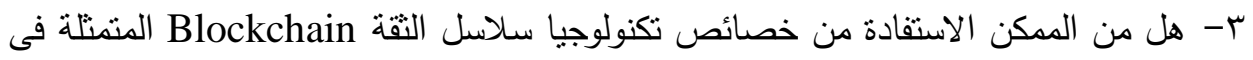

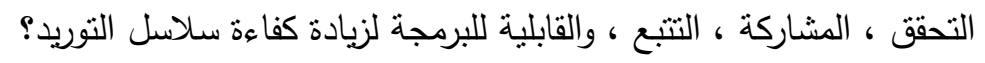

ب-أهمية البحث: يساهم البحث في التعرف علي خصائص نكنولوجيا سلاسل الثقة Blockchain حداثة الموضوع حيث قلة الدراسات المصرية التي تتاولت موضوع Blockchain وعلاقتته

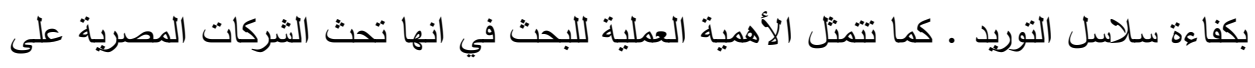

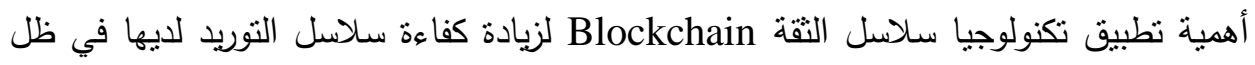
الظروف التتافية الحالية ورغبتها في البقاء والاستمرار بييئات الاعمال المختلفة . ع -هدف البحث : يهذف هذا البحث إلى التعرف على خصائص تكنولوجيا سلاسل الثنة Blockchain

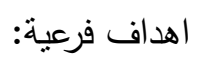

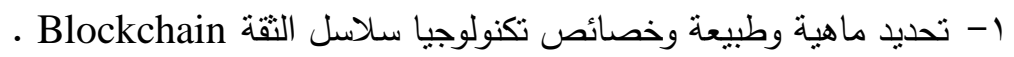
r- تحديد ابعاد القياس الخاصة بكفاءة سلاسل التوريد في الفكر المحاسبي.

r- بيان مدي الاستفادة من خصائص تكنولوجيا سلاسل الثقة Blockchain وأثزها

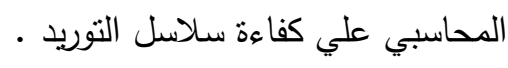

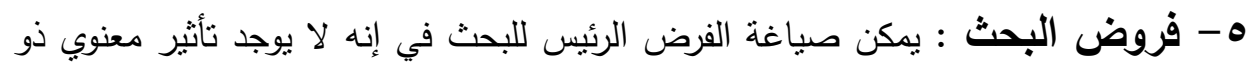

دلالة احصائية لخصائص تكنولوجيا سلاسل الثقة Blockchain علي كفاءة سلاسل التوريد .

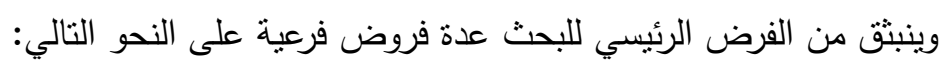

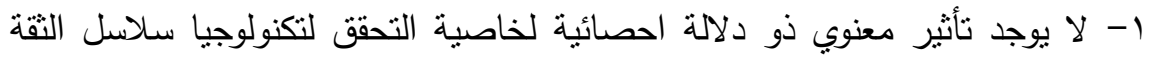

$$
\text { Blockchain }
$$

r- لا يوجد ثأثثر معنوي ذو دلالة احصائية لخاصية المشاركة لتكنولوجيا سلاسل الثقة

$$
\text { Blockchain }
$$

r- لا يوجد نأثيرمعنوي ذو دلالة احصائية لخاصية التتبع لتكنولوجيا سلاسل النقة

$$
\text { Blockchain }
$$


ع - لا يوجد تأثثر ذو دلالة احصائية لخاصية القابلية للبرمجة لتكنولوجيا سلاسل التقة Blockchain

צ- منهج البحث : يعتمد البحث على كل من المنهج الاستتباطي لبناء الاطار النظري للبحث وذلك من خلال استعراض ودراسة وتحليل الدراسات السابقة المرتبطة موضوع البحث والاطلاع على بعض اهم المراجع العربية والاجنبية ذات الصله بموضوع البحث، والمنهج الاستقرائي لقياس متغيرات الدراسة الميدانية واختبار فرض البحث الرئيسي وفروضه الفرعية ، والهي كما بعتمد البحث علي المنهج الاحصائي في معالجة وتحليل بيانات الدراسة الميدانية واجراء الاختبارات الاحصائية باستخدام برنامج SPSS - V متغيرات البحث: متغير مستقل ويتمثل فى تكنولوجيا Blockchain وخصائصه المتمثلك فى التحقق ، المشاركة ، التتبع ، القابلية للبرمجة ومتغير تابع يتمثل في زيادة كفاءة سلاسل التوريد . 1 - تنظيم البحث : تحقيقاً لهدف البحث وفي ضوء منهجيته سيتم تقسيم الأجزاء الباقية منه

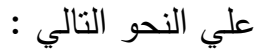
ثانياً : الدراسات السابقة ثالثا: الاطار النظري لتكنولوجيا سلاسل الثقة Blockchain ماسيا : رابعاً: سلاسل التوريد في الفكر المحاسبي. خامساً : مدى مساهمة خصائص تكنولوجيا سلاسل الثقة Blockchain في زيادة كفاءة سلاسل التوريد. سادساً : الدراسة الميدانية. ثانيا :الاراسات السابقة (1)دراسة (Kottler,2018) أوضحت هذه الدراسة معوقات وتحديات استخدام تكنولوجيا Blockchain إنشاء سلسلة علي مستوي الصناعة ، فضلا عن وجود نقص في البحوث الاكاديمية لتكنولوجيا Blockchain في مبادرة عمل جماعية للاتفاق علي معايير لتلك التكنولوجيا واعادة التفكير في دور بعض الجهات الفاعلة في الصناعة . 
(Y) (Tراسة (Treiblmaier,2018) استهدفت الدراسة استخدام تكنولوجيا Blockchain في Blockchain التأثير علي سلسلة التوريد ، واهم ما توصلت اليه الدراسة انه باستخدام تكنولوجيا

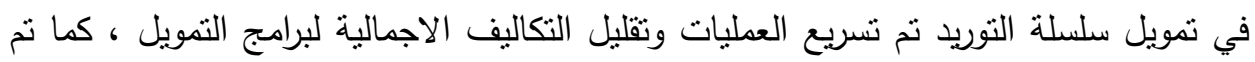
تبسيط طرق تأمين الدفع وتقليل الحاجة الي خطابات اعتماد ومن ثم تقليل رسوم المعاملات وزيادة السرعة والثفافية وتمكين الثركات من التعاقد علي الاسعار والجودة وتواريخ التسليم وهذا كله باستخدام خاصية العقود الذكية. (r)دراسة (Hofmann,et al,2018) استهدفت الدراسة الكثف عن الفرص المحتملة لتمويل باسل سلسلة التوريد عند استخدام تكنولوجيا Blockchain خاصة بعد ظهور العديد من العوائق ونقاط

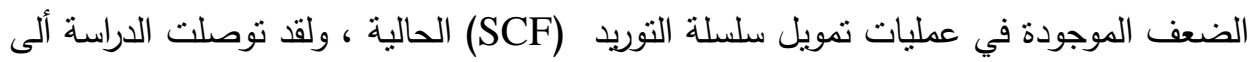
أن تكنولوجيا Blockchain ودفتر الاستاذ الموزع يقدم فوائد كبيرة لكافة الاطراف المشاركة في معاملات سلسلة التوريد (SCF) والاسراع في العمليات ومشاركة البيانات بأكثركفاءة ودقة وامان ، وتسريع التدفقات النقدية وتخفيض التكاليف الاجمالية وتقليل التعقيد

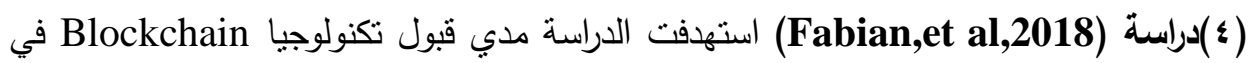
قدرتها علي التبع والثفافية لصناعات الاطعمة ، وبيان مدي أهمية التتبع المباثرعلي جودة سلسلة التوريد عند حدوث ابي عيب في المنتج وعند حدوث اخطاء من قبل الموردين وتحديدهم • واهم ما توصلت اليه الدراسة ، ان التبع يمكن ان يحسن جودة سلسلة التوريد حيث يخلق قيمة من خلال اليات مختلفة في اطار هيكلين مختلفين لسلسلة التوريد بالتوازي حيث لها القدرة علي تتبع الموردين كما لها القدرة علي تحسين جدوي التدفق النقدي لدي المشترين • (•) (دراسة) Meidayanti,et.al.,2019 ) قدمت هذه الدراسة تحليل وتصميم نظام التتبع في سلسله التوريد للحوم البقر على اساس تكنولوجيا سلاسل الثقة Blockchain ونم تحديد المنطلبات وتصميم نظام التتبع الذي يمكنه التقاط وجمع البيانات ذات الصله حيث يتم وصف نظام تتبع سلسة التوريد للحوم البقريه كتدفق عمليه تجارية ، حيث تم وصف اصحاب المصلحة المعنيين بمهمة واحتياجات ان النظام المصمح ، وبناء على تحليل المتطلبات تألف هذا النظام من اربع : اصحاب المصلحة، المزارع ،الصانع، تجار التجزئة. وكانت النتائج أن تكنولوجيا Blockchain 


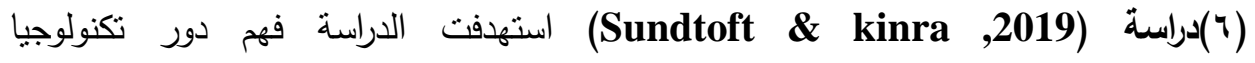
Blockchain

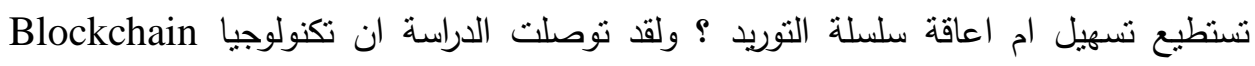
ينظراليها بانها فرصة لاستغلال الموارد والكفاءات الموجودة في سلسلة التوريد من خلال خاصية التهات

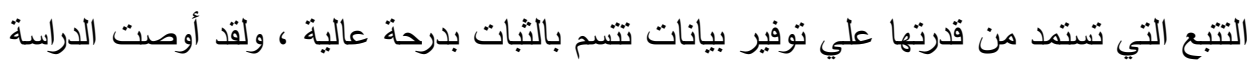
بالمزيد من الابحاث المستقبلية في مجال تكنولوجيا Blockchain وعلاقتتها بسلسلة التوريد اللتعرف علي نأثيراتها الهامة وتعقيداتها.

(P) دراسة ( Pankaj K.,2019) استهوفت الدراسة توضيح دور تكنولوجيا سلاسل الثقه Blockchain

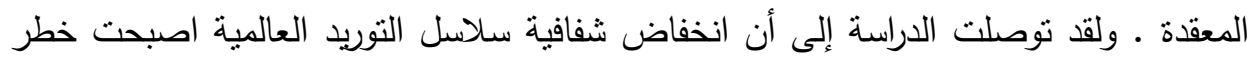

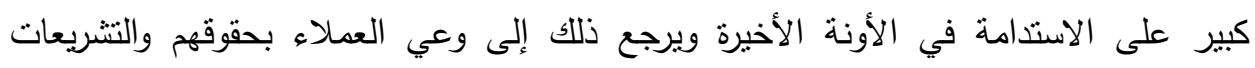

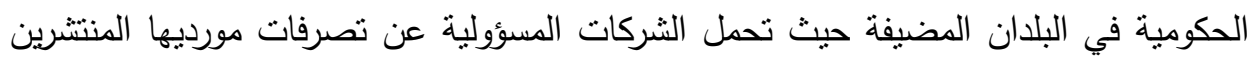
عالميا بالاضافة الى مخاوف العملاء حول جودة وسلامة المنتجات التي يستخدمونها من خلال

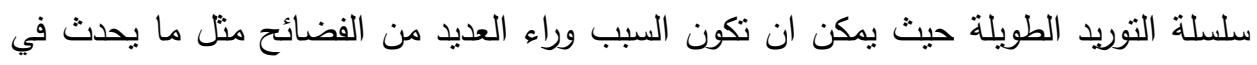

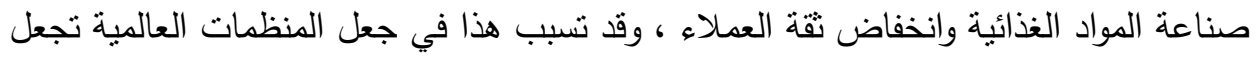

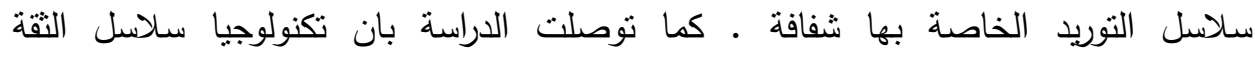
Blockchain تغييرات غير مسبوقة في العمليات المتعلقة بسلاسل التوريد العالمية ولتحقيق فوائد تشغيلية وتحقيق قدرة تنافسية مستدامة للثركات ـ ولقد اوصت الدراسة باهمية اجراء العديد من الابحاث

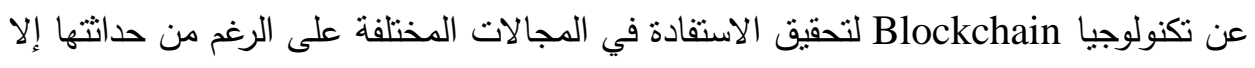
انها نحقق الاعمال المطلوبة بشكل سريع ودقيق وامن. (^)دراسة( Remko H.,2019) استهدفت الدراسة كيفية زيادة قيمة الثركات باستخدام

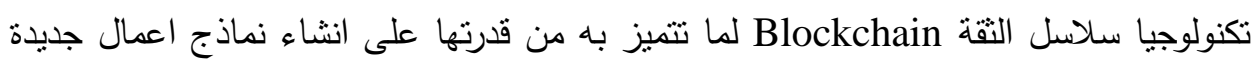

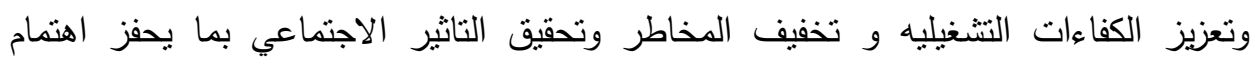

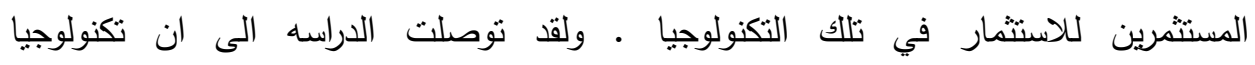

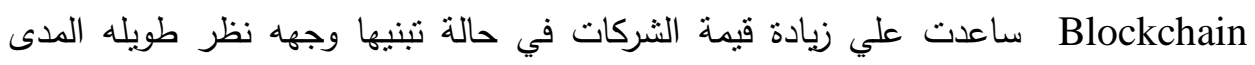


ستستغرق بعض الوقت لفهم كيفيه الاستفادة من قدرات Blockchain وتحويلها الي مصادر ملموسة ومستدامة للقيمة وخلق الدعم الاستراتيجي والتشغيلي المناسب ـ كما توصلت الدراسة بان التان التوسع في استخدام تكنولوجيا سلاسل الثنة Blockchain داخل سلسلة التوريد يتم بخطوتين :

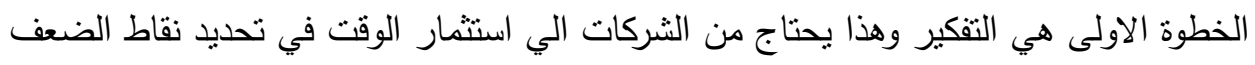

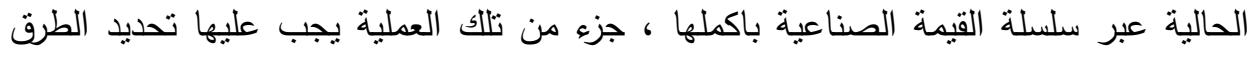

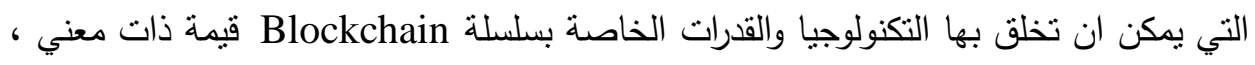
والخطوة الثانية هي التحقق من صحة حالات الاستخدام الممكنة لتلك التكنولوجيا حيث تحتاج

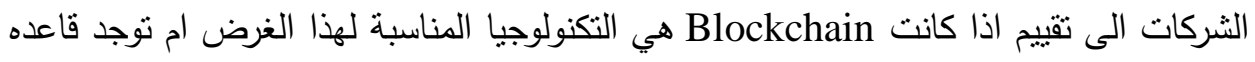

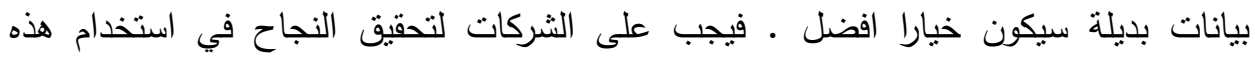
التكنولوجيا ولتوليد قيمة حقيقية قابلة للنطوير تبني وجهة النظرطويلة الاجل ووضع مجموعة من المعايير وتطبيق الحوكمة ووضع الاساس التقني السليم وتجميع عدد كافي من المشاركين واستهاف نقاط الضعف الرئيسيه وتحديد اولويات المناطق التي لها اهمية استراتيجية عالية او اولئي

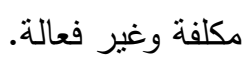

(9)دراسة ( Azzi,et.al.,2019 ) هدفت هذه الدراسة الى معرفة قوة سلسلة التوريد القائمة على فئلة تكنولوجيا سلاسل الثقة Blockchain ، ودراسة كيف يمكن ان يتم دمج سلاسل الثقة في بنية سلسلة التوريد لانثاء نظام موثوق وحقيقي وشفاف ، حيث بينت كيفية الوصول الى هذا الهدف

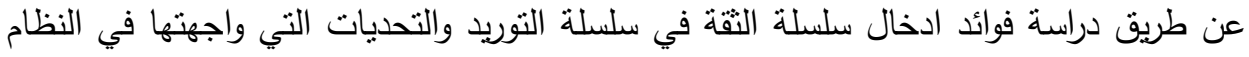
الايكولوجي لادارة سلسلة التوريد ، وقد تم الجمع بين الدراسات التطبيقية والنظرية والعالم الحقيقي

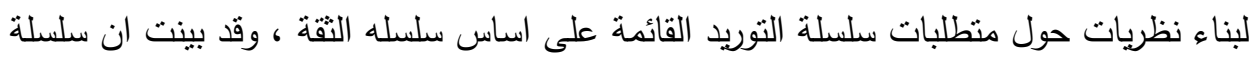
التوريد عبارة عن نظام بتألف من المنظمات والأفراد والأنشطة و المعلومات والموارد المشاركة في نقل منتج او خدمة من مورد الى عميل. (·) (1)وراسة(Khademi, et.al.,2019) وضحت هذه الدراسة تاثير تكنولوجيا سلاسل الثقة Blockchain معلومات الند للند ، حيث انه يشترك نظام حوسبي لامركزى يحتفظ بسجلات المعاملات الرقمية من خلال المكاتب الموزعة ، حيث تحل محل قواعد البيانات النقليدية التي يسيطر عليها الوسطاء منل البنوك والحكومات .وبينت سلسلة التوريد الحالية نموذج اقتصادي خطي يلبي 
احتياجات النوريد بشكل مباشر أو غير مباشر ، وان هذا النموذج لديه مشاكل مثل العلاقة بين اعضاء سلسلة التوريد وتتاقش طرق الاستفادة من تكنولوجيا Blockchain لتعزيز مرونة سلسلة الامداد في اوقات المخاطر المتزايدة وعدم اليقين. (1 (1)راسة ( Chod, et.al.,2019) : هدفت هذة الدراسة الى اعتماد تكنولوجيا سلاسل الثقة Blockchain Blockchain

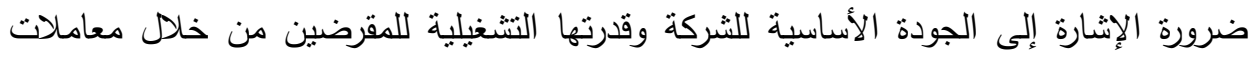

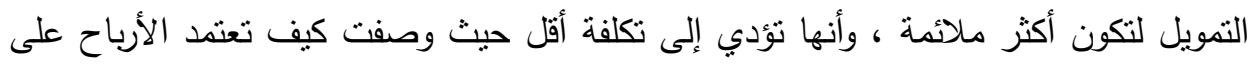

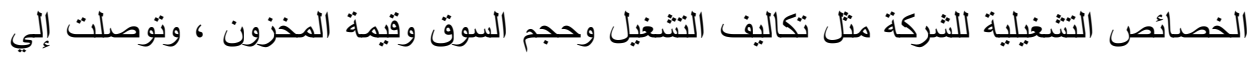
أن تكنولوجيا Blockchain بروتوكول مفتوح المصدر يعمل على استخدام بيتكوين لتوفير شفافية سلسله التوريد على نطاق واسع من حيث النكلفة. (r (1)دراسة ( Hastig ,Sohdi,2019 ) قدمت هذه الدراسة توجية بحوث إدارة العمليات حول تتفيذ أنظمة تتبع سلسلة التوريد من خلال تحديد منطلبات العمل والعوامل الحاسمة للتنفيذ الناجح ، حيث بينت أولا الحاجة إلى تتفيذ انظمة التتبع في صناعتن مختلفتين: تعدين الكوبالت والمستحضرات الطبية. ووصفت كيف اجرت تحليل موضوعي للمقالات حول تطبيق تكنولوجيا

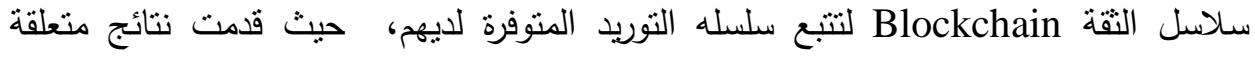
باحتياجات مختلف اصحاب المصلحة منل الموردين، المتنهكين والجهات التنظيمية. وبينت منظلبات العمل لانظمة التتبع إنها تحد من الممارسات غير القانونية وإنها تعمل على تحسين الاداء وزيادة الكفاءة الثتغيلية وتعزيز تتسيق سلسلة التوريد، وبينت عوامل النجاح الحاسمة للتنفيذ وقدرات الثركات على التعاون ـ وقد وفرت النتائج نموذجا قياسيا حديثا للعمل التجريبي

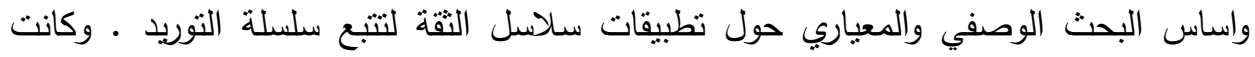
النتائج ان النحليل الموضوعي سمح بنطوير موضوعات فرعية لمنطلبات العمل وعوامل النجاح

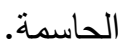

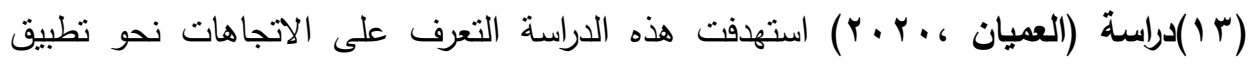

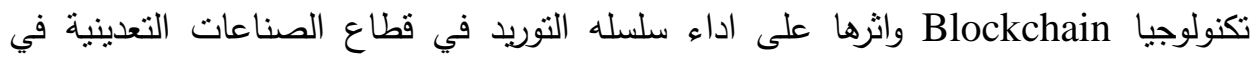
الاردن ، حيث تكونت عينه الدراسه من rم مستجييا من العاملين في قطاع الصناعات التعدينيه 
في الاردن ، وقد استخدمت الدراسة الاسلوب الوصفي التحليلي ، ولقد توصلت الدراسه الى عدة Blockchain نتائج ابرازها ان قطاع الصناعات التعدينية في الاردن لا يقوم بنطبيق تكنولوجيا بسماتها (اللامركزية ، الثفافية ، التتبع) ، وهذا يثير الى ان المدراء والموظفين العاملين في قطاع الصناعات التعدينية في الاردن بحاجه لمعرفة أهية تطبيق Blockchain بسماتها (اللامركزيه ، الثفافيه ، التبع) وفي ضوء النتائج التي نوصلت اليها الدراسة قدمت عدة توصيات منها ضرورة تدريب العاملين الحاليين على التعامل مع هذه التكنولوجيا بشكل يتتاسب مع مهام وظائفهم من اجل تحسين الاداء ، وضرورة تطوير نموذج دراسة جدوى مفصل لـ Blockchain ، وتطوير اطار شامل لحالات استخدام تكنولوجيا Blockchain في سلسلة التوريد وفقا لخصائص Blockchain ، والعمل على دمجها في بنية سلسلة التوريد لانشاء نظام موثوق حقيقي وشفاف وامن.

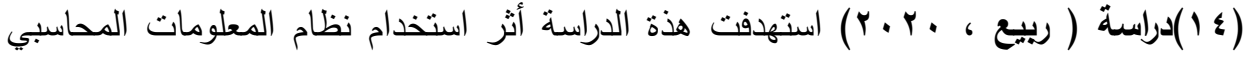
المستتد على تكنولوجيا Blockchain على تحسين اداء سلاسل التوريد المدعومة بتكنولوجيا الثورة الصناعية الرابعة ازاء مواجهة فيروس كورونا المستجد، واستخدمت الدراسة المنهج التجريبي من خلال توزيع قوائم استقصاء نم ارسالها لكل من الاكاديميين والممارسين (المهنيين) ، ولقد توصلت الدراسة الى أهمية تطبيق نظام المعلومات المحاسبي المستتدة على تكنولوجيا Blockchain توصلت إليه الدراسة في شقها النظري، الى أهمية تطبيق نظام المعلومات المحاسبي المستتد على تكنولوجيا Blockchain في التخفيف من حدة هذا الانتشار لفيروس كورونا المستجد من خلال ( انجاز المحاسبين لاعمالهم عن بعد ، والتبادل الالكتروني للوثائق المحاسبية لجميع الاطراف داخل سلسلة التوريد ، وتوفير المعلومات المتعلقة بالعثور على مصدر الامراض المنقولة ، والتبادل الإلكتروني للأموال) وتحسين أداء سلاسل التوريد من خلال (ت توحيد البيانات عبر سلسلة التوريد ، توفير معلومات دقيقة وموثوقة وفي الوقت المناسب ، وتجنب الاخطاء المحاسبية والتسويات، وكذلك توفير المعلومات المحاسبية فور حدوث الحدث بالاضافة إلي

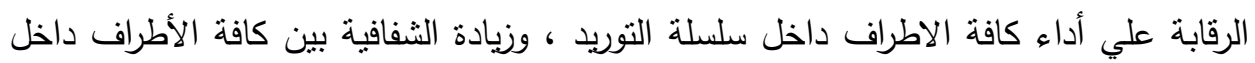
سلسلة التوريد وتخفيض الوقت المستغرق لتلبية رغبات العملاء وتخفيض تكلفة المعاملات وزيادة مبيعات وارباح سلسلة التوريد. 


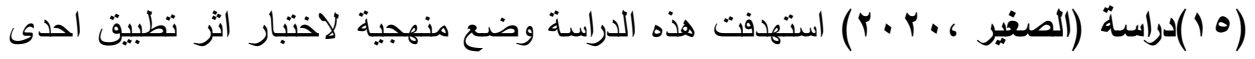

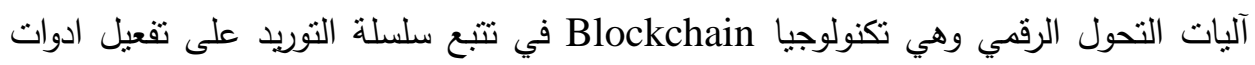
ادارة التكلفة البينية لتلك السلسلة ، وتم التزكيز على دور تللك التكنولوجيا في دعم كلا من اسلوب تحليل سلسلة القيمة لسلسلة النوريد وكذلك في دعم كلا من أسلوب التكلفة المستهدفة وأسلوب

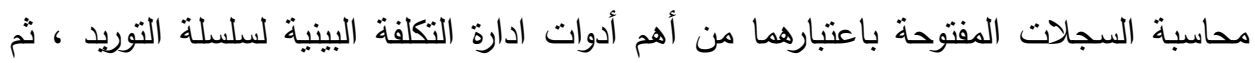

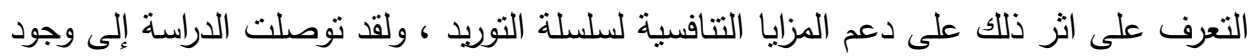
علاقة إرتباط احصائي ايجابية بين تطبيق تكنولوجيا Blockchain في تنتع سلسلة التوريد التصنيعية وتتسيق الجهود والعلاقات ودعم تحليل سلسلة القيمة فيما بين أطراف السلسلة ، كما فيا فيان توجد علاقة ارتباط ذات دلالة احصائية بين تطبيق تكنولوجيا Blockchain في تتبع سلسلة النوريد التصنيعية وتفعيل أسلوب النكلفة المستهدفة وأسلوب محاسبة السجلات المفتوحة كأدوات لادارة التكلفة البينية على امتداد السلسلة ايضا اثشارت النتائج إلى وجود علاقة ارتباط ذات دلالهة احصائية بين تطبيق تكنولوجيا Blockchain في تتبع سلسله التوريد التصنيعية ودعم المزايا التتافسية لتلاك السلسلة. (1 (1)دراسة ( Dnyaneshwar,et al,2020) استهدفت هذه الدراسة عدة قضايا مختلفة

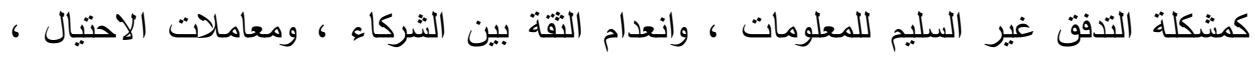

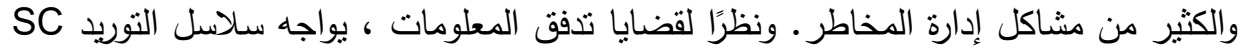

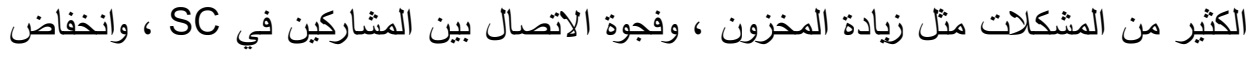

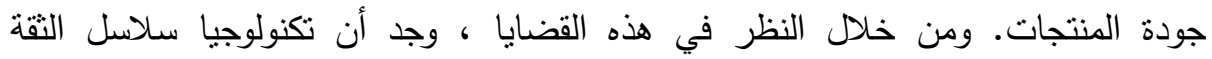
Blockchain

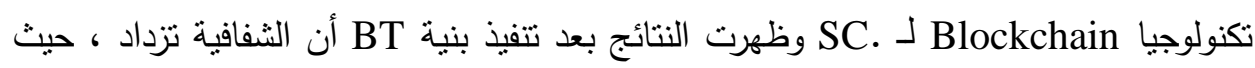

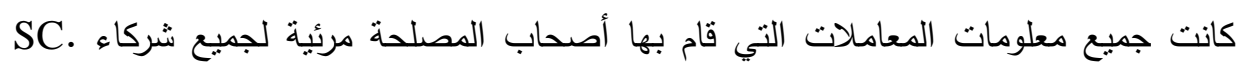

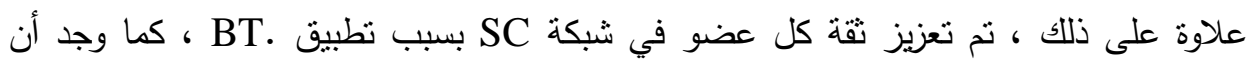

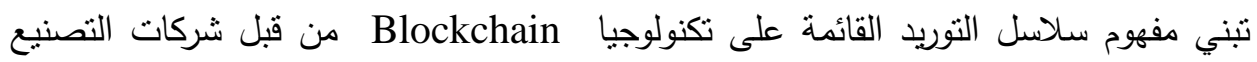

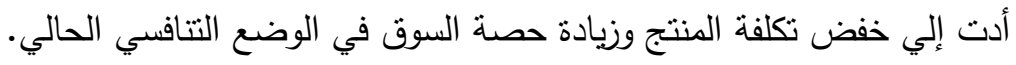
ويالرجوع للاراسات السابقة تبين للباحثة مايلي: 
ركزت الدراسات السابقة علي العلاقات الثائية بين الثركة الموردة والثركة الششتريه واثشارت إلي أن نجاح علاقات الثراكة يقوم علي الالتزام والتعاون والثقة المتبادلة بين اطراف العلاقة بسلسة التوريد والتي استطاعت تكنولوجيا سلاسل الثنة Blockchain توفيرها ، ولقداف تثابهت هذه الدراسة مع عدد من الدراسات السابقة Chod, ،Treiblmaier,2018 ترفيرها 2 Hofmann,et al,2018 ، et.al.,2019 من حيث الاستفادة من خاصية العقود الذكية (القابلية للبرمجة) التي تتميز بها تكولوجيا Blockchain في رفع كفاءة سلاسل التوريد ، كما تنتابهت مع دراسة Fabian,et al,2018 ودراسة 2019, Sundtoft, kinra ودراسة Hastig ودراسة Pankaj K.,2019 ودراسة Meidayanti,et.al.,2019

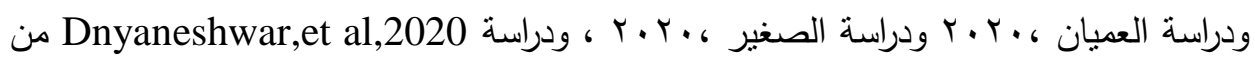

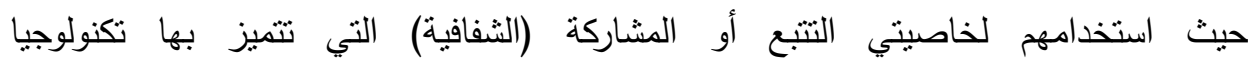
Blockchain

كما تبين للباحثة وجود نقص في البحوث الاكاديمية المصرية لتكنولوجيا Blockchain في

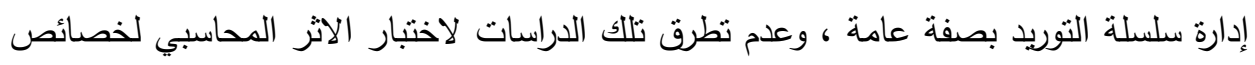

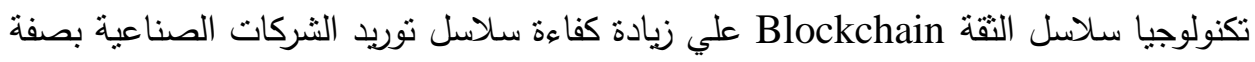

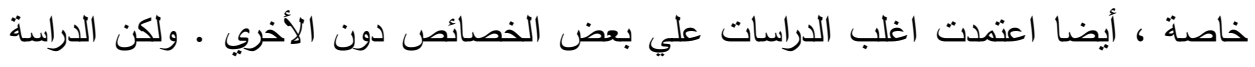

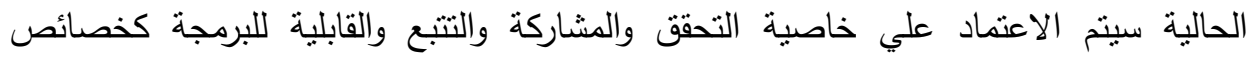

لسلاسل الثقة Blockchain والتعرف علي اثرها المحاسبي في زيادة كفاءة سلاسل التوريد .

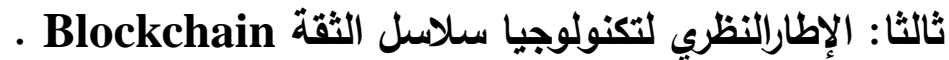

تعتبر تكنولوجيا سلاسل الثقة Blockchain بمثابة ابتكار رائد في تكنولوجيا

المعلومات. وبالرغم من أن هذه التكنولوجيا مازالت في مراحلها الأولى ولم تصل إلى اعتماد من التهات

قِبل الثركات بعد، إلا إن تطبيقات سلاسل النقة في حالة تقدم كبير ( Evelina \&

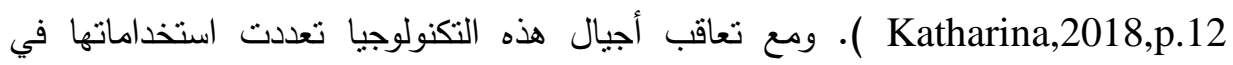

مجالات متعددة خاصة في المجال المحاسبي وعلى الاخص في معالجة البيانات المالية وتبادلها بطريقة آمنة وموثوقة وشفافة تمكن من سهولة وسرعة الوصول اليهال 


\section{Plockchain 1/ مفهوم وأنواع تكنولوجيا سلاسل الثقة}

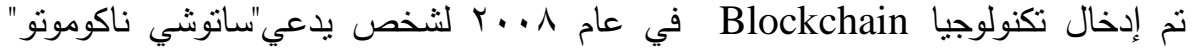
وكان بمثابة الجيل الأول لتطبيقات سلاسل الثنة Blockchain وهو أول نطبيق يدعم المعاملات البسيطة ، ويمثل التكنولوجيا الاساسية للعملات المشفرة منل عملة البيتكوين

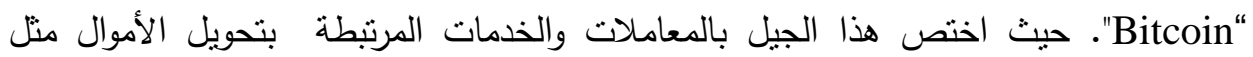
اليات الدفع وخدمات التحويلات عبر الانترنت ويقتصر دوره في كونه سجل يحتفظ بهذه المعاملات(Morkunas,et al 2019,p.2) . وفي عام \& ا. ب ظهر الجيل الثاني لنطبيقات سلاسل الثقة Blockchain وهو يختص ليس فقط بالعملات والخدمات المرتبطة بتحويل الاموال عبر الانترنت بل لديه القدرة على دعم و تتفيذ العقود الذكية ، والعقد هو رمز البرنامج الذي يمثل

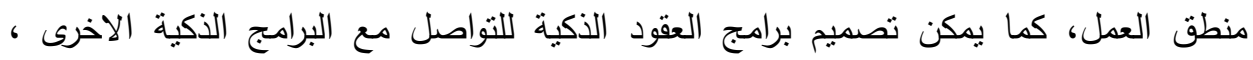

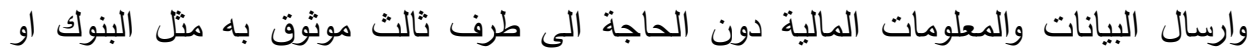

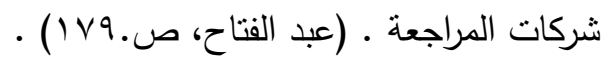
وتعرف تكنولوجيا سلاسل الثقة Blockchain بأنها سلسلة من الصناديق المرتبطة فيما بينها والتي تحتوي على بيانات مؤمنة بشفرة خاصة تدعم اللامركزية والأمن، وتختلف تكنولوجيا Blockchain للتحرير بينما في في الثبكات المركزية هناك دائما خطر الاحتيال أو هجمات المنسات التسللين الخارجين ، وبمعني اخر فهي مجموعة من الكتل تتضمن الكتل الجديدة طوابع زمنية غير قابلة

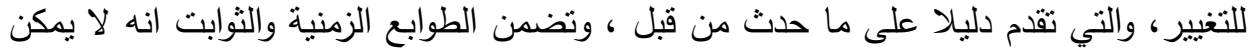
التلاعب بسلسلة من المعاملات لان كل كتلة اساسية تتثير الى الكتلة السابقة .Alex Hughes.

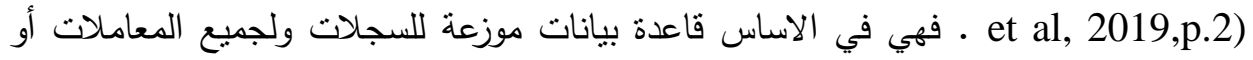
الاحداث الرقمية التي تم تتفيذها ومشاركتها بين الاطراف المشاركة في السلسلة ـ ويتم التحقق

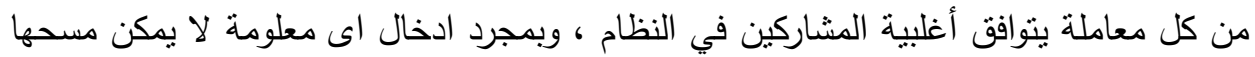
او تعديلها مطلقا(Simpi Khandelwal,2019,p.440)

ويوجد ثلاثة انواع من Blockchain :الاول Blochain :لعامه: وهي لامركزية ويطلق عليها النظير إلي النظير يمكن فيها لاي شخص استخدامه والوصول للمعلومات المتاحة علي العامة ، والثاني Blockchain الخاصه: وفيه يكون جميع المشاركين معروفين و موثوق 
بهم • ومن هنا فان التمييز بين Blockchain العامه والخاصة مرتبط بالجهة المسموح لها بالمشاركة في الثبكة ، حيث تسمح Blockchain العامه باجراء معاملات مرئية بشكل علني وقدرتها لاعطاء المعلومات لجميع المشاركين المحتملين ، بينما لا تحتوي Blockchain الخاصه إلاعلى عدد محدد مسبقا من المصرح لهم ، وعادة ماتكون Blockchain الخاصد ، لهاءع مركزيه تسمح بخاصية التحكم بالدخول للشبكة عن طريق وجود قواعد وشروط اتفق عليها مجموعة المؤسسين، والثالث Blockchain ذات التحالفات وهو يدار بمجموعة مختارة من القادة تتحالف مع بعضها البعض علي عكس Blockchain الخاصه تدار من قبل وحدة واحدة

(O'leary,2017,p139, Rebecca Yang,2020,p.2, Zheng,2018,p.357)

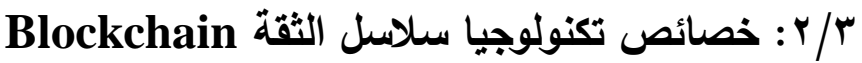

اختلف عدد من الباحثين في تحديد خصائص تكنولوجيا سلاسل التقة Blockchain فأوضحت دراسة (Zheng,2018) أربع خصائص هي اللامركزية.Decentralisation ودفية ، Auditability. Persistency و وعدم الكثف عن الهوية.Anonymity و والمتابعة

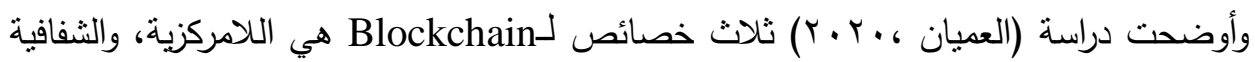
، والتتبع ، كما أوضحها (ICAEW,2018 ) بأنها تتمثل في:

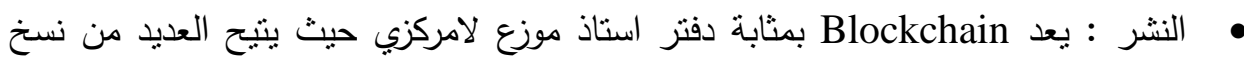
دفتر الاستاذ Blockchain ، ولا يوجد ما يسمى نسخه اصلية مما يمكن جميع المشاركين في الوصول الى نسخة كامله من دفتر الاستاذ وجميع النسخ منطابقة ومتكافئة ، ولا يوجد طرف لديه سيطرة على هذا الدفتر اي بدون تحكم مركزي ، ويتم نشر المعاملات الجديدة بسرعة ويتم نشرها على نسخ جميع المشاركين. الاستمرارية: جميع المعاملات والسجلات دائمة ولا يمكن العبث بها او ازالتها، فلا يمكن تعديل المعاملات السابقه بدون موافقة الاغلبيه. • القابلية للبرمجة: العديد من Blockchain قابلة للبرمجة ، مما يسمح لاتمتة المعاملات الجديدة والضوابط عبر العقود الذكية وهناك من أوضح ان خصائص Blockchain تتمثل في (سيد عبد الفتاح ص. . 1 ( ): • دفتر الاستاذ : تنتخدم تقنية Blockchain دفتز استاذ لتوفير سجل تاريخي كامل لكافه العمليات و المعاملات المالية 
الامن :تتسم تقنية Blockchain بالامن نظر لشمولها اجراءات وسياسات رقابة ذاتية

Blockchain مبرمجة تضفي المزيد من الثقة على معاملات

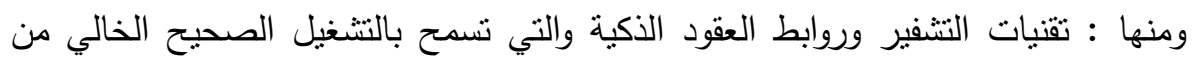

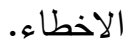

• المشاركة : ينت مشاركة دفتر الاستاذ بين كافة المشاركين في شبكة Blockchain بما

بساعد على دعم الثنفافية

• موزع : تتيح تقنية Blockchain التعامل المبانر بين طرفي المعاملة وعدم الحاج' إلي

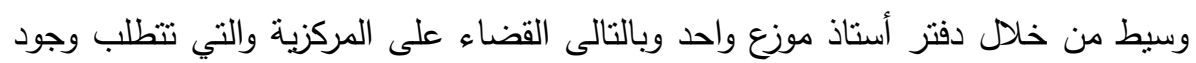
طرف ثالث في أي تعامل يقوم بالترخيص بالمعاملة وضمان حدوثها منل البنوك.

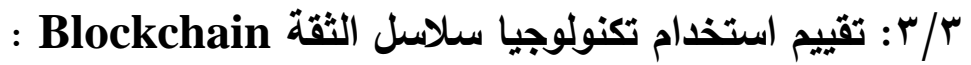

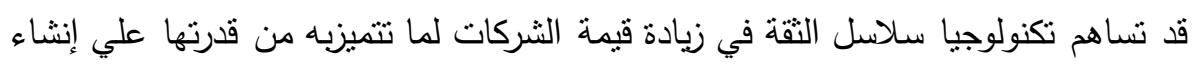

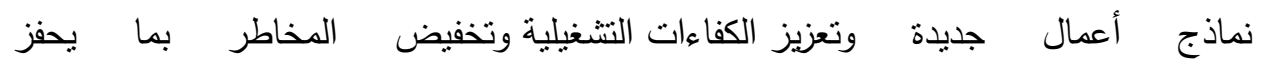

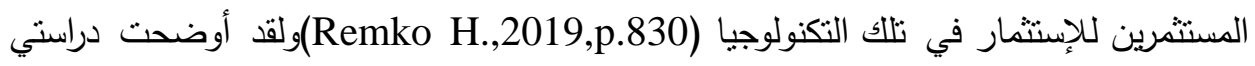
(Barbara W.,et al,2019) و (Fanning Kurt \& Centers D.,2016) فوائد تكنولوجيا سلاسل النقة Blockchain بقدرتها علي تسجيل وتخزين واسترجاع البيانات وخفض تكاليف

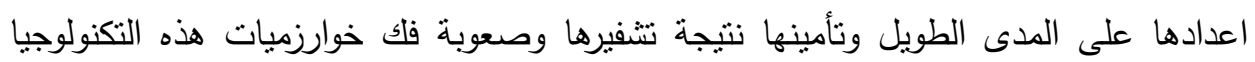
واختراقها ، كما اوضحا جودة وسلامة البيانات المالية المخزنة عليها لان عمليات الادخال تكون مكشوفة لجميع الاطراف ذات الصلة ، فهي تتميز بقدرتها علي المحافظة على البيانات المالية وامكانية تجديدها وتحديثها باستمرار حيث تحفظ البيانات ككتلة واحدة وبالتالي ينم تحديث

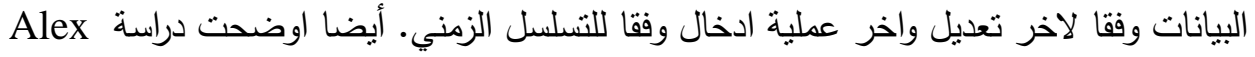
Hughes. et al, 2019 قبل كل طرف بريد مراسلة طرف رقمي اخر ، والأطراف التي ترغب المشاركة في المعاملة لا

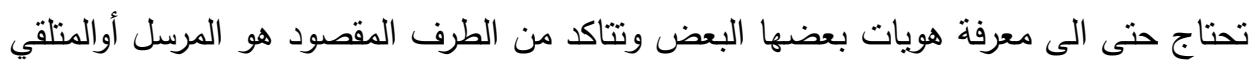
بأنه الطرف الدصرح له حق الوصول الى صفحة الدفتاح الخاصة به ولذا تعتبر تكنولوجيا Blockchain 
وفي سياق العملات المشفرة تمكن تطبيقات Blockchain مواجهة التلاعب بأن تمنع "الانفاق المزدوج" وتضمن خصم المعاملات من حساب واحد واضافتها الى حساب مختلف دون بان المخاطرة بتخصيص نفس الأموال اكثر من مرة ، نظراً لان المعاملات النقدية تتم بين الاطراف الفردية ، لذا فانها تقلل من المخاوف حول الثقة الموضوعة على المؤسسات المالية ، ومن ثم مثرة فأن التكاليف واوقات المعاملات يمكن تخفيضها بشكل كبير (Alex Hughes. et al,2019 )، ويمكن حصر أهم المزايا التي تتسم بها العملات الرقمية المشفرة في النقاط التالية:

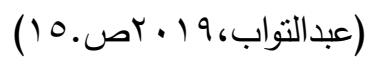
- - الرسوم المنخفضة : حيث تتميز العملات الرقمية المشفرة بأن المتعامل فيها لن يدفع أي مصاريف على النقل او التحويل والتى تفرض من خلال القنوات التقليدية لنقل الاموال بواسطه البنوك والمؤسسات المصرفية لأن العملة لم تتنقل بل رمز العملة هو ما خرج من هن محفظة المشتري ودخل الى محفظة البائع وهذه العملية تتم دون وسيط وتسمي الند للند. - السرعة والخصوصية والسرية: تتسم العملات الرقمية المشفرة بالخصوصية من حيث انه لا لاهن

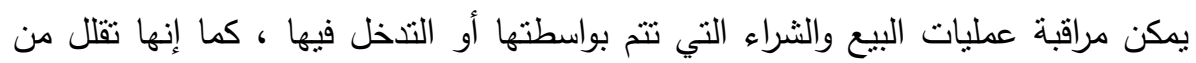

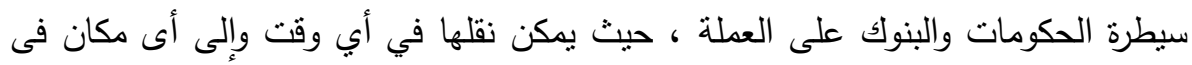

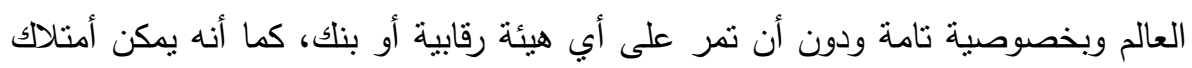

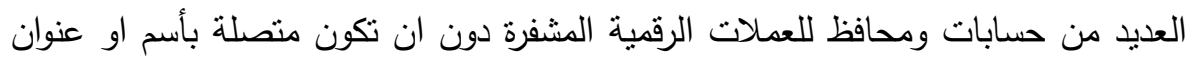

$$
\text { او أي معلومة عن ممتلكها. }
$$

- - العالمية : حيث تتميز العملات الرقمية المشفرة بأنها لا ترتبط بمنطقة جغرافية معينة، لأنها

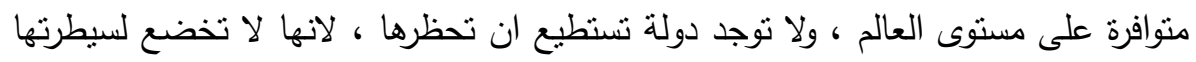

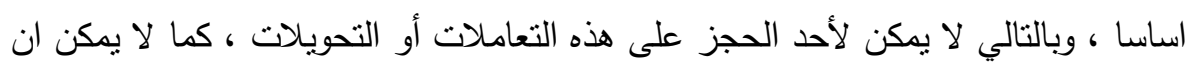

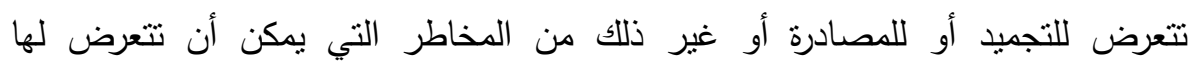
التحويلات بالعملات التقليدية اذا كان هناك شك في مشروعيتها. - - - الثفافية: تتميز العملات الرقمية المشفرة بشفافية البيانات المتعلقة بالمعاملات والأرصدة لدى كل مستخدم ، ففي عملة البيتكوين يقوم برنامج البيتكوين بتخزين أب عملية نم القيام

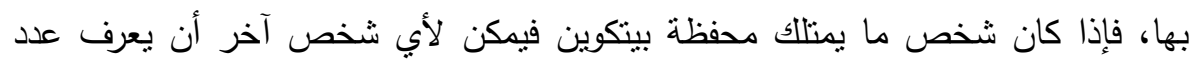


وحدات البيتكوين التي يمتلكها صاحب هذه المحفظة وعدد المعاملات التي تمت من خلالها ، حيث يشاهد الجميع وبشفافية تامة حركه نتقل العطلة بين المحافظ.

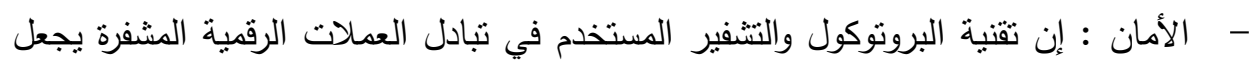
من الصعب نزويرها أو إعادة استتساخها ، كما يمكن للمستخدمين تشغيل ممارسات الأمان

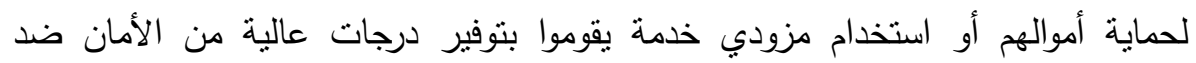
السرقة.

وعلى الرغم من المزايا التي تتسم بها العملة الرقمية المشفرة ، يوجد العديد من المشكلات التي نرتبط باستخدام تلك العملات منل التقلب المرتفع في القيمة ، مخاطر كبيرة في كي

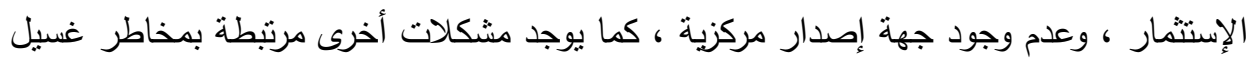

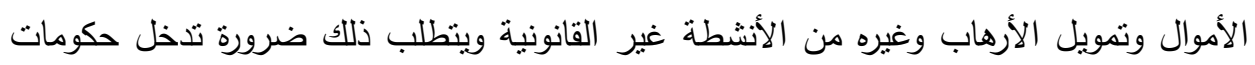
الدول بوضع الضوابط والتشريعات التي تحد من استخدام العملات الرقمية المشفرة في تلك

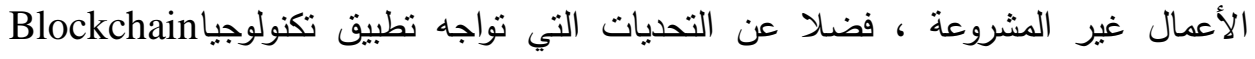
(Khandelwal,2019,p.448)

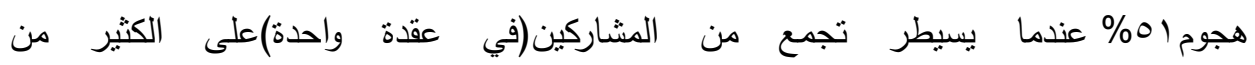

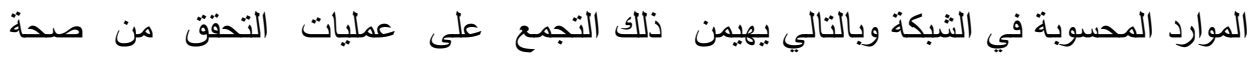
المعاملات والموافقة عليها، بالاضافة لعدم الفهم الكامل لتكنولوجيا سلاسل الثقة وتعتبر واحدة من أكبر المخاطر التشغيلية لسلاسل الثقة ويرجع ذلك لعدم التقبل التقافي للتغيير من قبل البعض أو لئاسئ الجهل بالتكنولوجيا وخصائصها وأمكانياتها مما يؤخر مرحلة الاعتماد والتطبيق، أيضا تكاليف

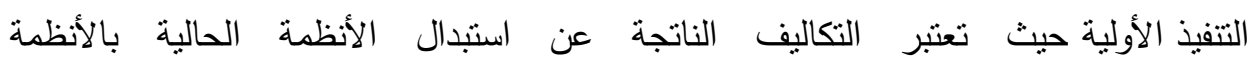
المستقبلية مرتفعة من حيث خسارة الأنظمة الحالية وأرتفاع أسعار الأنظمة المستقبلية وبالإضافة لتكاليف صيانتها ومراقبتها ومتابعتها وتدريب العاملين على التعامل معها، ولقد أكد Enrique عداد من الباحثين علي وجود بعض التحديات لتكنولوجيا Blockchain حيث أوضحا ) \& Michaela,2019 التحديات التي تواجه استخدام تكنولوجيا سلاسل الثقة في مجال المحاسبة والمراجعة وكيفية تحسين الابعاد المختلفة لجودة المعلومات المحاسبية، كما أوضحها (Jiapeng et al ,2019, Barbara W.,et al,2019, Michael C.,et Kottler,2018 al,2019 ) 
- الاخطاء البشرية عند ادخال البيانات واحتمالية اختراقها بالرغم من صعوبه عملية الاختراق وارتفاع تكاليفها. - لا يزال استخدامها غير قابل للتطبيق وخاصة في قطاع الخدمات - أن معظم التقنيات الحديثة لا تحكمها أطر قانونية وبالتالي توجد مخاوف متعلقة بالمعلومات فئ

$$
\text { المحاسبية وجودتها. }
$$

- - تحتاج الى مزيد من القيود والضمانات لجودة المعلومات المخزنة عليها واجراء عملية المراجعة على اساسها والتاكد من الحيادية التامة والاستقلال على المستوبين الداخلي

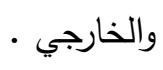

- - فوائدها غير مؤكدة في حالة عدم وجود نظام رقابة جيد يضمن سلامة البيانات التي ينت

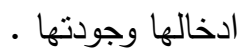

- وجود نقص معرفي في كيفية إنشاء سلسلة علي مستوي الصناعة ، فضلاً عن عدم وجود

$$
\text { معاييرمتفق عليها لتلك التكنولوجيا. }
$$

وينبغي على الثركات الاستفادة من الفرص ومواجهة التحديات الناتجة عن الانتشار الواسع لتطبيق تكنولوجيا سلاسل التقة Blockchain ويجب عليهم التعرف على تطورات تكنولوجيا Blockchain

$$
\text { التغييرات السريعة في عالم الاعمال. }
$$

\section{r/ع : تكنولوجيا سلاسل الثقة والمجال المحاسبي}

لقد توجهت أكبر مكاتب المحاسبة والمراجعة في العالم(Big Four) نحو استخدام تكنولوجيا سلاسل الثقة Blockchain كأكبر دليل علي تتامي استخدام تللك التكنولوجيا في المجال

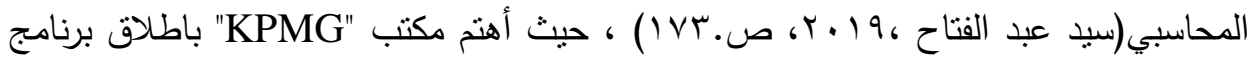

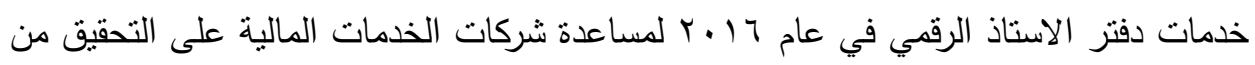
تطبيق تكنولوجيا Blockchain، فضلا عن اشتراكه الاستراتيجي مع شركة المايكروسوفت ودعم ، نظام Blockchain Nodes الذي تستخدمه الثركة لتوفير Blockchain كخدمة لعملائها حيث قدم المشورة للعملاء حول كيفية مساعدة Blockchain في تحسين سرعة المعاملات وأمانها وخفض التكاليف. 
Blockchain واستهدفت العديد من الدراسات التي تتاولت استخدام تكنولوجيا سلاسل التقة فوائد ومزايا استخدامها في المجال المحاسبي ( Stephen F.,et al,2019 ) ، حيث استهدفت دراسة ( Boon et al,2019) التعرف علي مدي امكانية تأثنرها على مهنة المحاسبة ، وهل سيكون للمحاسبين دور وسلطه كاملة على العمليات الحسابية أم سيقتصر دورهم على ادخال المعلومات فقط وسيتم معالجنها تلقائيا وتحديثها اول باول واعداد التقارير ، ولقد نوصلت إلى ان رقمنة النظام المحاسبي يقلل معدل الاخطاء والاحتيال ، كما نوصلت إلي ان المحاسبين لن يكون هم المسئولون عن اجراء العمليات الحسابية ، ولكنهم سيظلون مسئولون عن المحتوى المعلوماتي للتقارير المالية وأن استخدام تلك التكنولوجيا يعمل على تحسين كفاءة عملية المراجعة وخفض معدلات الاخطاء ، بينما استهدفت دراسة ( Jana etal,2019 ) التعرف على اثر استخدام تكنولوجيا سلاسل التقة Blockchain وتقنية دفتز الاستاذ الموزع التي تعتبر احد تطبيقاتها علي مستقبل مهنه المحاسبة والمراجعة ، ولقد توصلت إلى زيادة كفاءه تسجيل البيانات المحاسبية لضمان نزاهتها وكثف الاحتيال في العمليات المختلفة، وتخفيض كل من التكلفة والوقت اللازم لتوصيل المعلومات المحاسبية في ظل استخدام تلك التكنولوجيا .

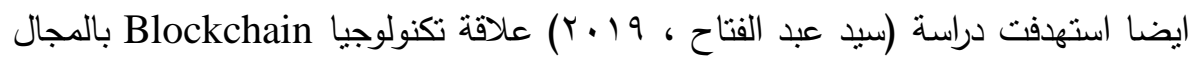
المحاسبي عن طريق تحليل و اختبار اثر خصائص تكنولوجيا Blockchain على تحسين انتاج وتوزيع واستخدام التقارير المالية الرقمية ، واهم ما توصلت اليه الدراسة وجود اثز ذو دلالة معنوية لخصائص تكنولوجيا Blockchain على تحسين انتاج وتوزيع واستخدام التقارير المالية الرقمية ، ولقد اوصت الدراسة بضروره انتاج وتوزيع واستخدام التقارير الماليه الرقمية بالاعتماد على تكنولوجيا Blockchain ، بينما تتاولت دراسة (الشرقاوي،9 1 ـ ب))إنعكاسات تكنولوجيا Blockchain علي البيئة المحاسبية وتوصلت إلى أن تكنولوجيا سلاسل الثقة Blockchain أدت الى تغيرات كبيرة على البيئة المحاسبية والأطراف الداخلة في عملية المحاسبة من الندان المحاسبين والمراجعين ، حيث أوجبت علي المحاسبين أن يكونوا قادرين على توسيع مهارتهم لتشمل فهم لمبادئ ووظائف Blockchain ، كذلك أثرت على المراجعين بأنها احدثت نغييراً عميقا في طريقه عمل المراجعات ، بخفض وقت عملية المراجعة نفسها واعطاء المزيد من الوقت لتصميم ومراجعة والتحقق من كيفية تدفق المعلومات بين الانظمة وبدلا من اجراء عمليات 
المراجعة على فترات منتظمة فان Blockchain والتعلم الالي يقدمان خاصية اجراء مراجعه

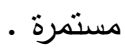

وهذا اتفق مع دراسة (Michael C.,et al,2019) ان استخدام تكنولوجيا سلاسل الثقه لا يلغى بشكل كامل دور المراجعين ولكن يغير الكيفية التي يقومون باداء اعمالهم بها وذللك من خلال الرصد المستمر والمراجعه بصورة مستمرة ، وبالتالي زيادة كفاءة عمليه المراجعة وتقليل مخاطرها ، كما اتفق مع دراسة (صبري ، ·r.r) التي اختبرت أثرتطبيق تكنولوجيا Blockchain

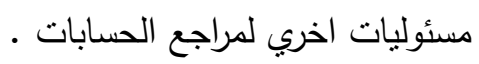

ومما تقدم يتضح أن استخدام تكنولوجيا سلاسل الثقة قد يضيف مزيدا من الدقة والثفافية في

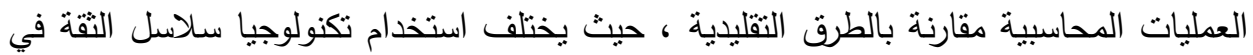
مجال المحاسبة والمعاملات المتعلقة بها عبر الانترنت عن استخدام المحاسبة التقليدية والطرق التقليدية المنمنلة في تسجيل العمليات المحاسبية في العديد من السجلات واعداد الفواتير و معالجه البيانات والجرد سواء بالطريقه اليدوية او بالبرامج المحاسبية التى تجرى كل عملية على حده (Aleksy K,2019 ) لذا يحقق تطبيق تكنولوجيا سلاسل الثقة Blockchain منافع محاسبية تتمثل في زياده شفافية وجودة ودقة المعلومات وإمكانية التتبع والمراقبة المستمرة وتخفيض الاحتيال بالاضافة إلي اهميتها في تخزين ومعالجة البيانات بطريقة مختلفة عن استخدام الطرق الإلكترونية المعتادة والمتعارف عليها وحذف أي جهد يدوي غير ضروري وزيادة كفاءة

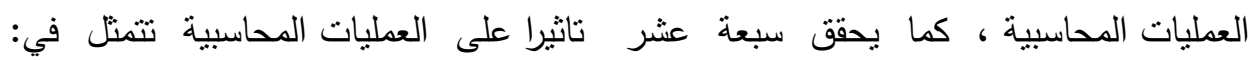

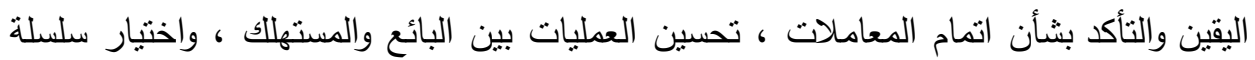
التوريد ، وموائمة وادارة الاهداف التتظيمية، وتحسين العلاقات بين الملاك والمديرين، واتمتة بعض المعاملات ، والتحقق من تطبيق قواعد المحاسبة ، وتجنب الاخطاء ، والثقة في المعلومات وفرض الجزاءات والمعاقبة على اخفاء المعلومات ، والتاكيد للأطراف باتمام المعاملات والأمن وخصوصية المعلومات ، والتأكيد علي ان المعلومات لم يتم العبث بها أو أو التلاعب بها ، وعدم القدرة على تغيير المعلومات ، وتخفيض البيانات المفقودة ، وإمكانية تتبع لتع 


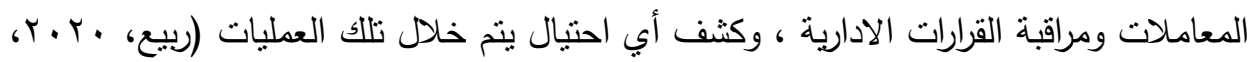
(19.0 رابعاً : سلاسل التوريد في القكر المحاسبي. ع/1 : مفهوم سلسلة التوريا .

تعرف سلسلة التوريد بإنها شبكة الكيانات التي تتدفق من خلالها المواد والمعلومات، وتتشل هذه الكيانات الموردين والمصنعين وتجار الجملة وتجار التجزئة والعملاء )

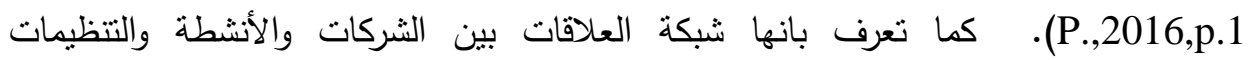
والتكنولوجيا التي تؤدي وظائف تدبير احتباجات العملاء من خدمات ومنتجات أو أموال أو بن بأ

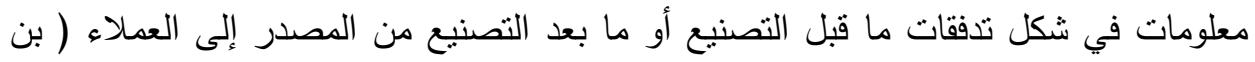

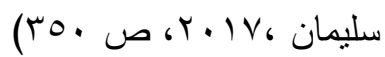
ايضا تعرف سلاسل التوريد بأنها مجموعة من الأنشطة المضيفة للقيمة عبر عده شركات بهدف إثباع احتياجات المستهلك النهائي ، وبطبيعة الحال يتطلب تحقيق الهدف السابق ضرورة تتسيق الأنشطة والعمليات اللوجستية داخل سلسلة التوريد بالإعتماد على المواد المعلوماتية بما

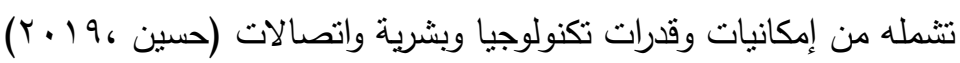
وتتمل سلسلة التوريد مجموعة اساسية من الاطراف تسمى اعضاء سلسلة التوريد وهم موردي المواد والاجزاء والمصنعين وموردي الخدمات اللوجستية والموزعين في شكل تجار جملة وتجار تجزئة ، كما تتضمن ابعاد سلسلة التوريد عمليات الثراء والتوريد والمناولة والتوزيع

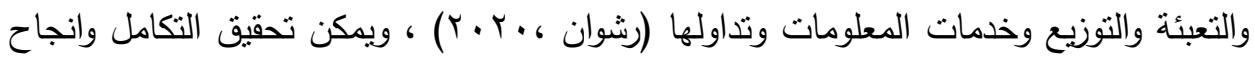
سلسلة التوريد عن طريق حسن اختيار اعضاء سلسلة التوريد والبحث عن افضل الطرق المتاحة لخفض التكاليف خلال انشطة السلسلة ، مع وضع حوافزتشجيعية للموردين في حالة خفض اسعار مبيعاتها للمنشأة ، لان نجاح المنشأة في تحقيق مركز تتافسي قوي في عصر الانترنت يعتمد بشكل كبير علي مدي قوة الارنباط والاداء المشترك بين اعضاء سلسلة التوريد مع ضرورة

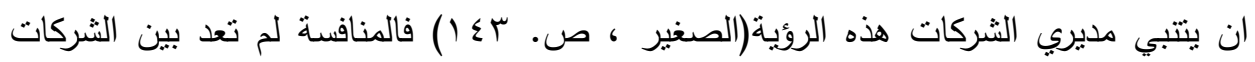

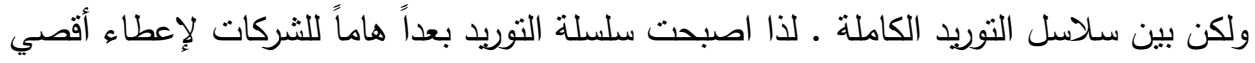
قدر من الاهتمام من أجل التفوق في بيئة تتافسية(Madhani P.,2016,p.1) وتزداد كفاءة سلسلة التوريد بتحسين وتحقيق أهداف سلسلة التوريد. 


\section{؟ / ץ: أهداف وأبعاد كفاءة سلاسل التوريد}

لقد ظهر مفهوم Supply Chain Management لتتسيق الموارد وتحسين الأنشطة عبر سلسلة القيمة للحصول على مزايا تتافسية ، وهو مفهوم يدمج جميع الأطراف عبر سلسلة

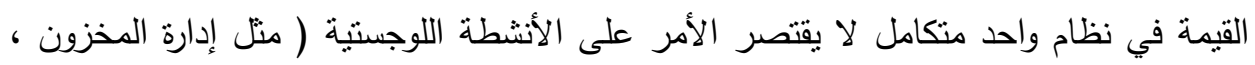

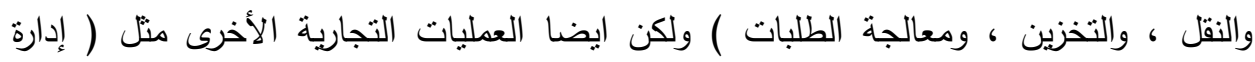

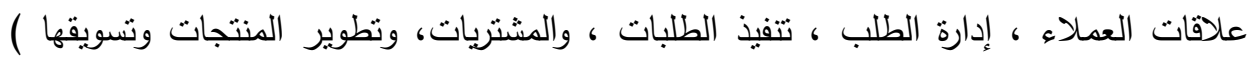

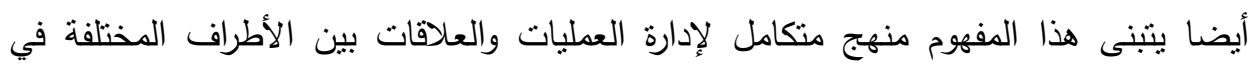
سلاسل النوريد وتركز على العمليات داخل سلسلة التوريد (Madhani,P,2016,p.4) يتمتل هدف إدارة سلسلة التوريد قصير الاجل في تعزيز الإنتاجية وخفض المخزون والوقت

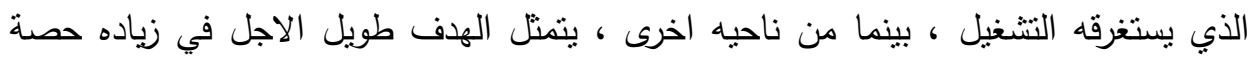

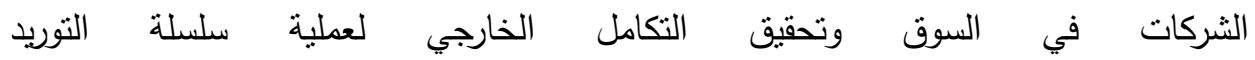
فقد اصبح مجال Supply Chain Management فاملا استراتيجيا رئيساً لتحسين اداء الثركات والحفاظ علي قدرتها التتافسية في السوق. (Madhani,P,2016,p.4 ) وبصفة عامة تتمثل أهداف سلسلة التوريد في : 1- دعم المزايا التنافسية سواء على المستوى المحلى أوالدولى ب- تحقيق الربط بين احتياجات ورغبات العملاء وأنثطة سلسلة النتوريد

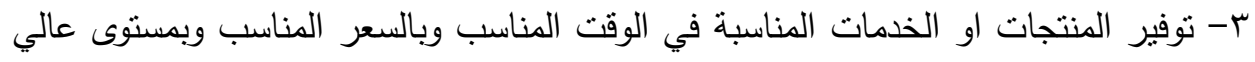

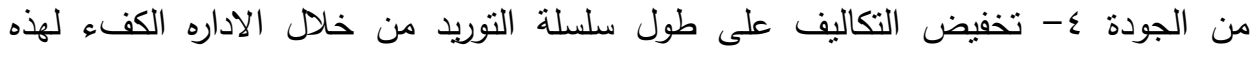

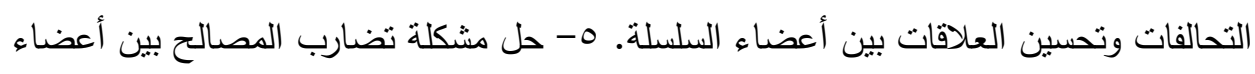

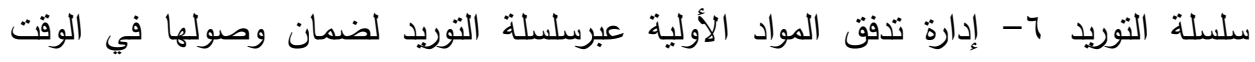

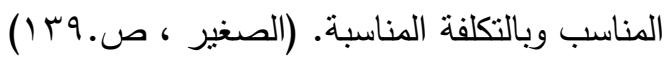
وهناك اتجاهات بحثية ركزت على قياس كفاءة سلسلة التوريد في ثناث أبعاد أبعاد أساسية لاداء

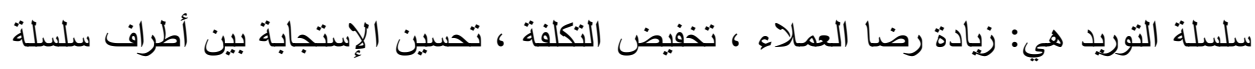

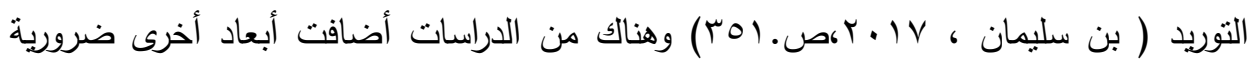

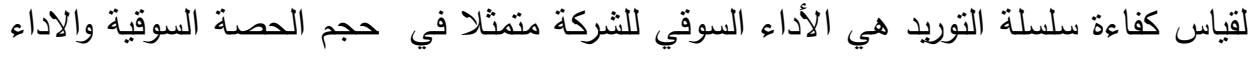

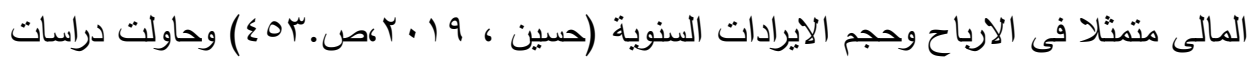


أخري في مجال اداء سلسلة التوريد تلخيص وتصنيف أبعاد الكفاءة في تصنيف عام من خلال مراجعة نظم الادبيات التي تتاولت هذا الموضوع خلال أخر عشر سنوات حيث صنفتها الى أبعاد كمية وأخرى غير كمية وأبعاد معتمدة على التكلفة وأخرى غير معتمدة على التكلفة وأبعاد

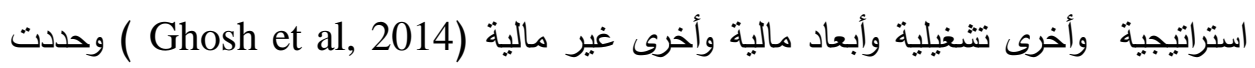

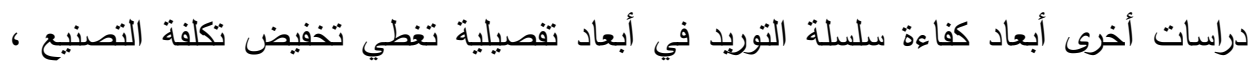
وتخفيض التكلفة الكلية ، وتخفيض تكلفة المخزون ، وزيادة الاستجابة لطلبات العملاء و زيادة مستوى الخدمة المقدمة للعملاء وتقليل معدلات نفاذ المخزون وتحسين الحصة السوقية للشركة ، وتحسين معدلات النمو وزياده حجم المبيعات (Singhry,2015) وتتأثر كفاءة سلسلة التوريد بوجود العديد من المشكلات التي تواجه سلسلة التوريد والتي من شأنها تؤدي إلي زيادة تكاليفها ، ومن أهم هذه المشكلات مشكلة عدم كفاءة ادارة المخزون، ومشكلة خطابات الضمان المكلفة والمستهلكة للوقت ، ومشكلة عدم القدرة علي تحديد المسئولية من عمليات السرقة والاحنيال ، ومشكلة عدم رضا العملاء ، ومشكلة التأخر في منابعة السلع المعيبة ، ومشكلة الاعتماد علي سماسرة الجمارك لتجنب الغرامات ، ومشكلة عدم كفاءة توجية وشحن المنتجات بما يؤثزعلي تكاليف الشحن(Kottler,2018,p.1) • وفي هذا السياق يظهر الفكر المحاسبي بعدين أساسيين لزيادة كفاءة سلاسل التوريد (فؤاد

$$
:(r \cdot 1)_{6}
$$

\section{أولا : تحقيق القيمة المضافة للمنتجات ومقابلة رغبات العملاء :}

تتحقق القيمة المضافة للمنتجات وتتحسن كفاءة سلاسل التوريد من خلال القيام: أ-

بتحسين العلاقة مع العملاء والتعرف على احتياجاتهم المتجدة ، والتخطيط لاشباع رغباتهم ، ץ- تحسين العلاقة مع الموردين لضمان تدفق مدخلات الانتاج بالمواصفات الملائمة فيما يتعلق

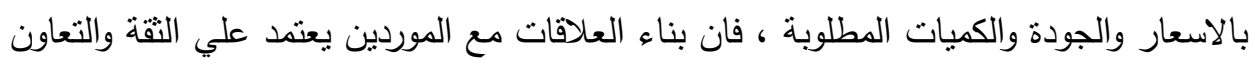
والثفافية في نبادل المعلومات والخبرات لتحقيق منفعة منبادلة ـ فالثقة عنصر مهم لأطراف سلسلة التوريد وهناك ارتباط وثيق بين النقة والحد من المخاطر في العلاقات المتبادلة بينهم سإدارة التدفقات العكسية (المرتجعات)، منل: مردودات المبيعات والمنتجات التالفة والعمل على لهلى تقليل هذه التدفقات. 


\section{ثانيا : تخفيض تكلقة المنتجات :}

لتحسين كفاءة سلسلة التوريد يجب ضمان استمرار تدفق المعلومات كما ونوعا بين أطراف سلسلة التوريد وفيمابين أقسام وادارات المنشأة الواحدة ، حيث بساهم تبادل ومشاركة المعلومات

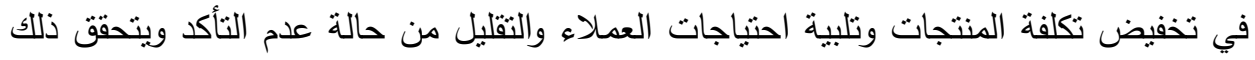

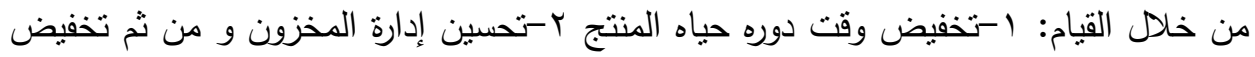

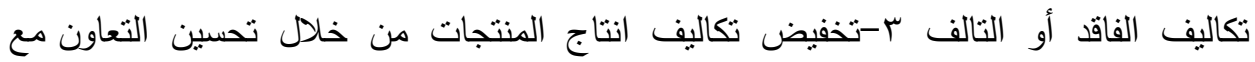
الموردين وتتسيق الجهود داخل اقسام وادارات المنثأة . ونجاح إدارة سلسلة التوريد ينوقف علي مدي حجم تبادل المعلومات المالية وغير المالية

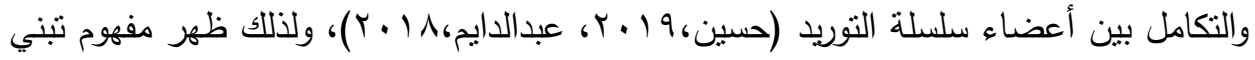
وتطبيق تكنولوجيا المعلومات الحديثة نظراً لقدرتها على بناء شبكة اطراف وعلاقات فعالة نساهم

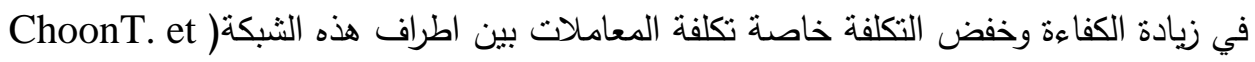

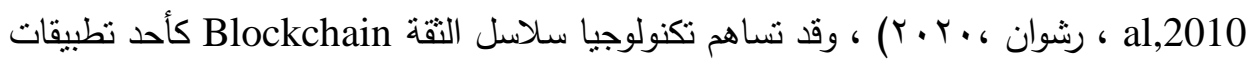

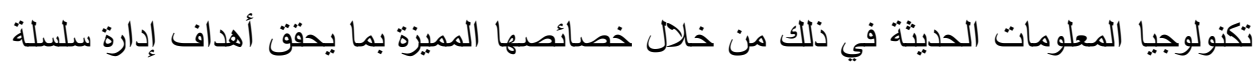
التوريد (التكلفة ، الجودة ، السرعة) .

\section{خامسا : مدى مساهمة خصائص تكنولوجيا سلاسل الثقة Blockchain في

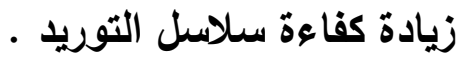
1/0 :علاقة تكنولوجيا المعلومات وتكنولوجيا Blockchain بسلسلة التوريد

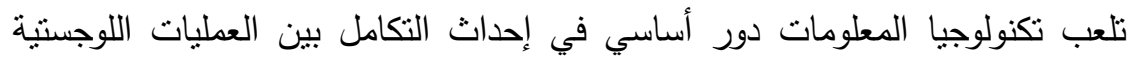

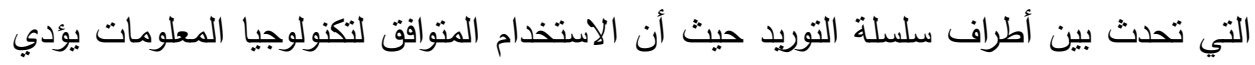
إلى زيادة التعاون والتتسيق بين أطراف سلسلة التوريد وترجع أهمية إحداث التكامل في التافي العلاقة

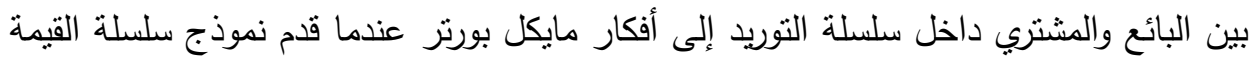
الذي اكد من خلاله على أهمية إحداث التكامل بين عمليات الأعمال عبر سلسلة من الأنثطة

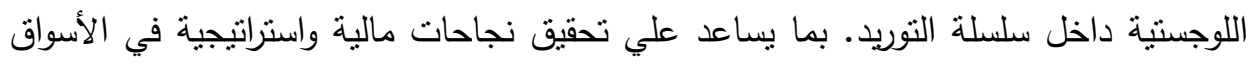
خاصة الأسواق العالمية ، ونظراً للأهية المتزايدة لتكنولوجيا المعلومات داخل سلسلة التوريد قد

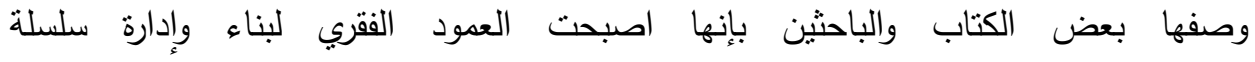
التوريد(Deraman,et al,2012). 
ولقد أوضحت دراسة (Deraman,et al,2012) دور المعلومات والإتصالات علي أداء

سلسلة التوريد حيث بينت الدور والتاثير الإيجابي الذي تحققه نظم المعلومات والإتصالات المتوافقة على أداء سلسلة التوريد ، كما أوضحت دراسة(Kaliani S.,etal,2016) الأثر غير المباشر الذي تلعبه المعلومات على خلق وتقوية علاقات تكامل داخل سلسلة التوريد بما يساهم في تحقيق أعلى مستوى لأداء الثركة ، وهذا أيضا ما أكدته دراسة (Singhry,2015) فيما يتعلق بضرورة تحسين قدرات الثركات من خلد الإهتمام بدعم وتطور قدرات تكنولوجيا المعلومات اللازمة لتحقيق تكامل الموردين والعملاء داخل سلسلة التوريد. كذلك أهتمت دراسة (فراج ،9 1 ( ) بدراسة كيفية تحقيق الثفافية و ضمان جوده المعلومات والإتصالات بين أطراف سلسلة التوريد لتحقيق ميزة تتافسية ، وأكدت دراسة (Yao, et al,2009)علي ضرورة توفير نظم معلومات حديثة قادرة على كسر الحواجز بين الموردين والمشترين لضمان تحسين أداء أطراف سلسلة التوريد.

ويمكن حصر المنافع التي تحققها تكنولوجيا المعلومات داخل سلسلة التوريد في تقليل أزمنة النقل ، نوافر المعلومات عند الحاجة ، توفير الدقة ، تحسين مستوى خدمة العملاء ، إنتاجية

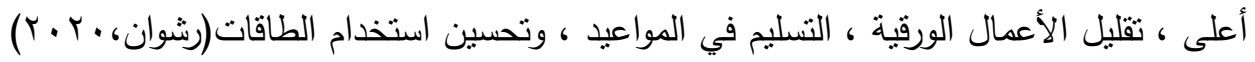
، وتعتبر تكنولوجيا سلاسل الثقة Blockchain كإحدي تكنولوجيات المعلومات وسيلة فعالة بشكل كبير للتحقق من صحة وسلامة المعلومات المقدمة من خلالها ، فهي ذات نفع كبير في Fanning Kurt \& Centers ) العديد من المجالات المختلفة بخلاف المجالات المالية

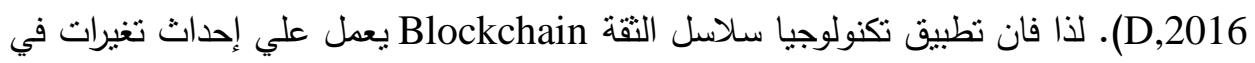
قطاعات الأعمال المختلفة كأسواق المال والحوكمة والبنوك وسلاسل التوريد والقطاع الصحي

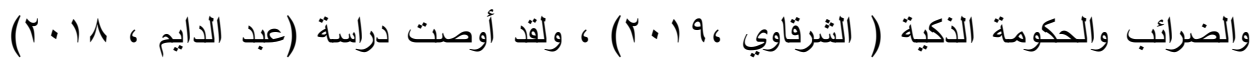
بضرورة تقييم اثار تطبيق تكنولوجيا سلاسل التقة Blockchain علي أهداف إدارة سلسلة التوريد (التكلفة ، الجودة ، السرعة، الحد من المخاطر ) .

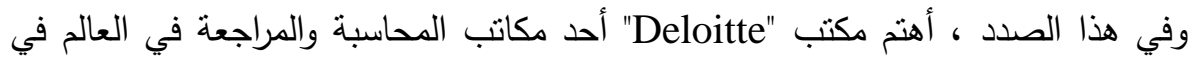
عام \& ا.ب باطلاق برنامج Blockchain كأحد اهم التقنيات المستخدمة في المحاسبة والمراجعة حيث اعتمدت عليه لتسريع عملية مراجعة معاملات Blockchain والاستفادة منه في Maria ) تطبيقات إدارة سلسلة التوريد والمسائل المتعلقة بالسلامة وقضايا المستهلك النهائي 
Karajovic,et al,2016)، ولقد أثنارت بعض الدراسات السابقة علي أهية نطبيق سلاسل التوريد لتكنولوجيا سلاسل الثقة Blockchain في تحسين الأداء المالي وأهميتها في تحسين

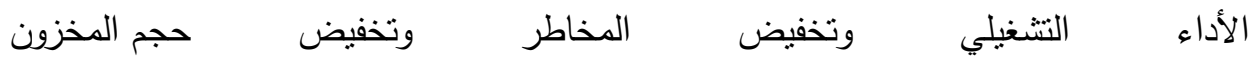

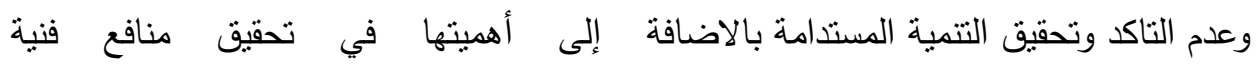

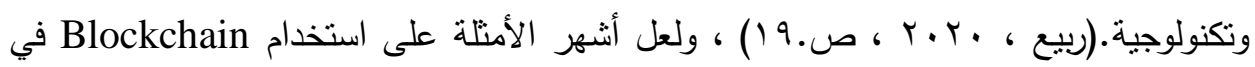

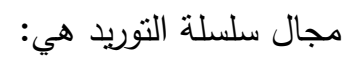

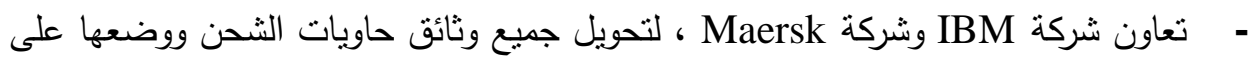
Blockchain ، مما يمكن من تنتع الحاويات ، كما يمكن لكل مشارك في سلسلة التوريد

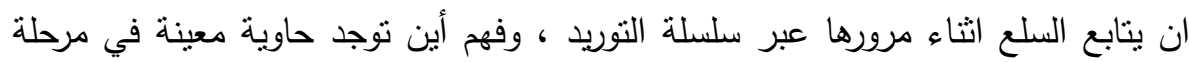

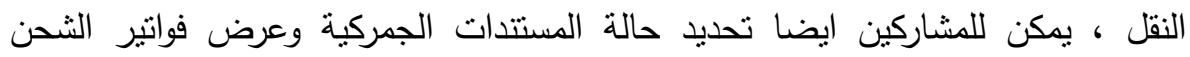

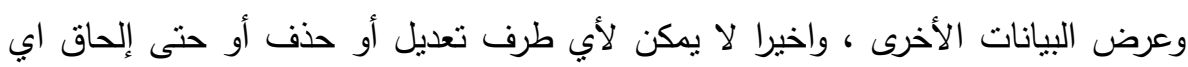
سجل دون إجماع من الاخرين على الثبكة(O'leary,2017,p.139 ).

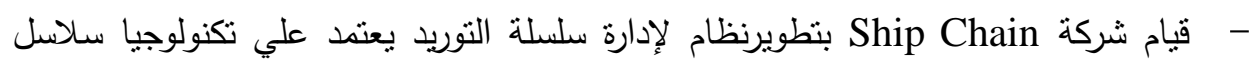

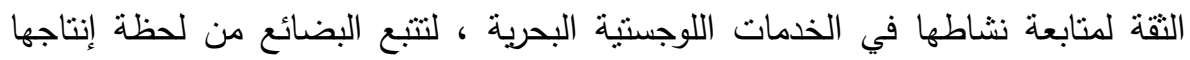

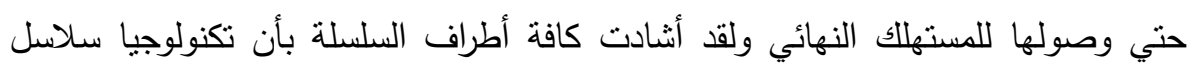
الثقة Blockchain سهت مشاركة المعلومات ، وخفضت تكاليف الأنشطة والمعاملات ، ودعمت الثقة في نعاملات الأطراف الدختلفة في السلسلة .

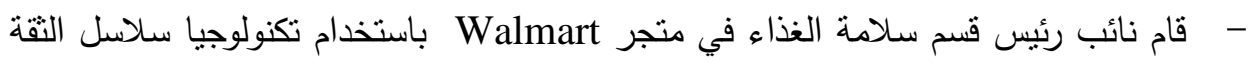
Blockchain

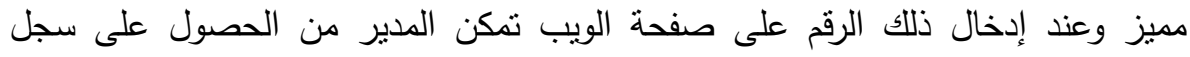

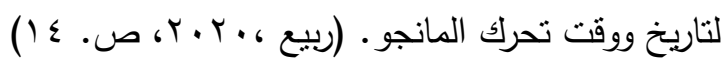

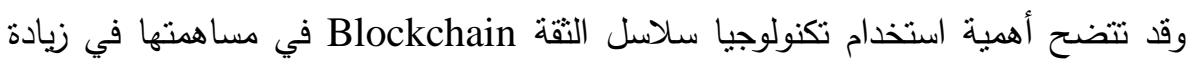

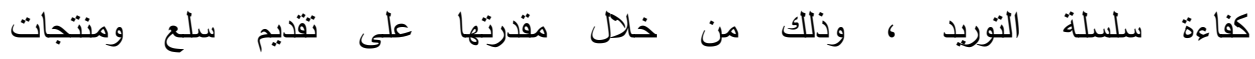
بجوده عالية وبالكمية المحدة في الوقت المحدد وبأقل تكلفة ممكنة ، فضلا عن سهولة تجهيز الاعمال الورقية ، حيث يتطلب التعامل مع سلسلة التوريد التقليدية كمية كبيرة من الأوراق والتي لئي 
تكلف الوقت والمال ، كما أن تلالك الأدوات معرضة للتلف كل هذه البنود لا حاجة لها في

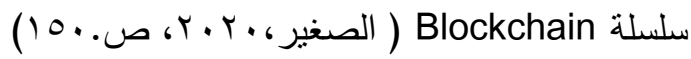

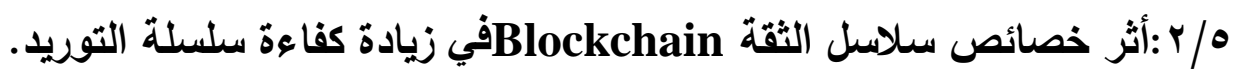
قد تساهم تكنولوجيا سلاسل الثقة Blockchain من خلال خصائصها المميزة المنتلة في خاصية التحقق والمشاركة والنتبع والقابلية للبرمجة في زيادة كفاءة وفاعلية سلسلة النوريد نظراً

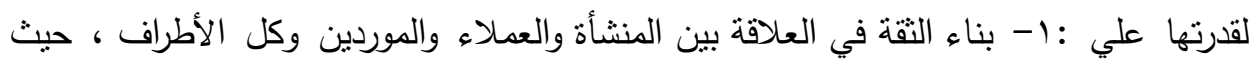
تسجل جميع معاملات الأطراف في شكل كتل يتم إعتمادها واقرار صلاحيتها في توقيتها

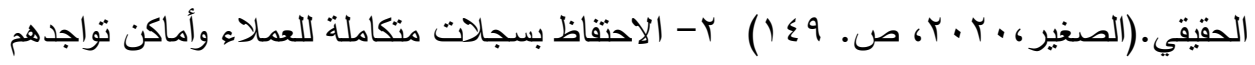

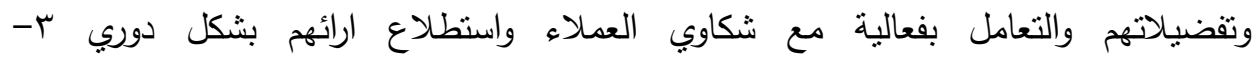

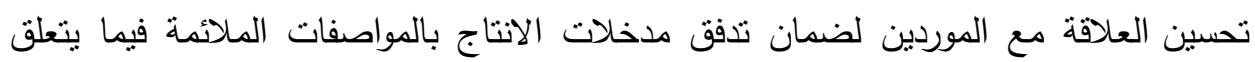

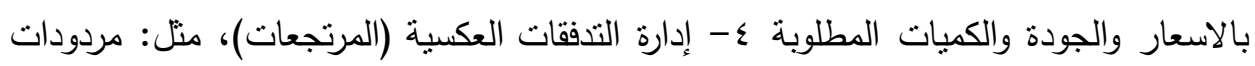

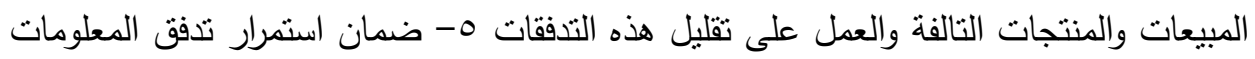

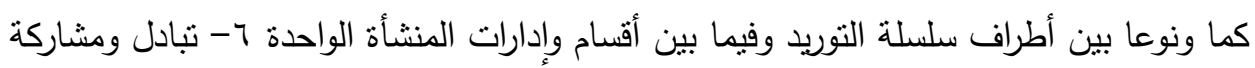
المعلومات في التوقيت المناسب ومن ثم تخفيض نكلفة المنتجات وتلبية احتياجات العملاء والتقليل من حالة عدم التأكد 〉- تخفيض وقت دورة حياه المنتج ^-تحسين إدارة المخزون ومن

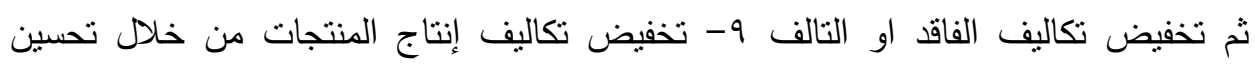

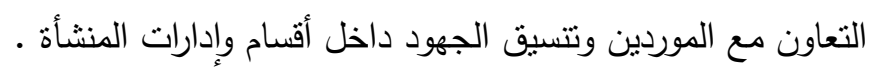
وقد تؤثر خصائص سلاسل النقة في كفاءة سلسلة التوريد وذلك علي النحو التالي :

أولاً : خاصية التحقق : تضمن هذه الخاصية تعزيز مرونة سلاسل الإمداد في أوقات

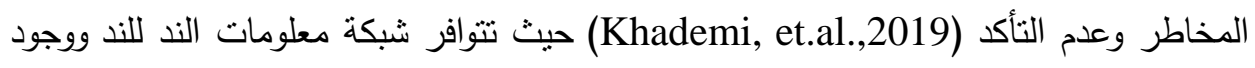

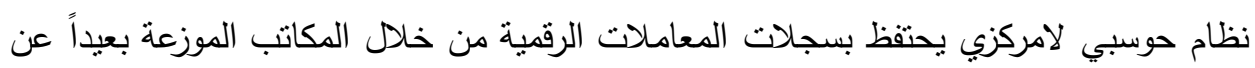
الوسطاء وما يسببه هؤلاء من وجود مشاكل بين اعضاء سلسله التوريد ، وتعني هذه الخاصية

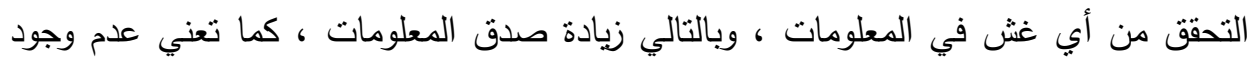

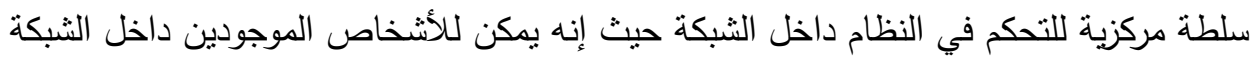

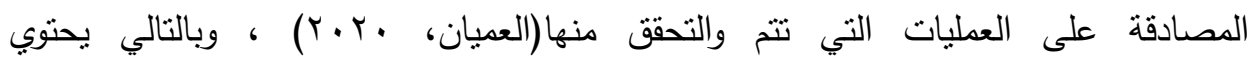
Blockchain 
فتضمن هذه الخاصية القدرة على التحقق من منشأ السلع وظروف تحويلها

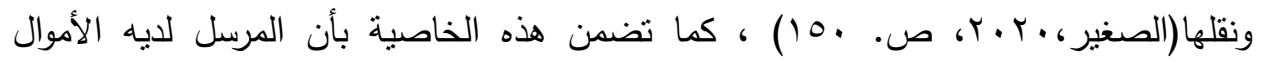

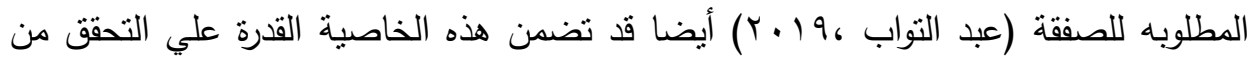
كافة المعاملات والانشطة والتعرف علي عدد الأنشطة اللازمة لتتفيذ عمل معين . ثانيا : خاصية المشاركة : تضمن هذه الخاصية من خلال دفتز الأستاذ الموزع توفير البيانات بأكثر كفاءة ودقة وأمان لكافة الأطراف المشاركة في معاملات سلسلة التوريد (Hofmann,etal,2018) ، وهي تعني القدرة على رؤية جميع المعاملات من خلال مشاركة دفتر الاستاذ بين كافة المشاركين في شبكة Blockchain بما يساعد على دعم الثفافية والتعرف علي مسببات التكلفة وتحديدها علي امتداد سلسلة التوريد ، كما تعرف بإنها عملية تسهيل تدفق المعلومات بشكل أكثر فعالية من خلال سلسله التوريد لوضوحها لدى جميع اطراف

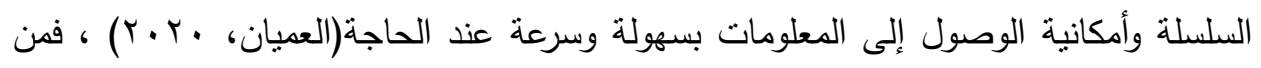

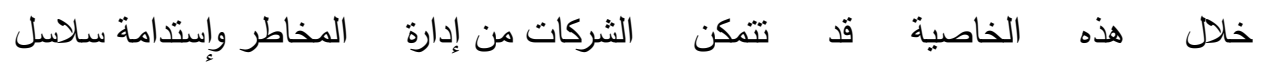

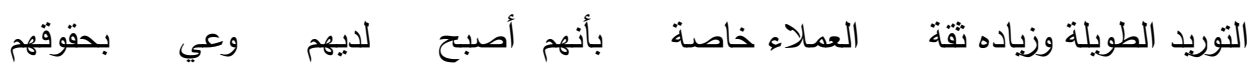

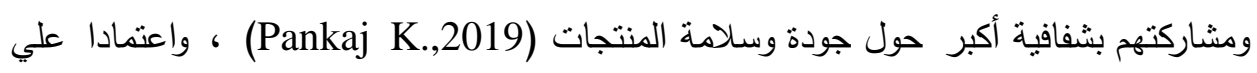
الثفافية يمكن دعم تفاعل المنشأة مع كافة أطراف سلسلة التوريد من مورديها وعملائها وموزعيها

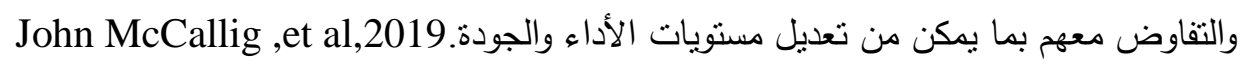

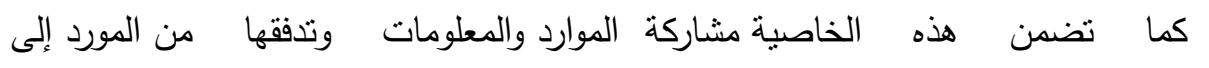
العميل (Azzi,et.al.,2019) وقد تمكن السماح للمحاسبين الدخول علي الثبكة وتجميع البيانات والمعلومات عن كافة أنشطة المنشأة وأنشطة العملاء والمورين والموزعين وتجار الجملة والتجزئة علي امتداد سلسلة التوريد. ثالثاً: خاصية التتبع : تضمن هذه الخاصية خلق قيمة مضافة للمنشأة بتتبع جودة سلسلة التوريد وتتبع الموردين وتوفير بيانات مالية وغير مالية عن عيوب المنتج وتحديد أطراف سلسلة

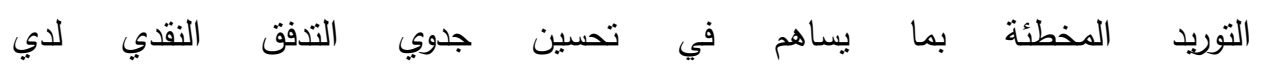
المشترين Fabian,etal,2018، وبما يساهم في استغلال الموارد والكفاءات الموجودة في سلسلة التوريد 2019, Sundtoft \& kinra وفي معرفة مدى تقدم السلع أثناء مرورها عبر سلسلة

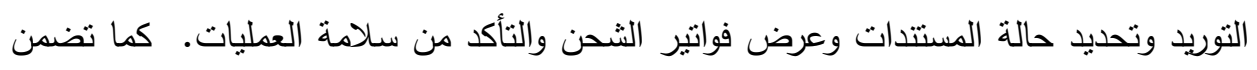


هذه الخاصية والخرائط التوضيحية المنسلسلة علي شبكة Blockchain توفير إمكانيات تخطيط

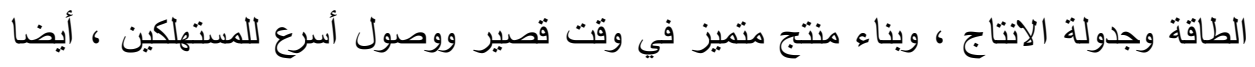

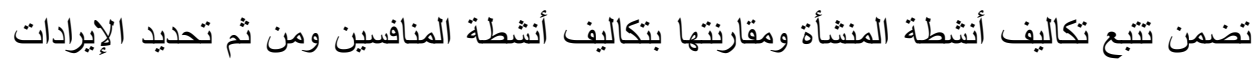
المحققة من أنثطة المنثأة. ولذا تعرف خاصية التتبع بانها آلية نستخدم لتنجيل أكبر قرر من البيانات حول عملية

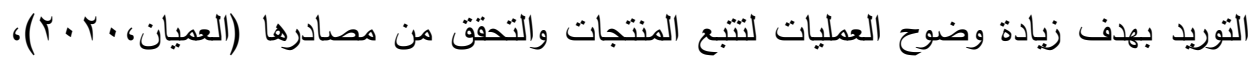
فالحصول علي صورة سريعة عن مصدر المنتجات والخامات وحركتها بين الأطراف بمنع تزييف

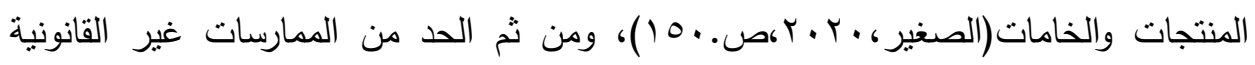
لأصحاب المصلحة من الموردين والمستهلكين والجهات التتظيمية وزيادة الكفاءة التثغيلية وتعزيز تتسيق سلسلة التوريد Sohdi,2019, Hastig. رابعاً: خاصية القابلية للبرمجة (العقودالذكية): تضمن هذه الخاصية إبرام عقود ذات

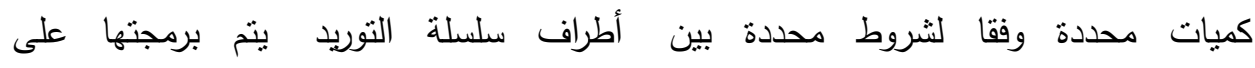

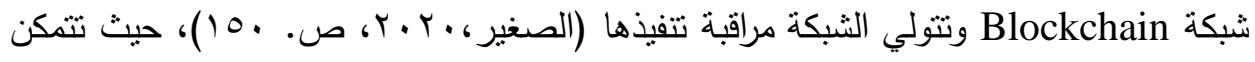

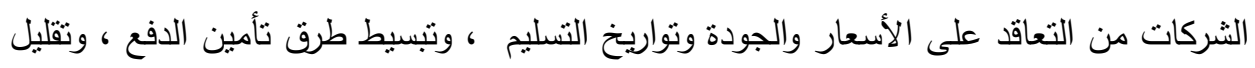

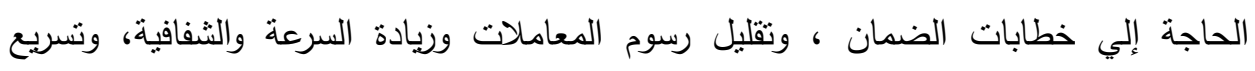
العمليات Treiblmaier,2018 والاستغناء عن الطرف الثالث (البنك) الذي كان يقوم بتنفيذ

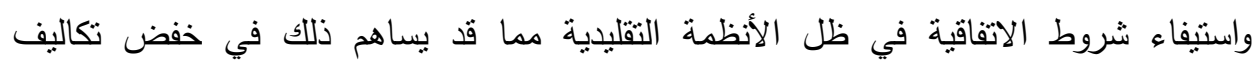

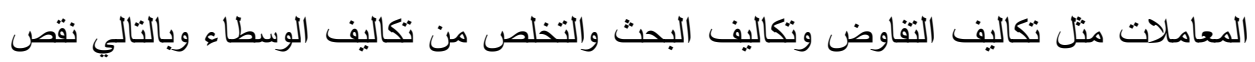

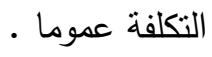
كما قد تضمن هذه الخاصية تخفيض الأنثطة المتكررة وغير المضيفة للقيمة مثل الأنثطة

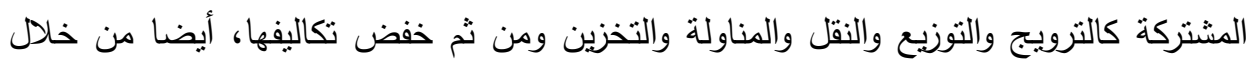

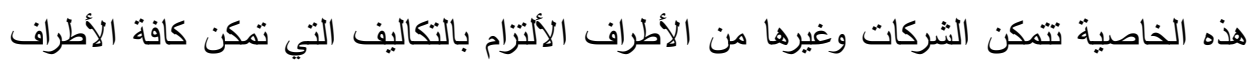

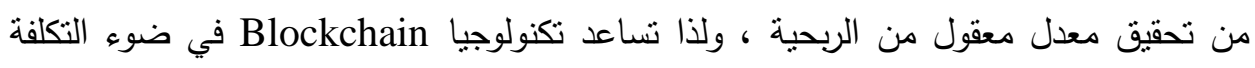
الاجمالية الناشئة عن العقود الذكية المبرمجة مراقبة التكاليف المنسوبة للموردين بشكل مستمر ولئ

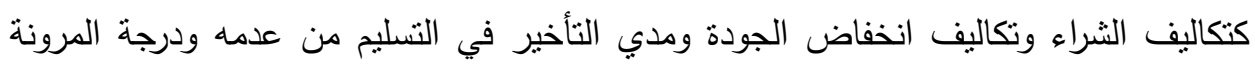
ودرجة الاعتمادية وإمكانية خفضها في حالة زيادتها. 
فالعقود الذكية تعرف على إنها عقود رقية ينم الإتفاق على شروطها من قبل طرفين ويتم برمجتها داخل تكنولوجيا Blockchain ولا يمكن لأي طرف التناعب في العقد ويتم الدفع

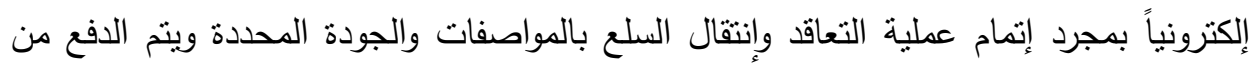

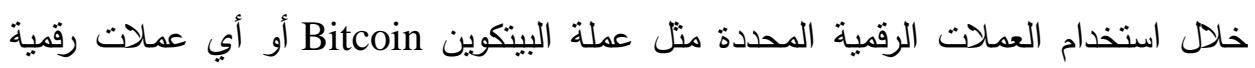

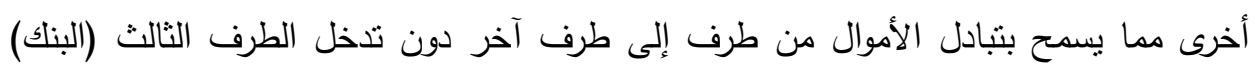

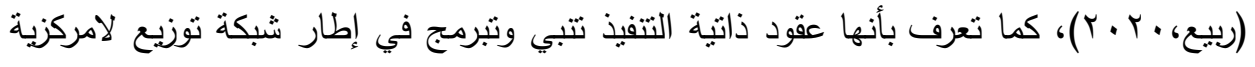

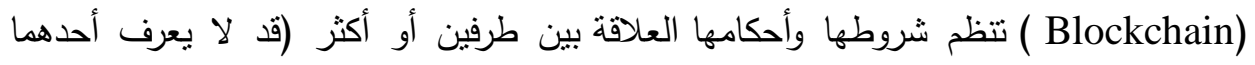

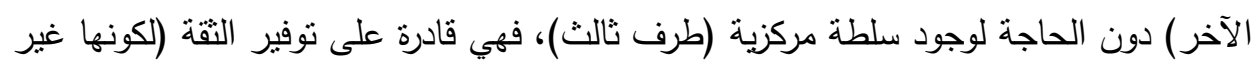

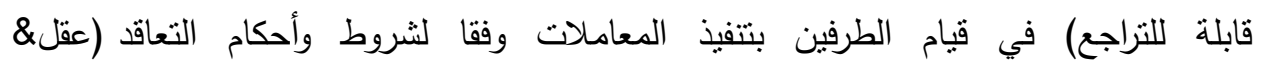

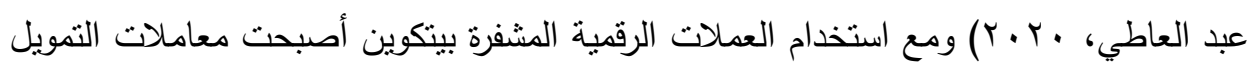

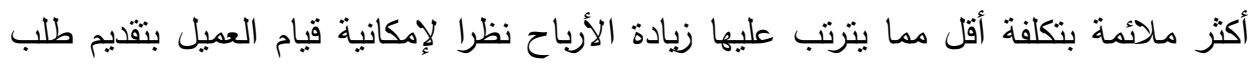
مبكر بحدود الكمية المطلوبة ، ويحتاج المورد فقط إلى إنهاء الطلبية التي تكون في حدود الالتزام

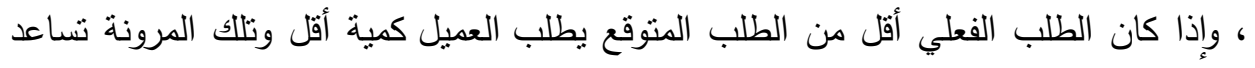

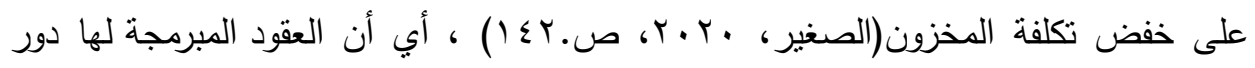

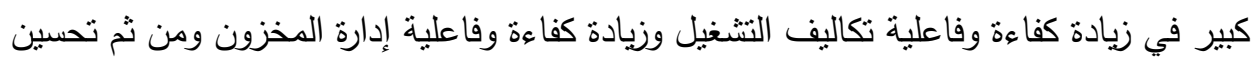
كفاءة سلسلة التوريد 2019.Chod, et.al. سادساً: الدراسة الميدانية: 1/ 1/ 1: منهجية الدراسة: 1/1/1/ المجتمع وعينة الدراسة: ينكون مجتمع البحث من كل من الأكاديميين من أساتذة

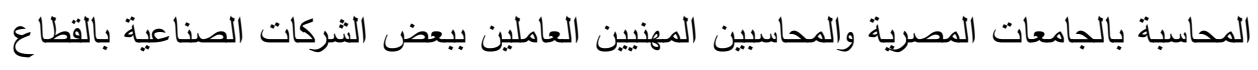

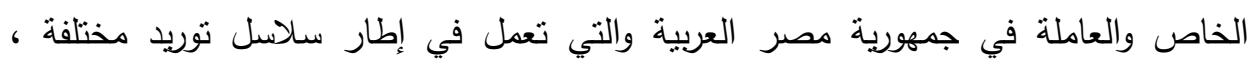

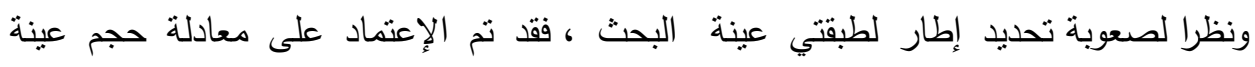

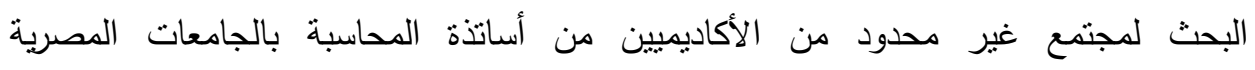

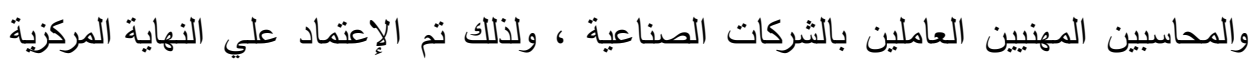

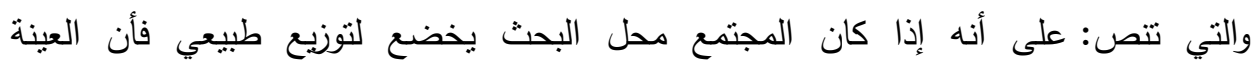

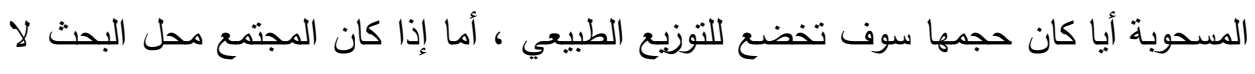

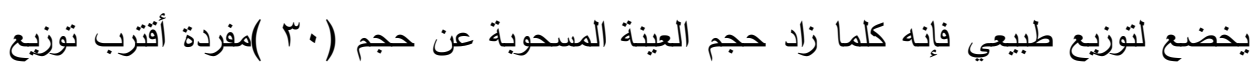


المعاينة المسحوبة من التوزيع الطبيعي ومن ثم دراسة اتجاهات المستقصى ارائهم وتقدير معالم معادلة حجم عينة البحث لمجتمع غير محدود ، بناء على المعادلة التالية:

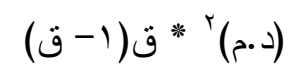

$(د)$

حيث أن : ن: حجم العينة ق : نسبة تتزاوح بين الصفر والواحد نفترضها م, · د : نسبة الخطأ السسموح به ونفترضها 0 ., :.

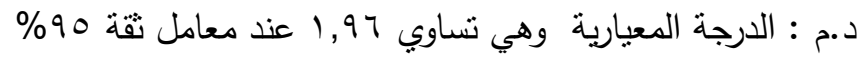
وبتطبيق القانون : $(\cdot, r) \cdot, \wedge *\ulcorner(1,97)$ مفرد $r \leqslant 7=$ $=\dot{0}$

$$
\text { Y(•,.0) }
$$

علما بأنه قد تم توزيع مفردات عينة البحث على أساس التوزيع المنساوي بين الأكاديميين من

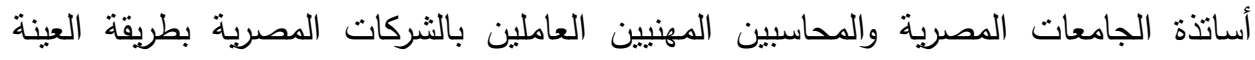

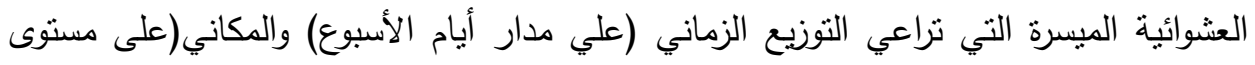

الجامعات والثركات الخاصة في جمهورية مصر العربية)

\begin{tabular}{|c|c|c|c|c|c|c|}
\hline المستخدم & المستبعد & الاستجابة & الاستقصاء & الاستقصاء & العينة & \\
\hline 85 & 5 & 73\% & 90 & 123 & 123 & الاكاديميين \\
\hline 80 & 4 & $68.3 \%$ & 84 & 123 & 123 & المهاسبين \\
\hline
\end{tabular}

استجابات مفرادت عينة البحث 


\begin{tabular}{|r|r|r|r|r|r|r|}
\hline 165 & 9 & $70.7 \%$ & 174 & 246 & 246 & $\begin{array}{r}\text { الاجمالي } \\
\text { العام }\end{array}$ \\
\hline
\end{tabular}

ז/T/ أسلوب جمع البيانات: قامت الباحثة بالإعتماد علي جمع البيانات اللازمة لإختبار الفروض من خلال استخدام أسلوب قائمة الاستقصاء حيث قامت بتصميم قائمة استقصاء تضمنت مجموعة من العبارات لقياس اتجاهات الافراد عينة الدراسة تجاه متغيرات

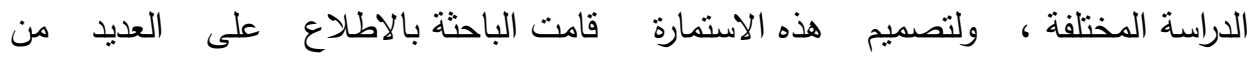
الدراسات السابقة في موضوع الدراسة ، ومن ثم قامت الباحثة بتصميم قائمة استقصاء موجهة

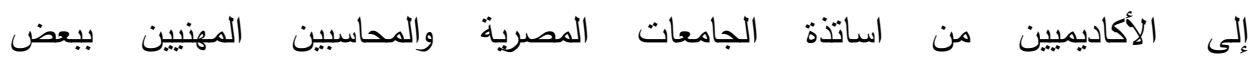
الشركات الصناعية المصرية ، وصممت الاستمارة بالاعتماد على طريقه ليكرت الخماسي

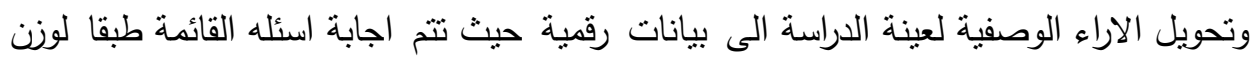
درجح يتراوح ما بين ا و 0 درجات وفقا لما يراه المستقصي منهم مناسبا ، والجدول التالي يبين

\begin{tabular}{|c|c|c|c|c|}
\hline موافق تماما & موافق & محايد & غير موافق & غير موافق \\
\hline 5 & 4 & 3 & 2 & 1 \\
\hline
\end{tabular}

أيضا احتوت قائمة الاسنقصاء علي اسئلة عامة عن المستقصي منه ومجال العمل الذي يعمل به ( المجال الأكاديمي أو مهنيين) وأتضح أن نسبة . . 1\% من المستقصي منهم حاصلين علي مؤهل عال ، حيث اتضح من تحليل عينة الأكاديميين أن جميعهم حاصلين علي الدكتوراه في حين اتضح من عينة الممارسين أن ؟؛ مفردة حاصلة علي دراسات عليا تتتوع بين دبلوم وماجستير ودكتوراه ـ وبتحليل البيانات الخاصة بعدد سنوات الخبرة المحاسبية لعينة الأكاديميين

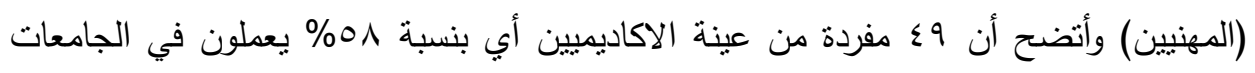

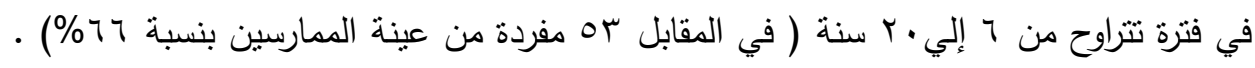
لذا تخلص الباحثة مما سبق توافر نسبة كبيرة من المستقصي منهم علي دراية بأحدث المستجدات في المجال المحاسبي بوجه عام سواء في المجال الاكاديمي أو المهني وهوما يؤكده المؤهل الدراسي والدراسات العليا الحاصلين عليه وخبرتهم في مجال العمل . 
آT/T/ آسلوب تحليل البيانات : بعد الإنتهاء من جمع البيانات نم الاستعانة بالحاسب

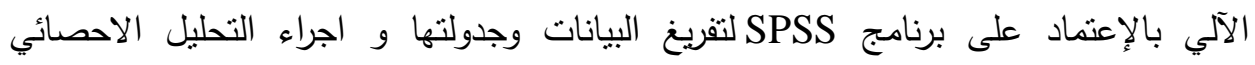

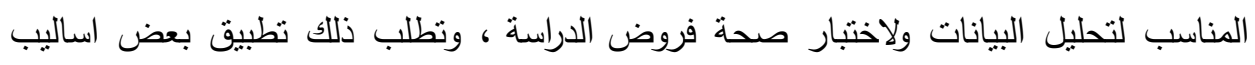

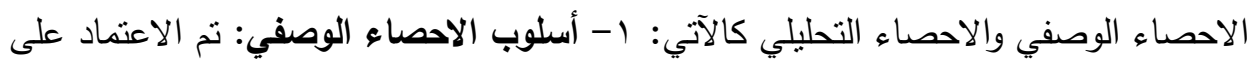

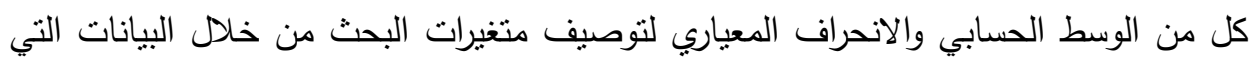

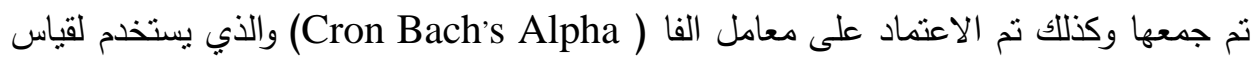

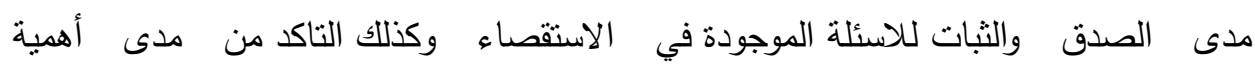

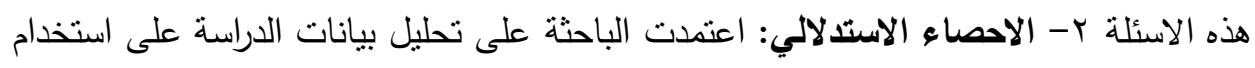
اساليب النحليل الاحصائي للنحقق من مدي صحة الفروض ، وهذه الاساليب هي تحليل

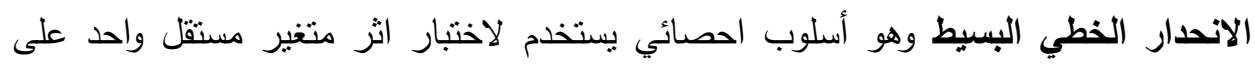

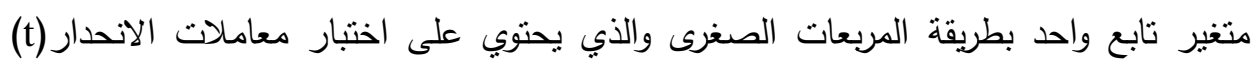

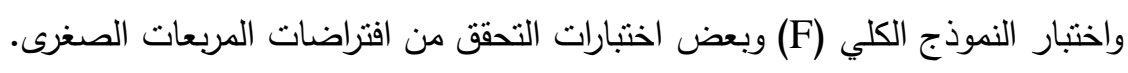

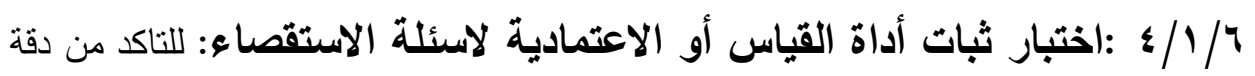

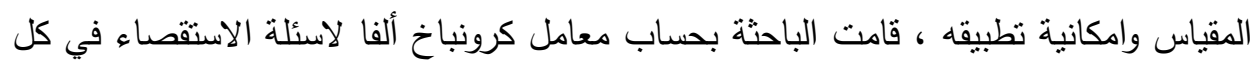
فئة من فئات الدراسة ، وذلك لبحث مدى امكانية الاعتماد على هذه الاسئلة في التحليل وكانت

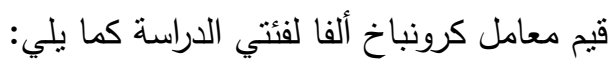
معامل كرونباخ ألفا لفئة الاكاديميين

\begin{tabular}{|c|c|c|}
\hline ألفاامل كرونباخ & عدد العبارات & الاسئلة \\
\hline .96 & 25 & شلاسائص تكنولوجيا سلاسل الثقة Blockchain وأنزهاعلي كفاءة \\
\hline .92 & 10 & العوامل التي نساهم في زيادة كفاءة سلاسل التوريد \\
\hline
\end{tabular}

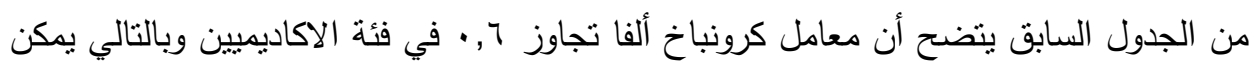

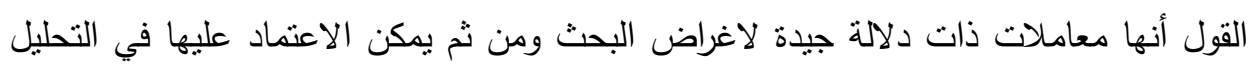
مع عدم استبعاد أي عنصر من عناصر المتغيرات محل الدراسة في هذه الفئة. 


\begin{tabular}{|c|c|c|}
\hline \multicolumn{3}{|c|}{ معامل كرونباخ ألفا لفئة المحاسبيين المهنيين } \\
\hline معامل كرونباخ & عدد العبارات & الاسئلة \\
\hline .97 & 25 & شلاسل التوريد تكنولوجيا سلاسل الثقة Blockchain وأنزهاعلي كفاءة \\
\hline .94 & 10 & العوامل التي تساهم في زيادة كفاءة سلاسل التوريد \\
\hline
\end{tabular}

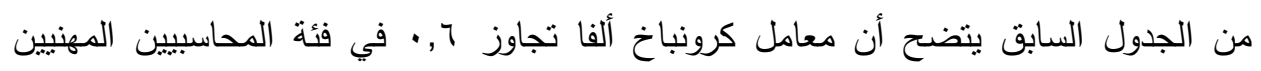

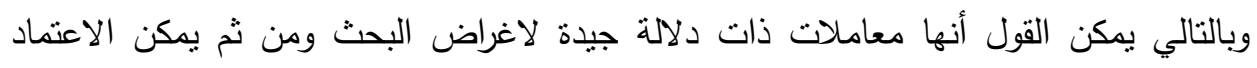
عليها في التحليل مع عدم استبعاد أي عنصر من عناصر المتغيرات محل الدراسة في هذه

\section{r/T : نتائج الاحصاء الوصفي لمتغيرات الدراسة:}

الإحصاء الوصفي لمتغيرات خاصية التحقق التي توفرها تكنولوجيا Blockchain

\begin{tabular}{|c|c|c|c|c|c|c|c|c|c|}
\hline \multicolumn{3}{|c|}{ إجمالي عينة الدراسة } & \multicolumn{3}{|c|}{ المحاسبين المهنييين } & \multicolumn{3}{|c|}{ |الأكاديميين } & \multirow{3}{*}{ رلمنغير } \\
\hline ترتيب & انحراف & الوسط & ترتيب & انحراف & الوسط & ترتيب & انحراف & الوسط & \\
\hline & معياري & الحسابي & & معياري & الحسابي & & معياري & الحسابي & \\
\hline 3 & .722 & 3.95 & 3 & .744 & 3.95 & 3 & .705 & 3.95 & $\mathrm{X} 1$ \\
\hline 2 & .578 & 4.01 & 2 & .562 & 3.98 & 2 & .595 & 4.04 & $\mathrm{X} 2$ \\
\hline 1 & .618 & 4.08 & 1 & .640 & 4.08 & 1 & .601 & 4.08 & X3 \\
\hline 5 & .525 & 3.76 & 5 & .515 & 3.75 & 4 & .536 & 3.78 & $\mathrm{X} 4$ \\
\hline 4 & .741 & 3.78 & 4 & .762 & 3.77 & 4 & .725 & 3.78 & X5 \\
\hline 5 & .525 & 3.76 & 5 & .515 & 3.75 & 4 & .536 & 3.78 & X6 \\
\hline & .483 & 3.89 & & . 486 & 3.88 & & .483 & 3.90 & كل \\
\hline
\end{tabular}

من خلال الجدول السابق يتضح ما يلي :

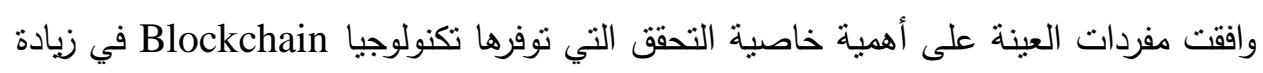

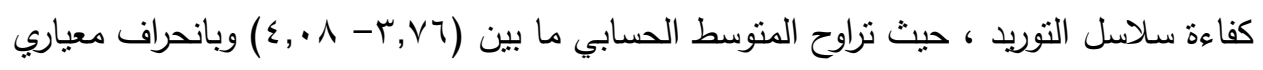




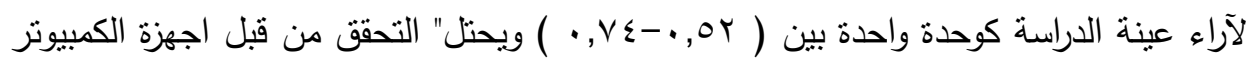
في شبكةBlockchain بأن المرسل لديه الأموال المطلوبة للصفقة " المرنبة الأولى لدى مفردات

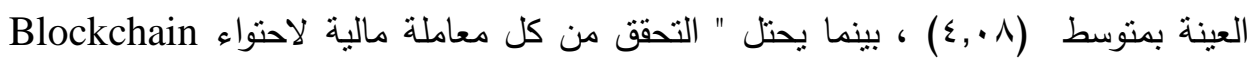
على سجل يضمن عدم حدوث اي خطا " المرتبة الثانية فى الترتيب لدى مفردات العينة بمتوسط

$$
\cdot(\varepsilon,+1)
$$

كما يحنل " التحقق من صدق البيانات والمعلومات التي توفرها سلاسل الثقة Blockchain باعتبارها نظام حوسبي لامركزي وشبكة معلومات نظير الي نظير في اوقات الخطر وعدم التأكد"

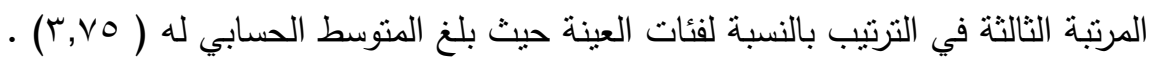

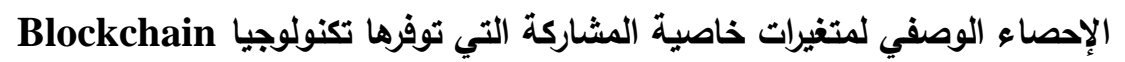

\begin{tabular}{|c|c|c|c|c|c|c|c|c|c|}
\hline \multicolumn{3}{|c|}{ إجمالي عينة الدراسة } & \multicolumn{3}{|c|}{ المحاسبين المهنييين } & \multicolumn{3}{|c|}{ الأكاديمبين } & \multirow{2}{*}{ رالمزغير } \\
\hline ترتيب & معياري & الحسابي & ترتيب & معياري & الحسابي & ترتيب & معياري & الحسبط & \\
\hline 1 & .651 & 4.21 & 1 & .663 & 4.20 & 1 & .643 & 4.22 & X7 \\
\hline 5 & .692 & 3.77 & 5 & .679 & 3.76 & 5 & .708 & 3.78 & X8 \\
\hline 4 & .657 & 3.88 & 4 & .682 & 3.87 & 4 & .636 & 3.89 & X9 \\
\hline 6 & .566 & 3.66 & 6 & .556 & 3.63 & 6 & .577 & 3.69 & X10 \\
\hline 2 & .648 & 4.13 & 2 & .670 & 4.13 & 2 & .632 & 4.12 & X11 \\
\hline 3 & .713 & 3.93 & 3 & .704 & 3.90 & 3 & .723 & 3.97 & $\mathbf{X 1 2}$ \\
\hline & .549 & 3.93 & & .557 & 3.91 & & .545 & 3.95 & كل الفقرات \\
\hline
\end{tabular}

من خلال الجدول السابق يتضح ما يلي :

وافقت مفردات العينة على أهمية خاصية المشاركة التي توفرها تكنولوجيا Blockchain في تهادي

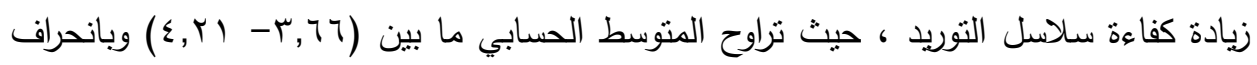
معياري لآراء عينة الدراسة كوحدة واحدة بين ( 07 , • -07, • ) ) ويحنل" مشاركة دفتز الاستاذ بين كافة المشاركين في شبكة Blockchain بما يمكن رؤية جميع المعاملات وبما يساعد على دعم الثفافية والتعرف علي مسببات التكلفة وتحديدها علي امتداد سلسلة التوربد" المرتبة الأولى لاى لهن مفردات العينة بمنوسط (I,Y, ) ، بينما يحتل " المشاركة لتكنولوجيا سلاسل الثقة 
Blockchain وموزعيها والتفاوض معهم بما يمكن من تعديل مسنويات الأداء والجودة " المرتبة الثنانية فى التزتيب لاى مفردات العينة بمتوسط ( ب ا,ـ) ، كما يحتل " المشاركة لتكنولوجيا سلاسل الثقة Blockchain كافة انثطة المنشأة وأنثطة العملاء والمورين والموزعين وتجار الجملة والتجزئة علي امتداد النياد

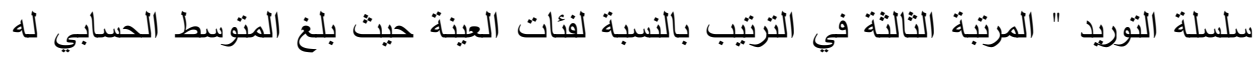
• ( $(r, q \mu)$

Blockchain الإحصاء الوصفي لمتغيرات خاصية التتبع التي توفرها تكنولوجيا

\begin{tabular}{|c|c|c|c|c|c|c|c|c|c|}
\hline \multicolumn{3}{|c|}{ إجمالي عينة الاراسة } & \multicolumn{3}{|c|}{ المحاسبين المهنييين } & \multicolumn{3}{|c|}{ الأكاديميين } & \multirow{3}{*}{ رمزي } \\
\hline ترتيب & انحراف & الوسط & ترتيب & | انحراف & | الوسط & ترتيب & انحراف & الوسط & \\
\hline & معياري & الحسابي & & معياري & الحسابي & & معياري & الحسابي & \\
\hline 1 & .753 & 4.00 & 1 & .779 & 4.00 & 1 & .731 & 4.01 & $\mathrm{X13}$ \\
\hline 4 & .445 & 3.94 & 3 & .443 & 3.92 & 2 & .448 & 3.96 & X14 \\
\hline 2 & .707 & 3.98 & 2 & .719 & 3.96 & 1 & .698 & 4.01 & X15 \\
\hline 5 & .529 & 3.92 & 4 & .508 & 3.91 & 4 & .551 & 3.92 & X16 \\
\hline 3 & .759 & 3.95 & 2 & .770 & 3.96 & 3 & .754 & 3.95 & $\mathbf{X 1 7}$ \\
\hline 6 & .630 & 3.89 & 5 & .616 & 3.88 & 5 & .647 & 3.90 & $\mathbf{X 1 8}$ \\
\hline & .514 & 3.95 & & .519 & 3.94 & & .512 & 3.96 & \\
\hline
\end{tabular}

من خلال الجدول السابق يتضح ما يلي :

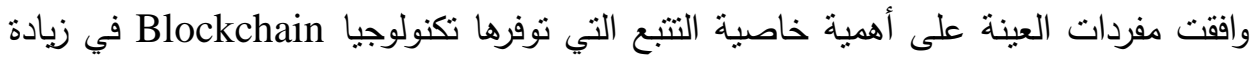

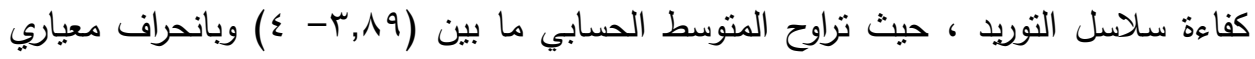

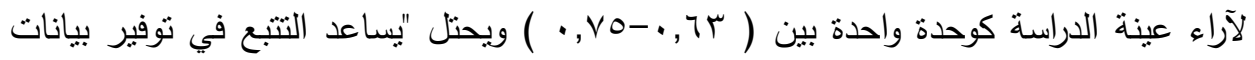

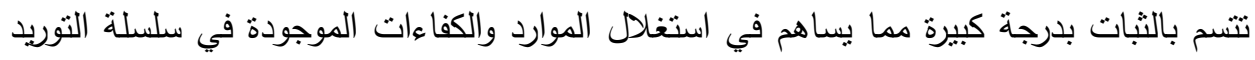

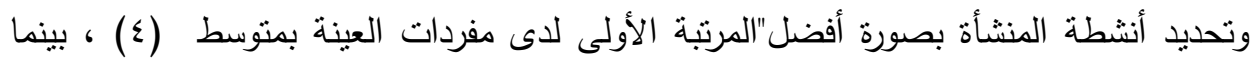
يحتل " التتبع لسلسلة التوريد يحد من الممارسات غير القانونية لاصحاب المصلحة من الموردين والمستهكين والجهات التنظيمية مما يقلل من المخاطر المتعلقة بعمليات الاحتيال وزيادة الكفاءات التشغيلية وتعزيز تتسيق سلسلة التوريد" المرتبة الثانية فى الترتيب لدى مفردات العينة 
بمتوسط ( ( 94 ) ، كما يحتل " تتبع تكاليف انشطة المنشأة من خلال المعاملات الواردة علي Blockchain

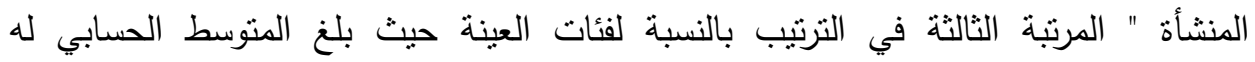
.$(r, 90)$

Blockchain الإحصاء الوصفي لمتغيرات خاصية القابلية للبرمجة التي توفرها تكنولوجيا

\begin{tabular}{|c|c|c|c|c|c|c|c|c|c|}
\hline \multicolumn{3}{|c|}{ إجمالي عينة الاراسة } & \multicolumn{3}{|c|}{ المحاسبين المهنييين } & \multicolumn{3}{|c|}{ الأكاديميين } & \multirow{3}{*}{ رمزي } \\
\hline ترتيب & انحراف & الوسط & ترتيب & انحراف & | الوسط & ترتيب & انحراف & الوسط & \\
\hline & معياري & الحسابي & & معياري & الحسابي & & معياري & الحسابي & \\
\hline 1 & .629 & 3.99 & 1 & .646 & 3.98 & 2 & .617 & 4.00 & X19 \\
\hline 5 & .654 & 3.78 & 6 & .615 & 3.77 & 6 & .691 & 3.78 & $\mathrm{X20}$ \\
\hline 3 & .657 & 3.88 & 4 & .682 & 3.87 & 4 & .636 & 3.89 & X21 \\
\hline 6 & .599 & 3.69 & 7 & .594 & 3.66 & 7 & .605 & 3.72 & X22 \\
\hline 2 & .722 & 3.90 & 3 & .729 & 3.88 & 3 & .720 & 3.92 & $\mathbf{X 2 3}$ \\
\hline 1 & .599 & 3.99 & 2 & .583 & 3.96 & 1 & .616 & 4.02 & $\mathbf{X 2 4}$ \\
\hline 4 & .769 & 3.81 & 5 & .774 & 3.78 & 5 & .769 & 3.83 & $\mathrm{X} 25$ \\
\hline & .541 & 3.86 & & .544 & 3.84 & & .541 & 3.88 & \\
\hline
\end{tabular}

من خلال الجدول السابق يتضح ما يلي :

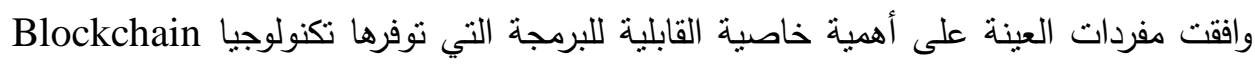

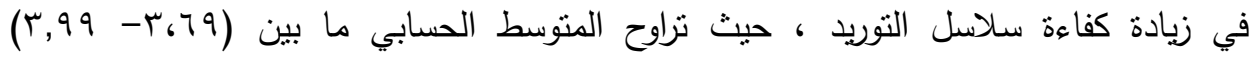
وبانحراف معياري لآراء عينة الدراسة كوحدة واحدة بين ( 09، .--بآ، ، ) ) ويحتلا " برمجة العقد الذكي داخل تكنولوجيا Blockchain يساهم في عدم التلاعب بالعقد الششفر والدفع الكترونيا بمجرد اتمام عملية التعاقد وباستخدام العملات الرقمية المحددة " و " تعزيز مراقبة التكاليف

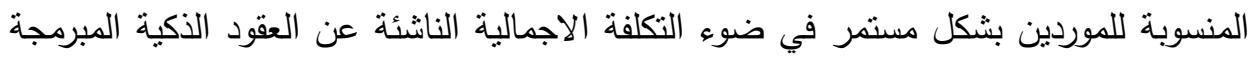

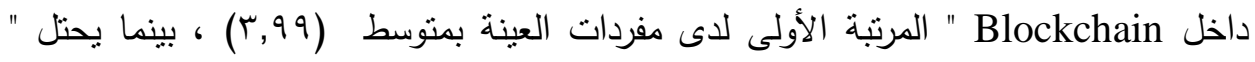
تخفيض الأنشطة المنكرة وغير المضيفة للقيمة مثل الأنشطة المشتركة كالترويج والتوزيع والنقل والمناولة والتخزين في ضوء العقود الذكية المبرمجة داخل Blockchain " الدرتبة الثانية فى الثى

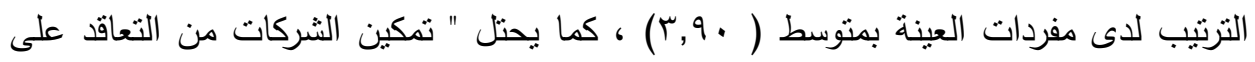


الاسعار والجودة وتواريخ التسليم والتكاليف اللوجستية ، وتبسيط طرق تأمين الدفع ، وتقليل

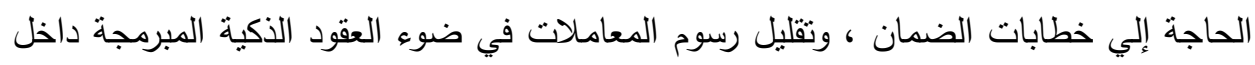

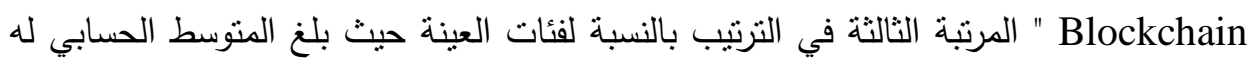
$\cdot(r, \wedge \wedge)$

الإحصاء الوصفي لمتغيرات كفاءة سلاسل التوريد

\begin{tabular}{|c|c|c|c|c|c|c|c|c|c|}
\hline \multicolumn{3}{|c|}{ إجمالي عينة الدراسة } & \multicolumn{3}{|c|}{ المحاسبين المهنييين } & \multicolumn{3}{|c|}{ الأكاديميين } & \multirow{3}{*}{ رمتزير } \\
\hline ترتيب & انحراف & الوسط & ترتيب & انحراف & | الوسط & ترتيب & انحراف & الوسط & \\
\hline & معياري & الحسابي & & معياري & الحسابي & & معياري & الحسابي & \\
\hline 8 & .780 & 3.86 & 7 & .797 & 3.85 & 9 & .768 & 3.87 & Y1 \\
\hline 7 & .759 & 3.94 & 6 & .719 & 3.96 & 8 & .798 & 3.92 & Y2 \\
\hline 4 & .569 & 4.07 & 4 & .581 & 4.06 & 5 & .560 & 4.08 & $\mathbf{Y 3}$ \\
\hline 4 & .573 & 4.07 & 4 & .581 & 4.06 & 4 & .569 & 4.09 & $\mathbf{Y 4}$ \\
\hline 1 & .677 & 4.16 & 1 & .676 & 4.15 & 1 & .681 & 4.18 & Y5 \\
\hline 2 & .651 & 4.12 & 2 & .648 & 4.10 & 2 & .657 & 4.14 & Y6 \\
\hline 3 & .709 & 4.09 & 3 & .707 & 4.07 & 3 & .714 & 4.11 & Y7 \\
\hline 6 & .594 & 4.00 & 6 & .583 & 3.96 & 6 & .606 & 4.03 & Y8 \\
\hline 9 & .497 & 3.81 & 8 & .479 & 3.81 & 10 & .515 & 3.82 & Y9 \\
\hline 5 & .573 & 4.01 & 5 & .573 & 4.00 & 7 & .576 & 4.02 & Y10 \\
\hline & .580 & 3.85 & & .594 & 3.80 & & .565 & 3.89 & $\mathbf{Y}$ \\
\hline
\end{tabular}

من خلال الجدول السابق يتضح ما يلي :

وافقت مفردات العينة على أهمية تحسين كفاءة سلاسل التوريد لما تحققه من قيمة مضافة

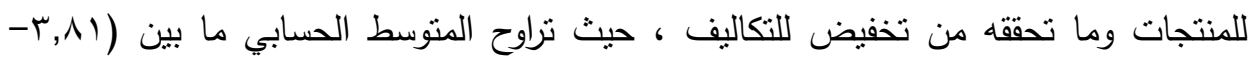

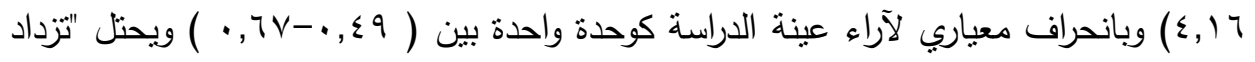

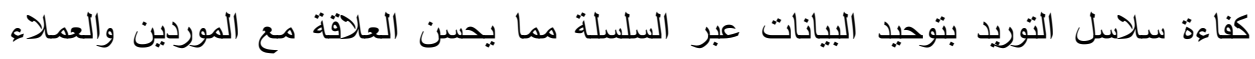
بمشاركة وتبادل المعلومات والافكار والخبرات فيما بينهم" المرتبة الأولى لدى مفردات الدئ العات العينة

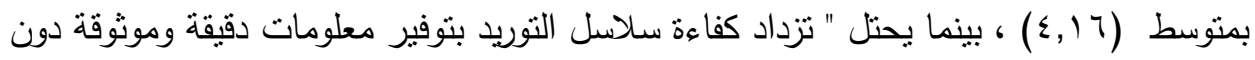


حجب او تزييف لكل أطراف سلسلة التوريد في الوقت المناسب" المرتبة الثانية فى الترتيب لدى

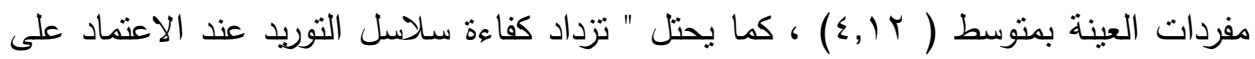

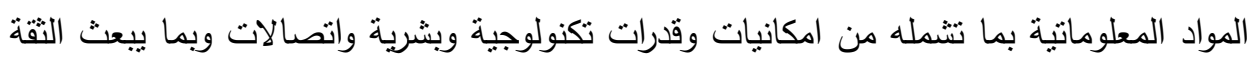
والثفافية لدي كافة أطراف سلسلة التوريد " المرتبة الثالثة في الترتيب بالنسبة لفئات العينة حيث التئ

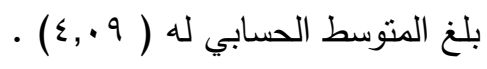

భ/ T/ : تحليل اختبارات الفروض : اختبار الفرض الرئيس للبحث:لا يوجد ثأثير معنوي ذو دلالة احصائية لخصائص تكنولوجيا سلاسل الثقة Blockchain علي كفاءة سلاسل

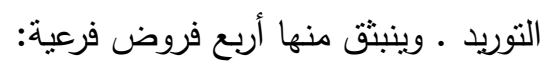

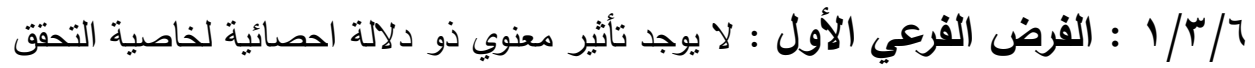

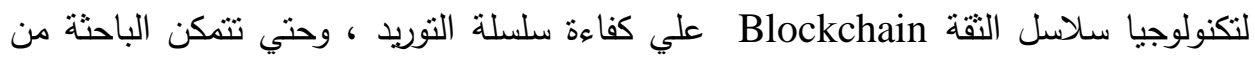
اختبار معنوية هذا الفرض قامت باستخدام تحليل الانحدار الخطي البسيط لقياس العلاقة بين

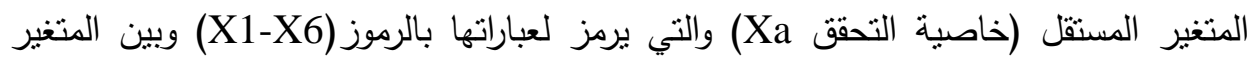

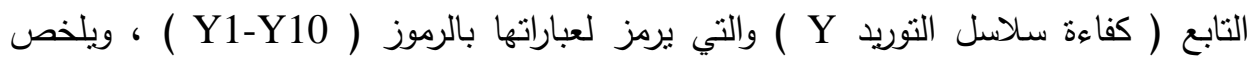

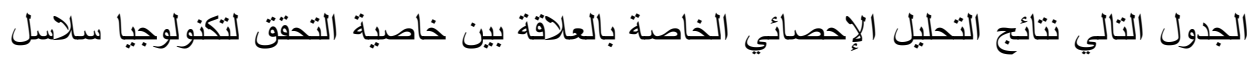
الثقةBlockchain وبين كفاءة سلاسل التوريد

\begin{tabular}{|c|c|c|c|}
\hline \multicolumn{3}{|c|}{ المتغير التابع كفاءة سلاسل التوريد (y ) } & \multirow[b]{2}{*}{ المتغير المستقل } \\
\hline مستوى المعنوية & قيمة (T) & Beta & \\
\hline .000 & 24.854 & .890 & التحقق(Xa) \\
\hline \multicolumn{4}{|c|}{ معامل الارتباط (R)= } \\
\hline \multicolumn{4}{|c|}{ معامل التحديد (R2)=790. } \\
\hline \multicolumn{2}{|c|}{ مستوي المعنوية (ف) = 000.} & \multicolumn{2}{|c|}{ قيمة (ف) الدحسوبة =617.698 } \\
\hline \multicolumn{2}{|c|}{ درجات الحرية= (164-1) } & \multicolumn{2}{|c|}{ مستوي الدلالة الإحصائية= 0.05} \\
\hline
\end{tabular}

يتضح من الجدول السابق أن قيمة معامل التحديد (R2) V9 (B), ، وهو ما بعنى أن المتغير

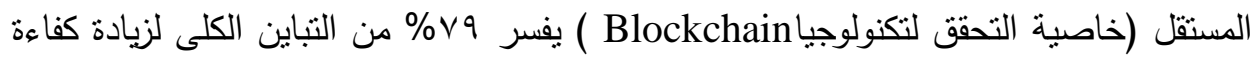


سلاسل التوريد ، كما يتضح وجود علاقة ارتباط قوية بين خاصية التحقق لتكنولوجيا

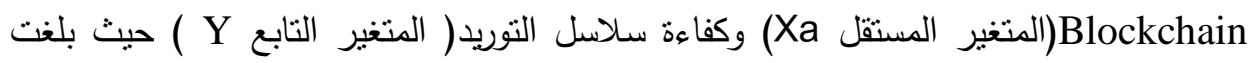

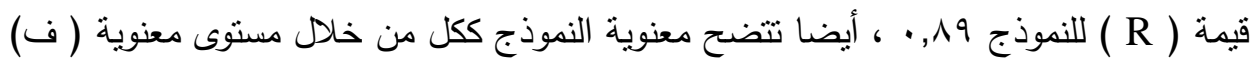

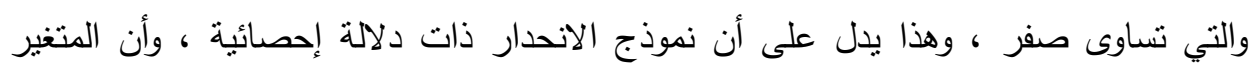

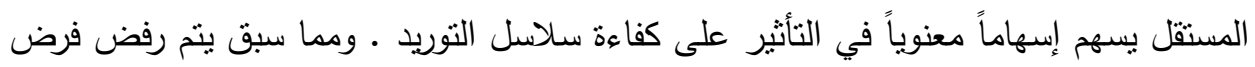
العدم وقبول الفرض البديل يوجد تأثير معنوي ذو دلالة احصائية لخاصية التحقق لتكنولوجيا سلاسل الثقة Blockchain علي كفاءة سلسلة التوريد

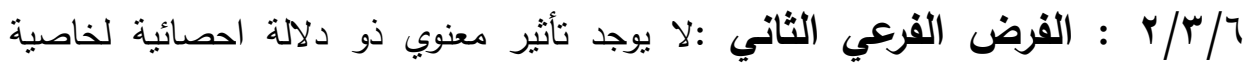
المشاركة لتكنولوجيا سلاسل النقة Blockchain علي كفاءة سلاسل التوريد وحتي تتمكن الباحثة من اختبار معنوية هذا الفرض قامت باستخدام تحليل الانحدار الخطي البسيط لقياس العلاقة بين

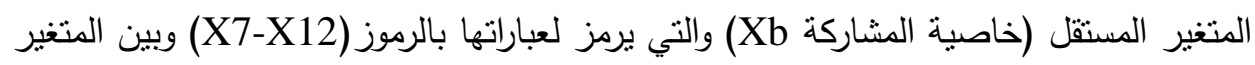

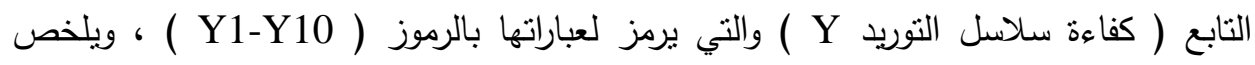

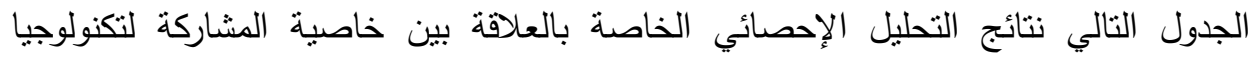
سلاسل النقة Blockchain وبين كفاءة سلاسل التوريد

\begin{tabular}{|c|c|c|c|}
\hline \multicolumn{3}{|c|}{ المتغير التابع كفاءة سلاسل التوريد (y) } & \multirow[b]{2}{*}{ المتغير المستقل } \\
\hline | مستوى المعنوية & قيمة (T) & Beta & \\
\hline .000 & 17.113 & .802 & المشاركة (Xb) \\
\hline \multicolumn{4}{|c|}{ معامل الارتباط (R) =802. } \\
\hline \multicolumn{4}{|c|}{ معامل التحديد (R2)=642. } \\
\hline \multicolumn{2}{|c|}{ مستوي المعنوية (ف) = 000.} & \multicolumn{2}{|c|}{ قيمة (ف) المحسوبة =292.847 } \\
\hline \multicolumn{2}{|c|}{ درجات الحرية= (164-1) } & \multicolumn{2}{|c|}{ مستوي الدلالة الإحصائية= 0.05} \\
\hline
\end{tabular}

يتضح من الجدول السابق أن قيمة معامل التحديد (R2) \& T, ، ، ، وهو ما بعنى أن المتغير

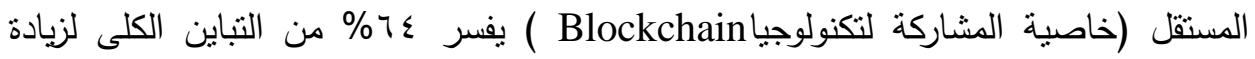
كفاءة سلاسل التوريد ، كما يتضح وجود علاقة ارتباط قوية بين خاصية المشاركة لتكنولوجيا 
Blockchain (المتغير المستقل Xb) وكفاءة سلاسل التوريد( المتغير التابع Y ) ) حيث بلغت

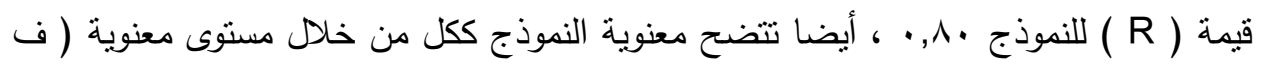
) والتي تساوى صفر ، وهذا يدل على أن نموذج الانحدار ذات دلالة إحصائية ، وأن المتغير

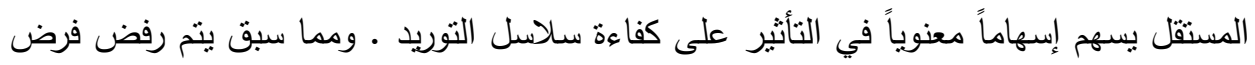
العدم وقبول الفرض البديل يوجد تأثير معنوي ذو دلالة احصائية لخاصية المشاركة لتكنولوجيا سلاسل الثقة Blockchain علي كفاءة سلسلة التوريد

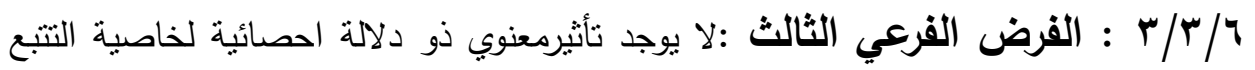

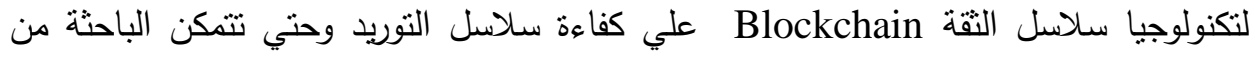
اختبار معنوية هذا الفرض قامت باستخدام تحليل الانحدار الخطي البسيط لقياس العلاقة بين المتغير المستقل (خاصية التتبع Xc) والتي برمز لعباراتها بالرموز (X13-X18) وبين المتغير لإنيل

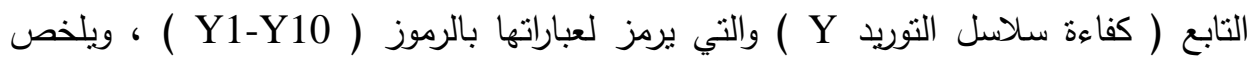
الجدول النالي ننائج التحليل الإحصائي الخاصة بالعلاقة بين خاصية التتبع لتكنولوجيا سلاسل النقة Blockchain وبين كفاءة سلاسل التوريد.

\begin{tabular}{|c|c|c|c|}
\hline \multicolumn{3}{|c|}{ المتغير التابع كفاءة سلاسل التوريد (y ) } & \multirow[b]{2}{*}{ المتغير المستقل } \\
\hline |مستوى المعنوية & قيمة (T) & Beta & \\
\hline .000 & 12.960 & .712 & التبعع (Xc) \\
\hline \multicolumn{4}{|c|}{ معامل الارتباط (R) = 712.} \\
\hline \multicolumn{4}{|c|}{ معامل التحديد (R2)= 507.} \\
\hline \multicolumn{2}{|c|}{ مستوي المعنوية (ف) = 000.} & \multicolumn{2}{|c|}{ قيمة (ف) المحسوبة =167.951 } \\
\hline \multicolumn{2}{|c|}{ درجات الحرية= (164-1) } & \multicolumn{2}{|c|}{ مستوي الدلالة الإحصائية= 0.05} \\
\hline
\end{tabular}

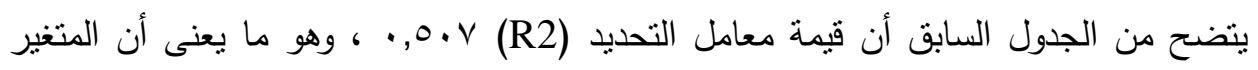

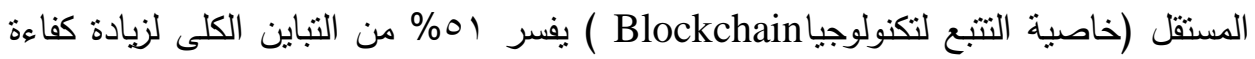

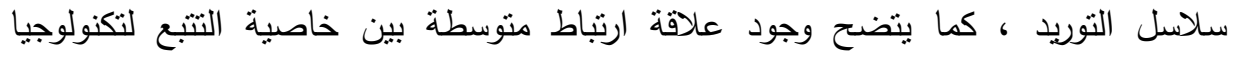
Blockchain

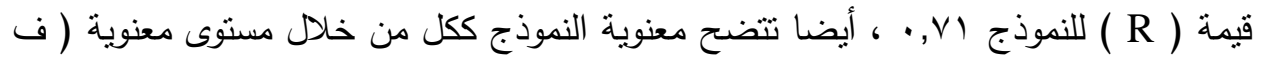


) والتي نساوى صفر ، وهذا يدل على أن نموذج الانحدار ذات دلالة إحصائية ، وأن المتغير

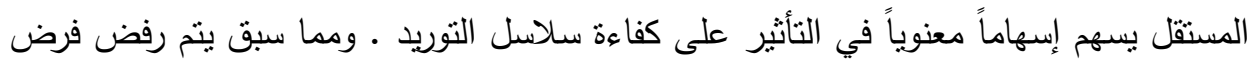
العدم وقبول الفرض البديل يوجد تأثير مغنوي ذو دلالة احصائية لخاصية التتبع لتكنولوجيا سلاسل الثقة Blockchain علي كفاءة سلسلة التوريد

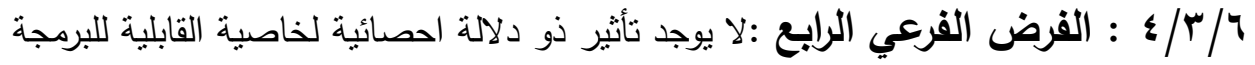
لتكنولوجيا سلاسل الثقة Blockchain علي كفاءة سلسلة التوريد وحتي تتمكن الباحثة من اختبار معنوية هذا الفرض قامت باستخدام تحليل الانحدار الخطي البسيط لقياس العلاقة بين

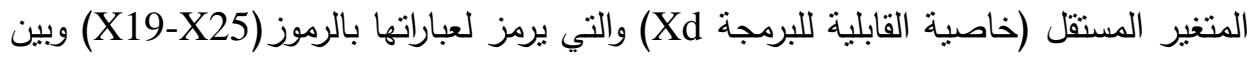

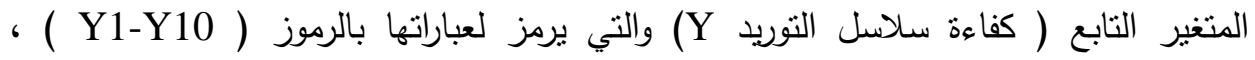
ويلخص الجدول التالي نتائج التحليل الإحصائي الخاصة بالعلاقة بين خاصية القابلية للبرمجة لتكنولوجيا سلاسل الثقة Blockchain وبين كفاءة سلاسل التوريد

\begin{tabular}{|c|c|c|c|}
\hline \multicolumn{3}{|c|}{ المتغير التابع كفاءة سلاسل التوريد (y ) } & \multirow[b]{2}{*}{ لمتغير المستقل } \\
\hline مستوى المعنوية & قيمة (T) & Beta & \\
\hline .000 & 37.587 & .947 & القابلية للبرمجة (Xd) \\
\hline \multicolumn{4}{|c|}{ معامل الارتباط (R) =947. } \\
\hline \multicolumn{4}{|c|}{ معامل التحديد (R2)=897. } \\
\hline \multicolumn{2}{|c|}{ مستوي المعنوية (ف) = 000.} & \multicolumn{2}{|c|}{ ثيمة (ف) المحسوبة =1412.76 } \\
\hline \multicolumn{2}{|c|}{ درجات الحرية= (164-1) } & \multicolumn{2}{|c|}{ ستوبي الدلالة الإحصائية= 0.05} \\
\hline
\end{tabular}

يتضح من الجدول السابق أن قيمة معامل التحديد (R2 (19 ), · ، وهو ما يعنى أن المتغير

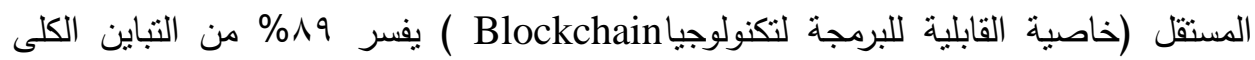
لزيادة كفاءة سلاسل التوريد ، كما يتضح وجود علاقة ارتباط قوية بين خاصية القابلية للبرمجة التيانة

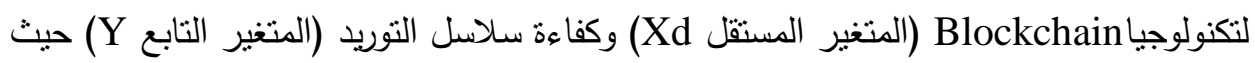


بلغت قيمة ( R ) للنموذج ؟ 9, · ، أيضا تتضح معنوية النموذج ككل من خلال مستوى معنوية ( ف ) والتي تساوى صفر ، وهذا يدل على أن نموذج الانحدار ذات دلالة إحصائية ، وأن المتغير المستقل يسهم إسهاماً معنوياً في التأثير على كفاءة سلاسل التوريد . ومما سبق يتم رفض فرض العدم وقبول الفرض البديل يوجد تأثير معنوي ذو دلالة احصائية لخاصية القابلية للبرمجة لتكنولوجيا سلاسل الثقة Blockchain علي كفاءة سلسلة التوريد وفي ضوء ما سبق قامت الباحثة باستخدام تحليل الانحدار الخطي المتعدد لقياس العلاقة بين المتغيرات المستقلة (خصائص تكنولوجياهlockchain) والتي يرمز لعباراتها بالرموز (Xa-Xb)

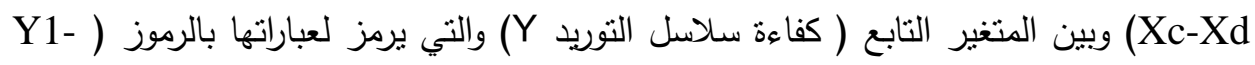

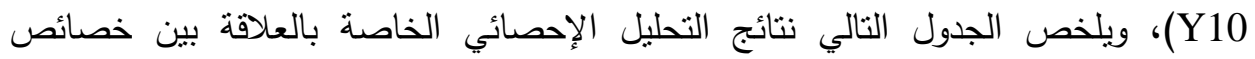
تكنولوجيا سلاسل الثقة Blockchain وبين كفاءة سلاسل التوريد

\begin{tabular}{|c|c|c|c|}
\hline \multicolumn{3}{|c|}{ المتغير التابع كفاءة سلاسل التوريد (y) } & \multirow[b]{2}{*}{ المتغير المستقل } \\
\hline مستوى المعنوية & قيمة (T) & Beta & \\
\hline .456 & -.748 & -.066 & التحقق (Xa) \\
\hline .201 & -1.284 & -.085 & المشاركة (Xb) \\
\hline .301 & 1.038 & .052 & التتبع (Xc) \\
\hline .000 & 12.904 & 1.043 & القابلية للبرمجة (Xd) \\
\hline \multicolumn{4}{|c|}{ معامل الارتباط (R)=948. } \\
\hline \multicolumn{4}{|c|}{ معامل التحديد (R2)=898. } \\
\hline \multicolumn{2}{|c|}{ مستوي المعنوية (ف) = 000. } & \multicolumn{2}{|c|}{ قيمة (ف) المحسوبة =353.427 } \\
\hline \multicolumn{2}{|c|}{ درجات الحرية= (164-1) } & \multicolumn{2}{|c|}{ مستوي الدلالة الإحصائية= 0.05} \\
\hline
\end{tabular}


يتضح من الجدول السابق أن قيمة معامل التحديد (R2) A9, · ، وهو ما يعنى أن المتغيرات المستقلة (خصائص تكنولوجيا Blockchain ) تفسر \$19\% من التباين الكلى لزيادة كفاءة سلاسل التوريد ، كما يتضح وجود علاقة ارتباط قوية بين خصائص تكنولوجيا Blockchain (Y حيث بلغت قيمة ( R ) للنموذج ع 9, ، ، ويتضح أيضا للباحثة أن خصائص تكنولوجيا Blockchain

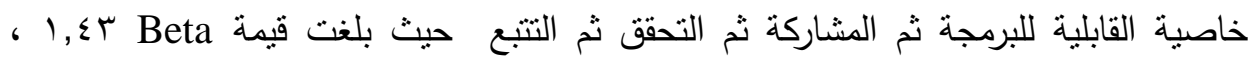

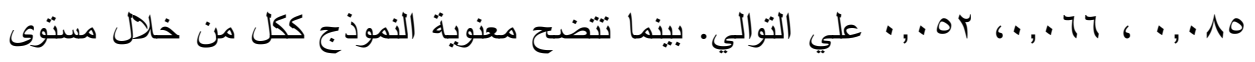

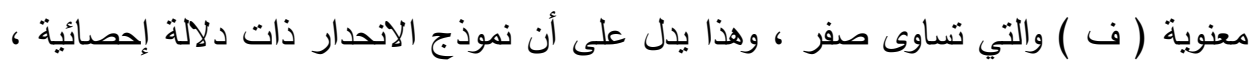

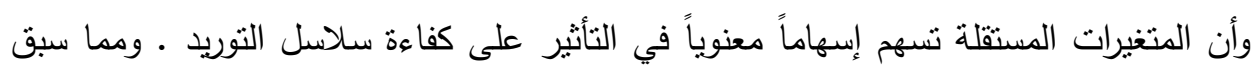
يتم رفض فرض العدم وقبول الفرض البديل يوجد تأثير معنوي ذو دلالة احصائية لخصائص تكنولوجيا سلاسل الثقة Blockchain علي كفاءة سلاسل التوريد

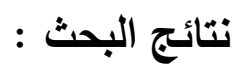

ا. تؤثر تكنولوجيا Blockchain متمنتة في خاصية التحقق علي كفاءة سلاسل التوريد تأثيراً معنوياً فيما يتعلق بإمكانية التحقق بأن أطراف سلسلة التوريد لليهم الأموال اللازمة لاتمام الصفقات وبما يضمن عدم حدوث أى أخطاء في إتمام المعاملات المالية . r. تؤثر تكنولوجيا Blockchain متمنلة في خاصية المشاركة علي كفاءة سلاسل التوريد تأثنيراً معنوياً فيما يتعلق بإمكانية رؤية جميع المعاملات والتعرف علي مسببات التكلفة وتحديدها علي امتداد سلسلة التوريد وبما يمكن من تفاعل الثركة مع كافة الأطراف لتعديل مستويات الأداء والجودة والسماح للمحاسبين الدخول علي الثبكة وتجميع البيانات والمعلومات عن كافة أنشطة المنشأة وأنشطة كافة العملاء والموزعيين وتجار الجملة والتجزئة علي امتداد سلسلة التوريد. r. تؤثر تكنولوجيا Blockchain متمنتة في خاصية التتبع علي كفاءة سلاسل التوريد تأثيراً معنوياً فيما يتعلق باستغلال الموارد والكفاءات الموجودة في سلسلة التوريد وتتبع أنشطة المنشأة بصورة أفضل والحد من الممارسات غير القانونية لأصحاب المصلحة من الموردين والمستهلكين مما يقلل من المخاطر المتعلقة بعمليات الاحتيال. 
ع. تؤثر تكنولوجيا Blockchain متمثلة في خاصية القابلية للبرمجة علي كفاءة سلاسل التوريد تأثيراً معنوياً ببرمجة العقد الذكي والدفع إلكترونياً بمجرد اتمام عملية التعاقد وتعزيز مراقبة تكاليف الموردين بشكل مستمر وتخفيض الأنثطة المنكررة وغير المضيفة للقيمة متل

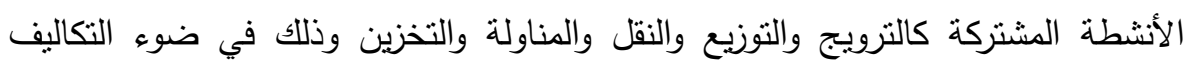
الاجمالية الناشئة عن العقود الذكية المبرمجة داخل Slockchain.

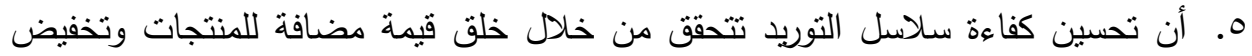
النكاليف وذلك يتم عن طريق توحيد البيانات عبر سلسلة التوريد وبمشاركة وتبادل المعلومات والافكار والخبرات بين العملاء والموردين، وعن طريق نوفير معلومات دقيقة

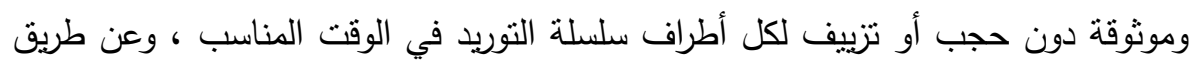
الاعتماد علي المواد المعلوماتية بما تثمله من إمكانيات وقدرات تكنولوجية وبثرية التهاتية واتصالات وبما يبعث الثقة والثفافية لدى كافة أطراف سلسلة التوريد. T. وجود علاقة إرتباط قوية بين خصائص تكنولوجيا Blockchain منمتلة بالترتيب في

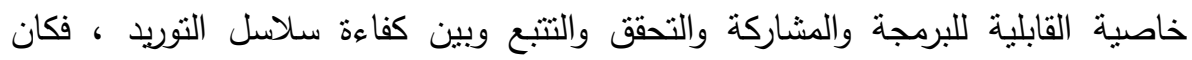

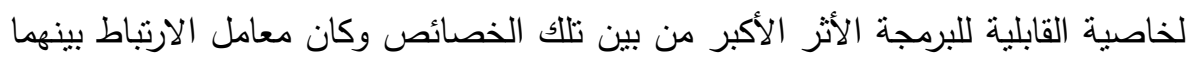

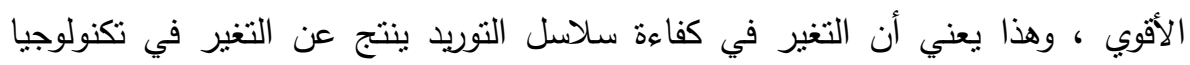
Blockchain أساتذة المحاسبة والمحاسبين بشركات العينة لنلاك الخاصية حيث التعامل مع العقود المشفرة والتعاقد علي الأسعار والجودة مع اطراف سلسلة النوريد ومراقبة النكاليف المنسوبة للموردين بشكل مستمر وتخفيضها في ضوء النكلفة الاجمالية الناشئة عن العقودالذكية المبرمجة. توصيات البحث

ا. ضرورة الاهتمام بالأنظمة الحديثة من قبل إدارة سلاسل التوريد التي تضمن استمرار الثركات وبقائها في ظل ما تثهده بيئة الاعمال سريعة التغير.

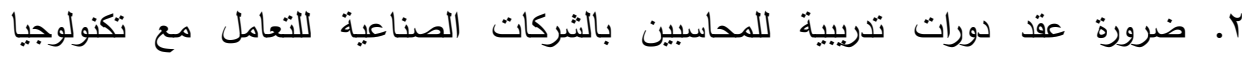
Blockchain بما يتناسب مع مهام وظائفهم لتحسين كفاءة سلاسل التوريد والتي بدورها تساهم في تحسين اداء الثركة ككل . 
r. الحث علي تطبيق تكنولوجيا سلاسل الثقة Blockchain بإدارة سلاسل التوريد في الثركات الصناعية لإنشاء نظام موثوق وحقيقي وشفاف وآمن ولما تحققه من خلق قيمة مضافة

للمنتجات وسرعة الاستجابة لرغبات العملاء ومراقبة التكاليف المنسوبة للموردين.

ع. توصي الباحثة بعمل أبحاث مستقبلية في مجال علاقة تكنولوجيا سلاسل الثقة بحوكمة الشركات وفي مجال أثز التكامل بين تكنولوجيا سلاسل الثقة Blockchain وبين تحليلات

$$
\begin{aligned}
& \text { البيانات الضخمة Big Data علي أداء سلاسل التوريد . } \\
& \text { مراجع البحث: : } \\
& \text { أولاً : المراجع العربية انع }
\end{aligned}
$$

ا ـ د. أحمد عبد العال رشوان ، " تأثير درجة الثقة المتبادلة بين أطراف سلسلة التوريد واستخدام

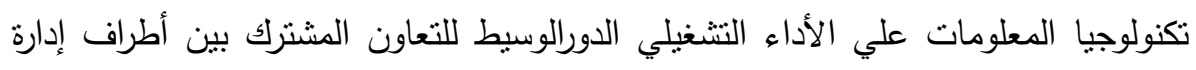
سلسلة التوريد دراستةطبيقية علي الثركات الصناعية في مصر "، مجلة جامعة الإسكندرية للعلوم الإدارية ، كلية التجارة ، جامعة الاسكندرية ، المجلد OV، العدد الثالث ، يوليو . r. . .

ז. د. أيمن محمد صبري ، "اثر استخدام تكنولوجيا سلسلة الكتل الرقمية "البلوك شين" على

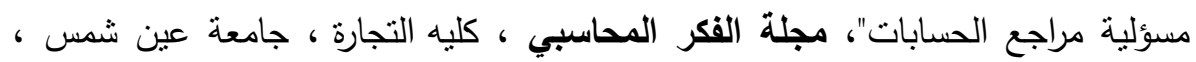

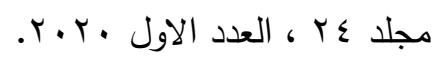
r. دانية حابس العيان ، "الاتجاهات نحو تطبيق تكنولوجيا سلسلة الكتل واثرها على اداء سلسلة التوريد دراسة ميدانية في قطاع الصناعات التعدينية في الاردن" ، رسالة ماجسنير

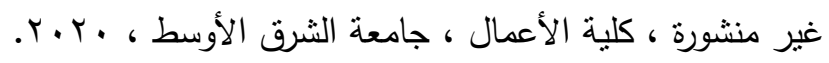

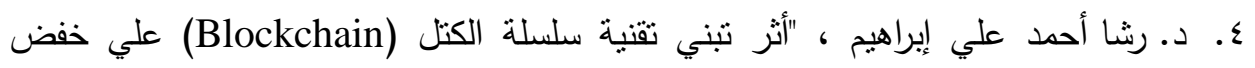
تكلفة الخدمات المصرفية والارتقاء بها بالبنوك التجارية دراسة ميدانية، مجلة الفكر بالية

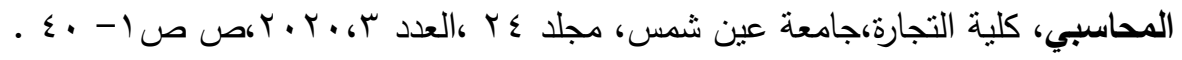
0. ريمون ميلاد فؤاد ، " أثز تكامل حوكمة ممارسات سلسلة التوريد وأساليب المحاسبة الإدارية

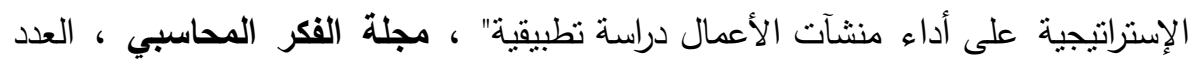

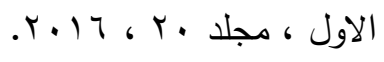


T. د.سلوي عبد الرحمن عبد الدايم ، "أثز أدوات إدارة التكلفة علي أداء الثركة في ظل

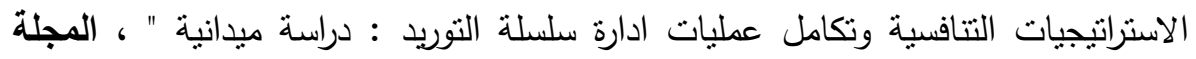

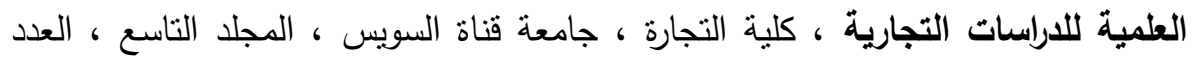

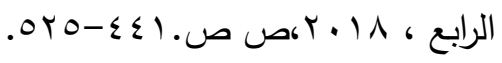

V. د. سيد سيد عبدالفتاح ،"اثر خصائص Blockchain علي تحسين التقارير المالية الرقمية:دراسة ميدانية ، مجلة الاراسات التجارية المعاصرة ،كلية التجارة ،جامعة كفر الثيخ

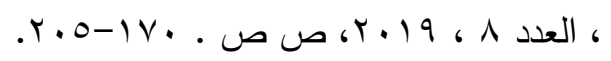

^. د عمرو مصطفي حسين ،" دور إدارة سلسلة التوريد في تحسين المركزالتنافسي لمنظمات الأعمال"، المجلة العلمية للاقتصاد والتجارة ، كلية التجارة ، جامعة عين شمس ، العارة العدد

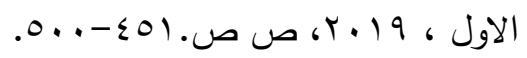

9. د.فهد بن سليمان النافع ،" زيادة فعالية النموذج المحاسبي لممارسات إدارة سلاسل التوريد"، مجلة الاسكندرية للبحوث المحاسبية ، كلية التجارة ، جامعة الاسكندرية ، المجلد الأول،

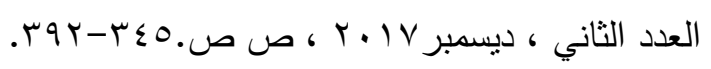

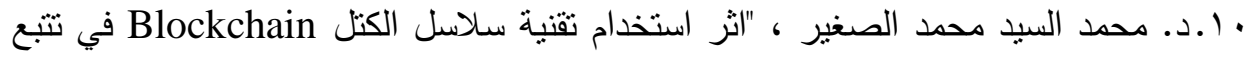
سلاسل التوريد التصنيعية على تقعيل ادوات ادارة التكلفة البينية وتعزيز القدرة التنافسية

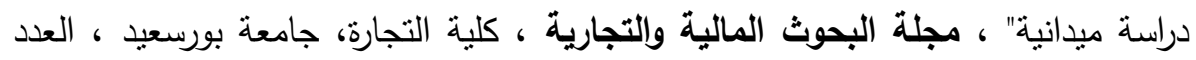

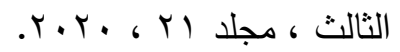

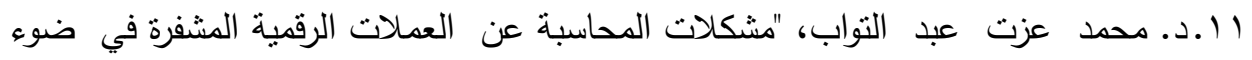

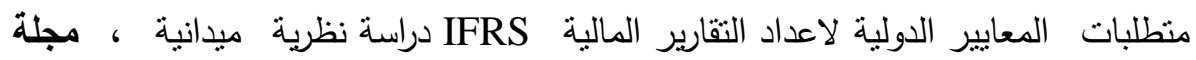

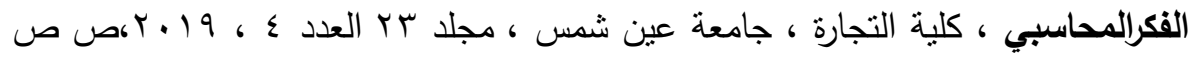
$.7 \cdot-1$

r ا.د محمد محمود أبو خشبة ، "تاثير قدرات تكنولوجيا المعلومات على اداء المنظمة

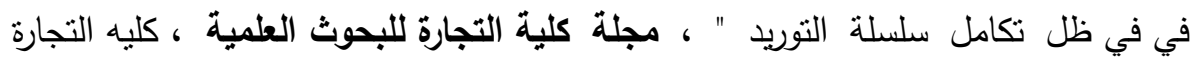

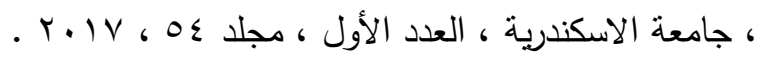

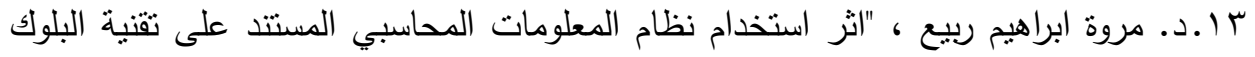
تثتين علي تحسين اداء سلاسل التوريد المدعومة بتكنولوجيا الثورة الصناعية الرابعة إزاء 
مواجهة فيروس كورونا المستجد مع دراسة تجريبية" ، مجلة الإسكندرية للبحوث المحاسبية

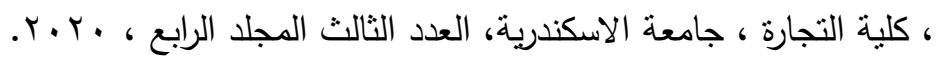

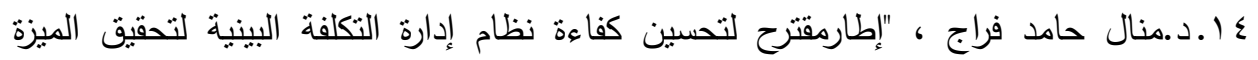

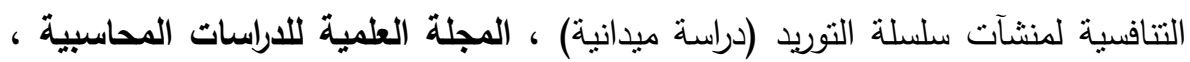

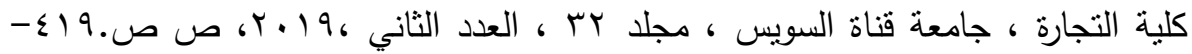

10.د. منى حسن ابو المعاطي، "دراسة تحليلية لأثر فاعلية تكنولوجيا سلاسل الثقة

Blockchain

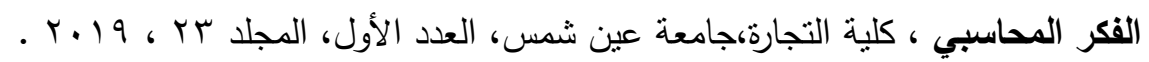

71 .د ناصر فراج مصطفى ، "منهج مقترح للمحاسبة والافصاح عن العملات المشفرة وفق

نموذج الاعمال في إطار تكنولوجيا سلاسل الكتل وتحت مظلة المعايير الدولية للتقارير

المالية IFRS دراسة استطلاعية للسوق المصري ، المجلة العلمية للاراسات المحاسبية ،

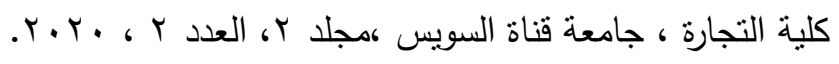

V V . إيونس حسن عقل ، د. سمحي عبد العاطي،"مشكلات المعاملة الضريبية لأنشطة وعمليات

تكنولوجيا البلوك تشين Blockchain في مصر دراسة دولية مقارنة " ، مجلة الفكر

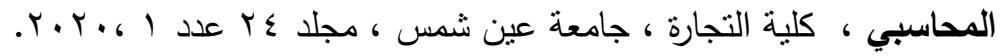

ثانياً : المراجع الأجنبية:

1. Aleksy Kwillinski ,"Implementation of Blockchain Technology in Accounting Sphere", Academy of Accounting and Financial Studies Journal, 2019 .

2. Alex Hughes, et al ,Beyond Bitcoin : What blockchain and Distributed ledger Technologies Mean for Firms, Business HorizonsFebruary 2019, DOI: 10.1016/j.bushor.2019.01.002.

3. Azzi R. et al , the power of aBlockchain Based Supply chain, elsevier , 2019 ,pp. 582-592.

4. Barbara S.White, et.al ,'Blockchain Security Risk Assessment and the Auditor ", journal of Corporate Accounting \& Finance, 2019

5. Boon Seng T.\& Low K. Y.,Blockchain as the Database Engine in the Accounting System, Australian Accounting Review, 2019. 
6. Chod J.Trichakis et al, "On rhe Financing Benefits of supply chaian transparency and Blockchain Adoption ", Management Science Forthcoming ,2019.

7. Choon tan k., Kannan v.,Hsu c. \& keong leong G.," Supply chain information and relational alignments : mediators of edi on firm performance ",international Journal of physical distribution \& Logistics management.40(5), 2010,pp.377-394.

8. Deraman R. Salleh , Beksin A. M. ,Alashwal A. M. , Abdullahi B. C. , Abdullah A.A. , " the roles of information and communication technology (ICT) Systems in construction supply chain management and barriers to their implementation ",African Journal of business management 6(7),2012.

9. Dnyaneshwar, et al, Architecture to Enhance Transparency in Supply Chain Management using Blockchain Technology, Procedia Manufacturing ,51 , 2020 ,PP. 1614-1620.

10. Enrique B. \& Michaela B.," Blockchain and its Implication for accounting and Auditing", Meditàri Accountancy Research ,Vol. 27,No. 5,2019,PP.725-740.

11. Evelina Petersson \& Katharina Baur, "Impacts of Blockchain Technology on Supply Chain Collaboration", Master Thesis in Business Administration, Jonkoping University,2018.

12. Fabian Sander, Semeijin Janjaap and dominik m., The acceptance of blockchain technology in traceability and transparency, british food journal ,Vol.120 ,No. 9, 2018,PP.2066-2079.

13. Fanning Kurt \& Centers D. P.,'Blockchain and its Coming Impact on Financial Services", Journal of Corporate Accounting \& Finance, 27(5), 2016.

14. Ghosh A., Das S. \& Deshpande A.," Effect of responsiveness and process integration in Supply chain coordination", IUP Journal of Supply chain management, 11(1),2014.

15. Hasting G. \& Sodhi S., "Blockchain for Supply Chain Traceability: Business Requirements and Critical Success Factors ", Forthcoming Production and operation Management doi.org/10.1111/Poms.13147,2019.

16. Hoek van Remko, Exploring blockchain Implementation in the Supply chain , International journal of Operations \& Production Management, Vol.39, No. 6 , 2019, PP.829-859. 
17. Hofmann Erik, Strewe, Urs Magnus, Bosia and Nicola, Supply Chain Finance and Blockchain Technology, www.Springe.com, 2018.

18. Institute of Chartered Accountants in England and Wales , (ICAEW), (2018), "Blockchain and the Future of Accountancy", ICAEW's IT Faculty, Available At: http://www.icaew.com/itfac.

19. Jana Schmitz \&Leoni G., Accounting and Auditing at the Time of Blockchain Technology : Aresearch Agenda, Australian Accounting Raview , 2019.

20. Jiapeng Wu ,et al ,"Application of Internet of things and Blockchain technologies to Improve Accounting information Quality" ,IEEE Access, 7, 100090-100098, 2019.

21. John McCallig, et al, Establishing the representational Faithfulness of Financial Accounting Information Using Multiparty Security, Network Analysis and a Blockchain, International Journal of Accounting Information Systems, 2019.

22. Kaliani Sundram V. Chandran V. G. \& Awais Bhatti M. ," Supply chain practices and performance : the indirect effects of Supply chain integration.Benchmarking “, An international Journal ,23(6), 2016 ,pp.1445-1471.

23. Khademi \& Mehran M. ," Implication of Blockchain Technology on Supply chain Performance", the International Cobference on Web Research, Tehran ,: Iran .2019.

24. Kottler Frank, Potential and Barriers to Implementation of Blockchain Technology in Supply Chain Management, www.SSRN.com, 2018.

25. Kumar Pankaj,Role of blockchain Enabled Transparency in Risk Management and Sustainability of the Complex global Supply chains, www.SSRN.com, 2019.

26. Madhani P M , "Application of Six Sigma in Supply Chain Management Evaluation and Measurement Approach", the IUP Journal of Supply Chain Management, Vol 13, No 3, 2016,pp. 3453.

27. Maria Karajovic , Henry M. Kim, Marec Lasksowski, " Thinking outside the Block : Projacted Phases of Blockchain Integration in the Accounting Industry", www.SSRN.com, 2016.

28. Meidayanti k. et al , Analysis and Design of Beef Supply Chain Tracebility System Based on Blockchain Technology ,Earth and environment Science Vol: 315-335 Doi :10.1088/ 1755./315 /1/01.2012. 
29. Michael Casey et al , the Impact of Blockchain Technology on Finance : A Catalyst for Change, ICMB, 2018

30. Michael p. Canemi, "Blockchain Auditing Accounting the need for Automated Audits ", EDPACS ,59(4),2019, pp.1-11.

31. O'leary Daniel E ,Configuring Blockchain Architectures for transaction Information Blockchain Consortiums:the case of accounting and Supply Chain Systems", IntellSys Acc Fin Mgmt ,No.24, 2017,pp 138-147.

32. Paul Haynes et al, "Governance in Blockchain Technologies \& Social Contract theories”, Dublin City University , 2016.

33. Qiang ZHANG, Baoyu LIAO, Shanlin YANG Application of blockchain in the field of intelligent manufacturing: Theoretical basis, realistic plights, and development suggestions, Front. Eng. Manag., 7(4),2020: 578-591.

34. Rebecca Yang, et al, "Public and private blockchain in construction business process and information integration", Automation in Construction, No. 118, 2020 ,pp.1-21.

35. Simpi Khandelwal , Blockchain Technology : Heart of Digital Financial Infrastructure for Managing Trust and Governance System , www.SSRN.com, 2019, pp 440-451.

36. Singhry H. B.," Effect of Supply chain Technology ,Supply chain Collaboration and innovation capability on supply chain performance of manufacturing companies ,Journal of business studies ,quarterly ,7(2),2015.

37. Stephen H. Fuller, \& Markelevich A," Should Accountants Care About Blockl Corporate" Accounting\& Finance, 2019.

38. Sundtoft Kim \& Kinar Aseem, How the blockchain enables and constrains supply chain performance www.researchgate.net/publication/331487549,2019.

39. Ting $\mathrm{Yu}$ et.al, Blockchain:the Introduction and its Application in Financail Accounting ,journal of Corporate Accounting\& Finance,29(4),2018.

40. Treiblmaier Horst, the Impact of the blockchain on the supply chain, international Journal, Vol.23,No. 6, 2018, PP.545-559.

41. Vida J. Morkunas et al, How Blockchain Technologies Impact You Business Model, , www.sciencedirect.com, BUSHOR-1558; No. of Pages 12,2019, pp1-10. 
42. Yao Y. ,Dresner, M. \& Palmer J. W.," Impact of boundary Spanning information Technology and position in chain on firm performance, Journal of supply chain management , 45(4), 2009,pp.3-16.

43. Yunsen Wang \& Alexander Kogan, Designing Confidentiality preserving Blockchain Transaction Processing, International Journal of Accounting Information Systems ,30,2018, pp1-18.

44. Zheng zibin \& Shaoan hong, Blockchain Challenges and Opportunities : asurvey, Int. J. Web and Grid Services , Vol.14,No.4, 2018,pp. 352-374.

قائمة استقصاء

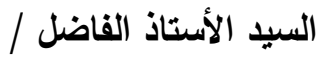

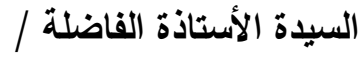

السلام عليكم ورحمة الله ويركاته ،، ؛

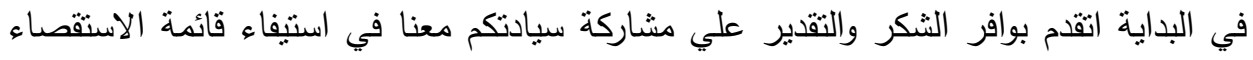

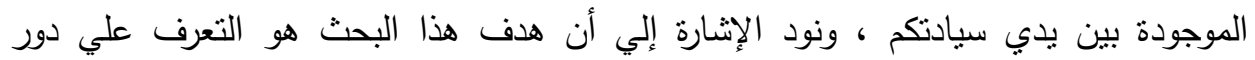
تكنولوجيا سلاسل الثقة Blockchain كأحد اتجاهات تكنولوجيا المعلومات الحديثة وخصائصها

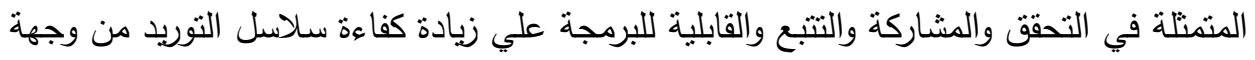
نظر الفكر المحاسبي ، لذلك أرجو من سيادتكم وضع علامة ( / / ) أمام الإجابة التي تراها ملائمة من وجهة نظر سيادتكم ، وأحيط علم سيادتكم بأن آرائكم تتمتع بالسرية الكاملة وأنها ستستخدم فقط لأغراض البحث العلمي.

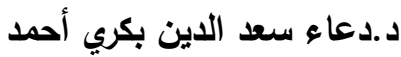
مدرس الدحاسبة والمراجعة - كلية التجارة ، جامعة السويس 
أولاًا : البيانات الثخصية:

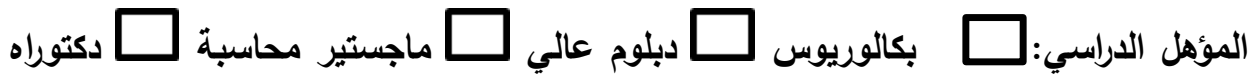

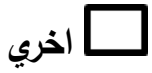

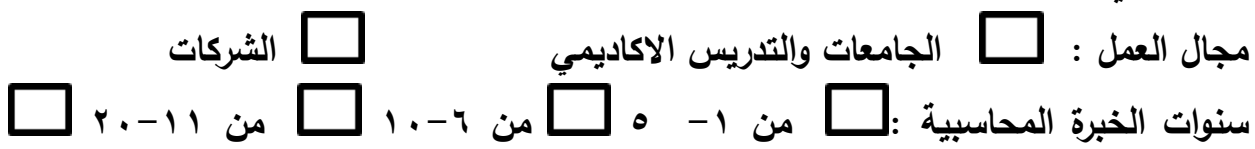

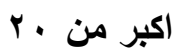

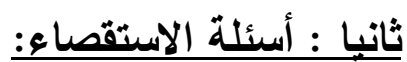

السؤال الأول : حدد مدي موافتتلك علي كيفية الاستفادة من خصائص تكنولوجيا سلاسل الثقة Blockchain - المتمثلة في التحقق والمشاركة والتتبع والقابلية للبرمجة - في زيادة كفاءة

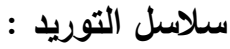

\begin{tabular}{|c|c|c|c|c|c|}
\hline تماماً & موافق & محايد & 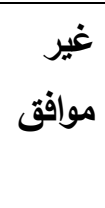 & تموافير & التحقق \\
\hline & & & & & 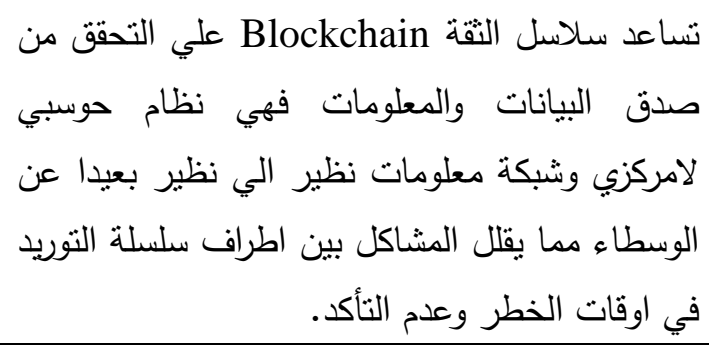 \\
\hline & & & & & كل معاملة مالبة وبما يضمن عدم حدوث ابي خطا . Blockchain على سلتحق من \\
\hline & & & & & 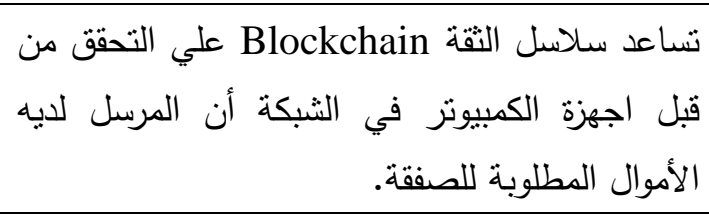 \\
\hline & & & & & تشأعدأ سلاسلع وظروف تحويلها ونقاها. \\
\hline
\end{tabular}




\begin{tabular}{|c|c|c|c|c|c|}
\hline & & & & & 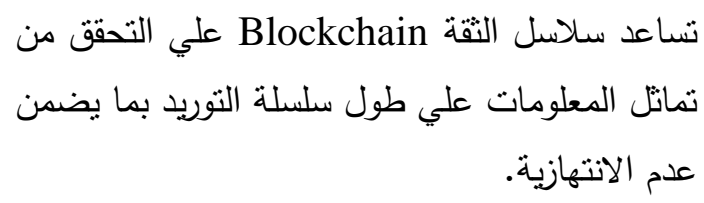 \\
\hline & & & & & 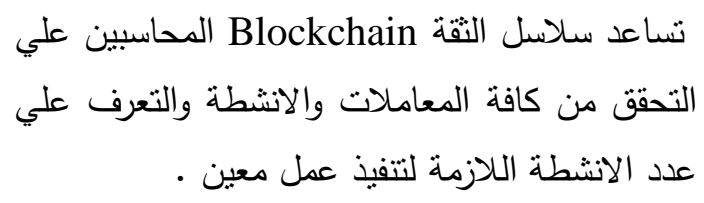 \\
\hline \multirow[t]{5}{*}{ تماماً } & موافق & محايد & غوافق & غمافير & المشاركة \\
\hline & & & & & من في شلال مشاركة دفتر الاستاذ بين كافة المشاركين \\
\hline & & & & & 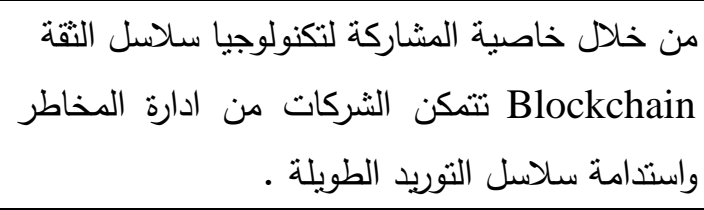 \\
\hline & & & & & 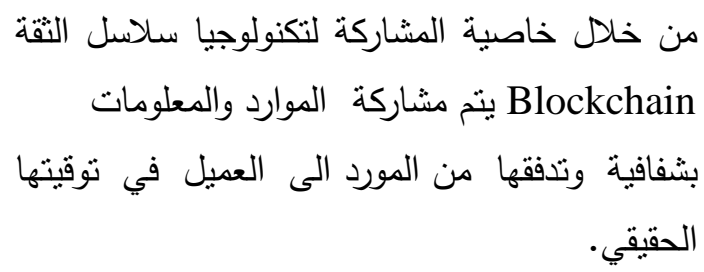 \\
\hline & & & & & 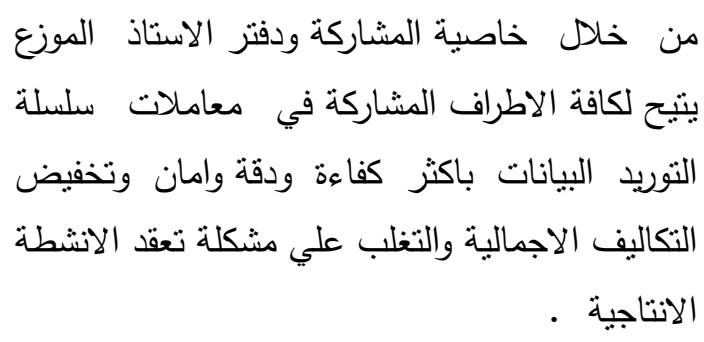 \\
\hline
\end{tabular}




\begin{tabular}{|c|c|c|c|c|c|}
\hline & & & & & 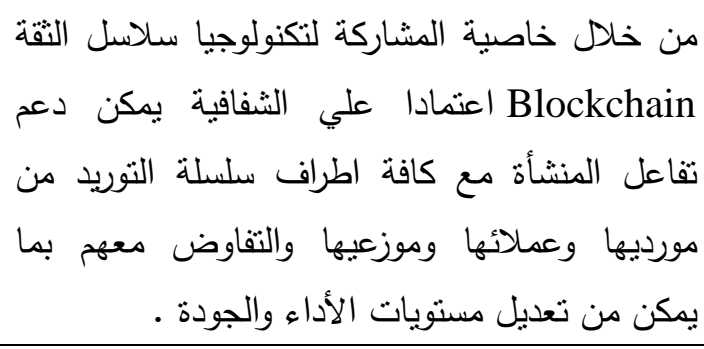 \\
\hline & & & & & 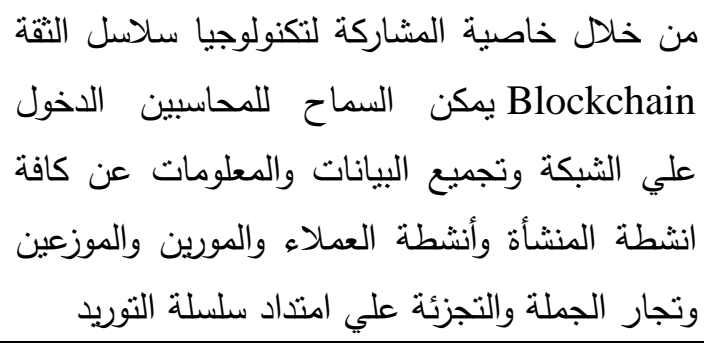 \\
\hline \multirow[t]{4}{*}{ تماماً } & موافق & محايد & غير & تماذر & التتبع \\
\hline & & & & & من بالثبات بلد خاصية التبع يتم توفير بيانات نتسم \\
\hline & & & & & 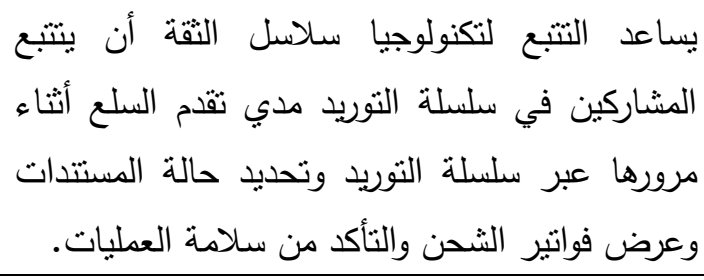 \\
\hline & & & & & 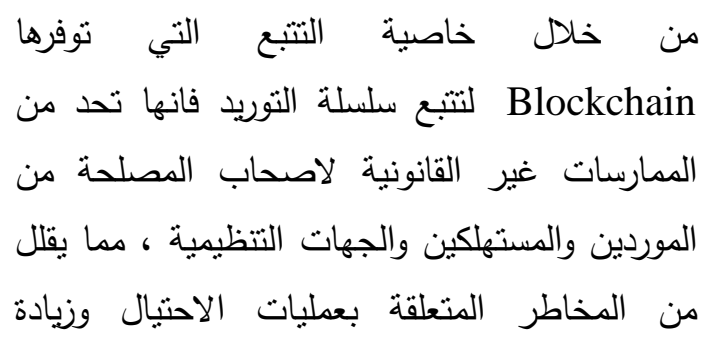 \\
\hline
\end{tabular}




\begin{tabular}{|c|c|c|c|c|c|}
\hline & & & & & الكفاءات التتغيلية وتعزيز تتسيق سلسلة التوريد. \\
\hline & & & & & 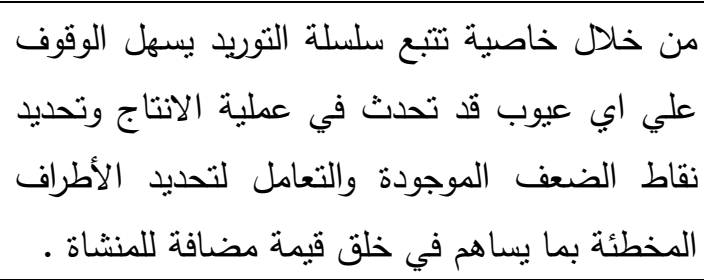 \\
\hline & & & & & التبع تكاليف انشطة المعاملات الواردة علي سلاسل الثقة يمكن \\
\hline & & & & & 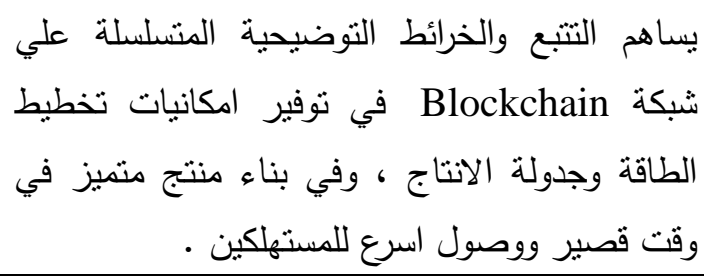 \\
\hline \multirow[t]{3}{*}{ تماماً } & موافق & محايد & غوافير & تماذر & القابلية للبرمجة \\
\hline & & & & & 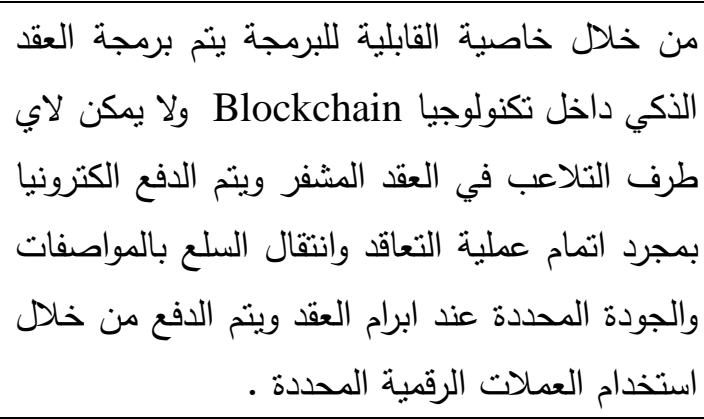 \\
\hline & & & & & التكنة خلال خاصية القابلية للبرمجة يتم اعداد العقود \\
\hline
\end{tabular}




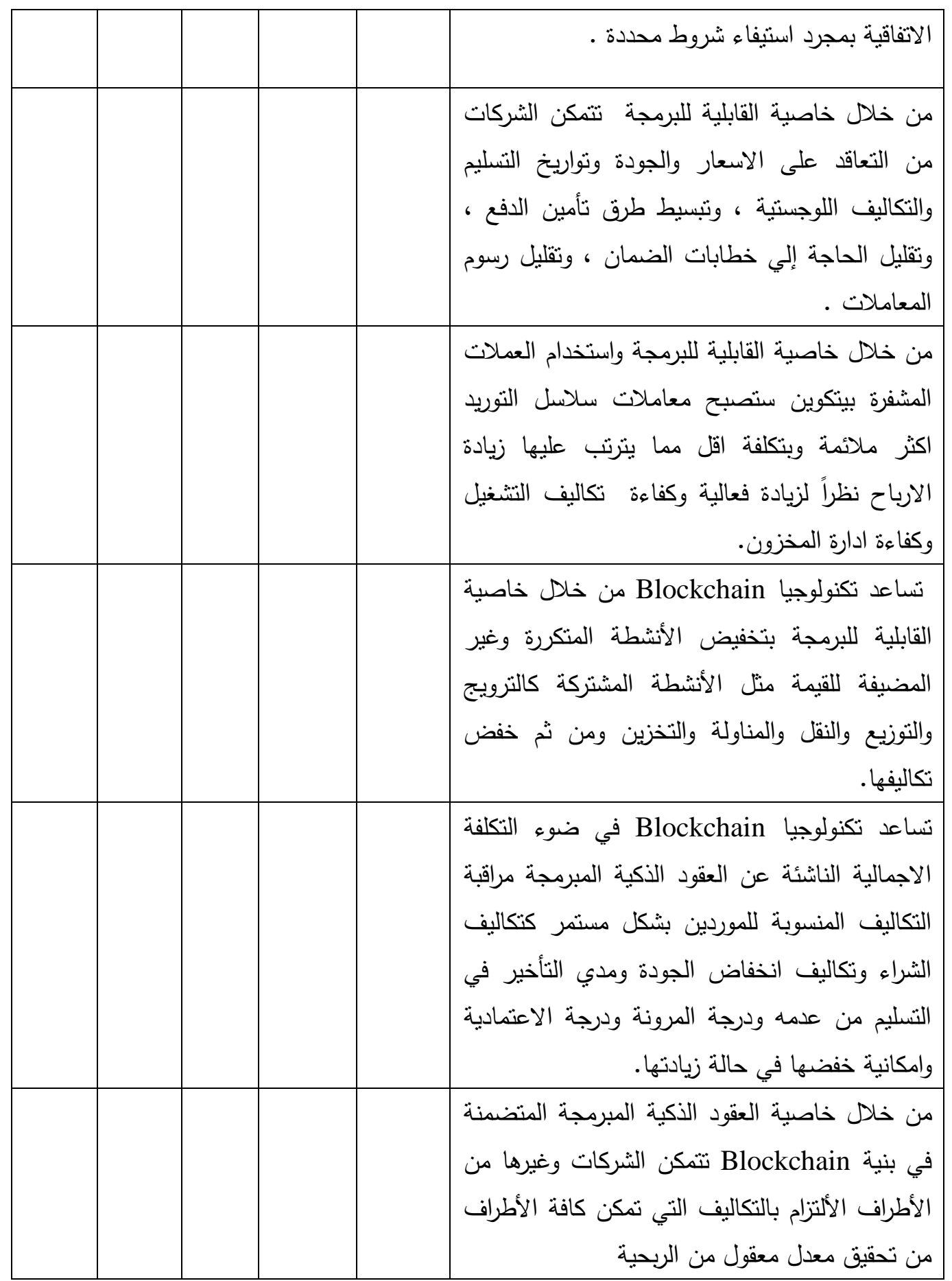


السؤال الثاني :حدد مدى موافقتلك علي العوامل التي تساهم في زيادة كفاءة سلاسل التوريد

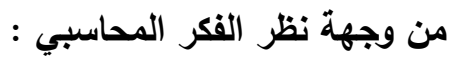

\begin{tabular}{|c|c|c|c|c|c|}
\hline تموافق & موافق & محايد & 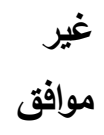 & تماماً موافق & كفاءة سلسلة التوريد \\
\hline & & & & & 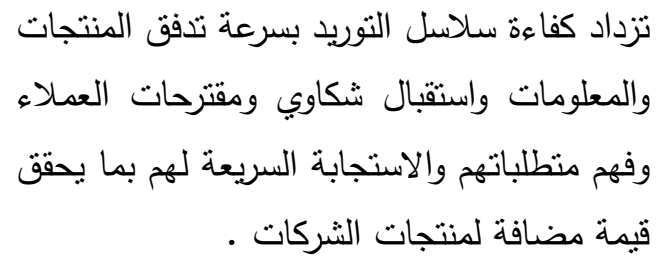 \\
\hline & & & & & 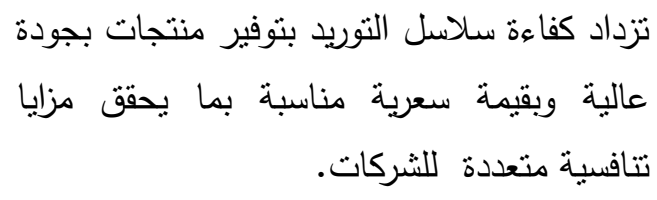 \\
\hline & & & & & تزدداد كفاءة سلاسل التوريد بتفعيل الدور الرقابي \\
\hline & & & & & 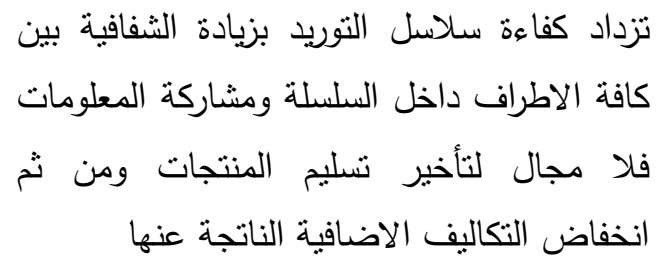 \\
\hline & & & & & 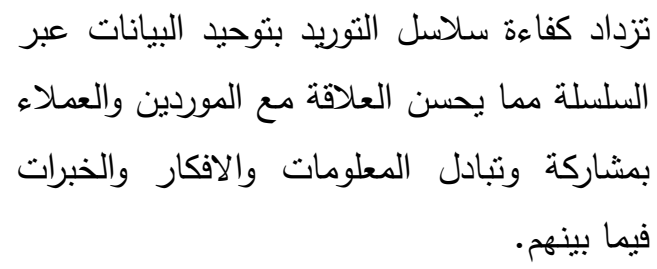 \\
\hline & & & & & 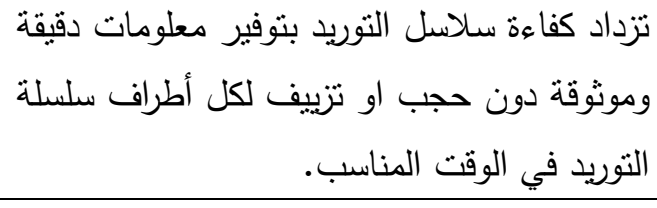 \\
\hline & & & & & 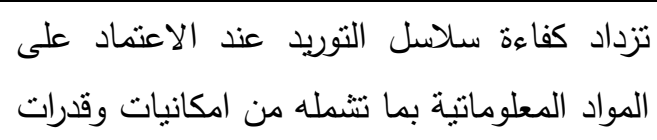 \\
\hline
\end{tabular}




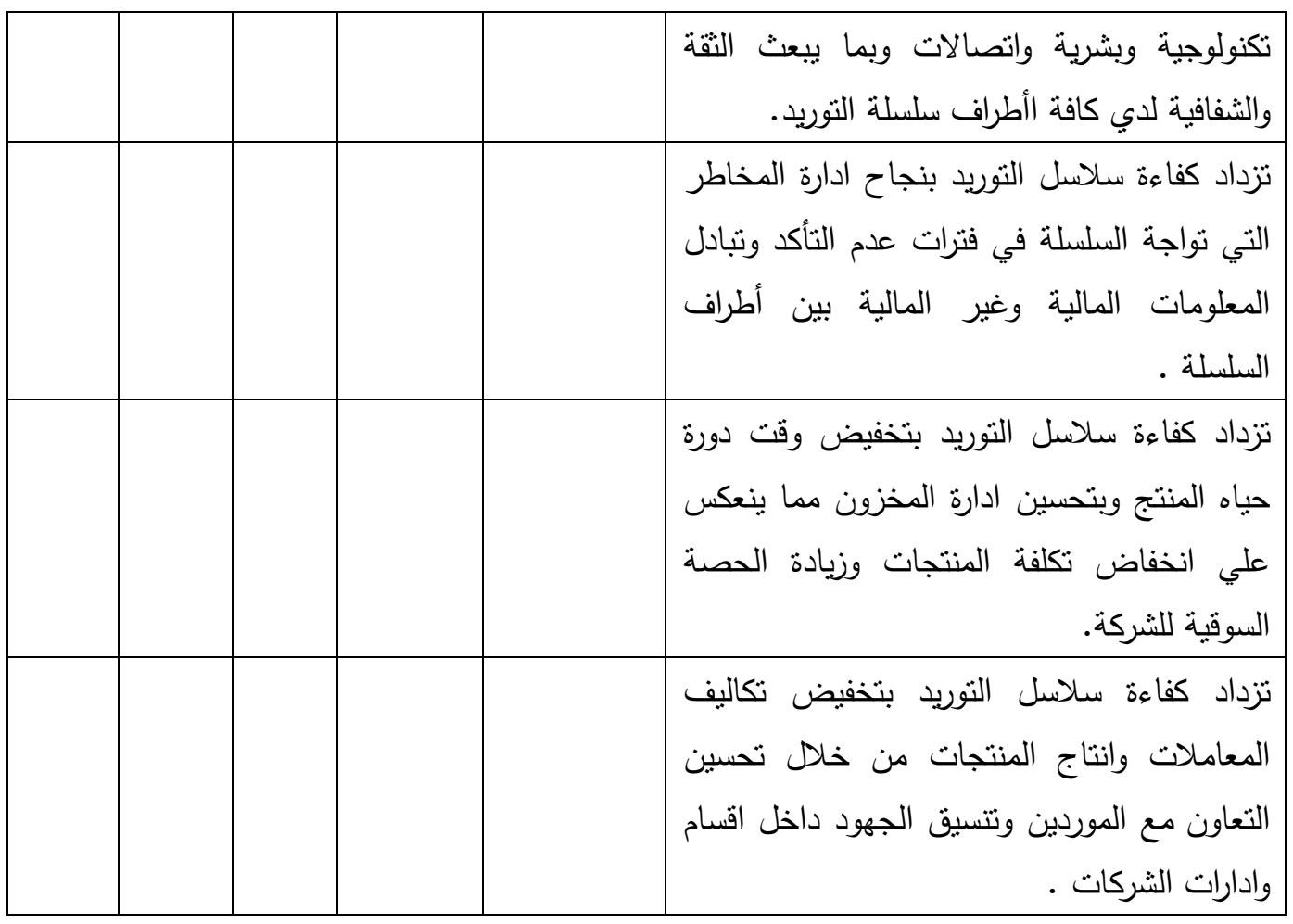

